\title{
Die Aetiologie des infectiösen fieberhaften Icterus (Weil'sche Krankheit).
}

\author{
Ein Beitrag zar Kenntniss septischer Erkrankungen und der Pathogenität \\ der Proteus-Arten. \\ Von \\ Stabsarzt Dr. H. Jaeger, \\ Privatdacenten far Hygiene an der Technisehen Hochschule in Stuttgart. \\ (Hierzu TaP. I-VII.)
}

Ueber die von Weil $1886^{1}$ erstmals beschriebene und seither meist nach ihm benannte "Weil'sche Krankheit" ist schon ziemlich viel geschrieben, namentlich hat eine reiche Kasuistik klinischer Beobachtungen viel Material zur Lösung der schon von Weil aufgeworfenen, aber auch von ihm noch offen gelassenen Frage beigebracht, ob die mit Betheiligung der Nieren, der Milz und des Centralnervensystems unter schwerem Icterus und hohem Fieber einhergehende Infectionskrankheit eine neue bisher unbekannte Erscheinung sei.

Ein infectiöser fieberhafter Icterus ist an sich nichts Neues: man beobachtet einen solchen bei Recurrens (dem biliösen Typhoid Griesinger's), beim Gelbfieber, bei der acuten gelben Leberatrophie; endlich muss auch der Icterus, welcher als Complication des Abdominaltyphus und der Pyämie vorkommt, in diese Gruppe des Infections-Icterus gerechnet werden. - $\mathrm{Ob}$ auch. der katarrhalische Icterus in letzter Linie als ein infectiöser Process anzusehen sei, mag hier zunächst ausser Betrachtung bleiben. - Weil hat Anstand genommen, seine Fälle ohne Weiteres unter eine der obigen Kategorieen unterzubringen, und wenn er

1 Weil, Ueber eine eigenthümliche, mit Milztumor und Nephritis einhergehende acute Infectionskrankheit. Deutsches Archiv für klinische Medicin. Bd. XXXIX. 
auch zu dem Resultate gelangt, dass das von ihm geschilderte Krankheitsbild am ehesten in den Rahmen eines Abdominaltyphus mit Icterus und Nephritis passe, so lässt er doch daneben die Auffassung gelten, es möchte sich in den fraglichen Fällen um einen "Morbus sui generis" handeln.

Im Verlauf der letzten Jahre sah man die Ansichten der meisten klinischen Beobachter sich immer mehr dahin einigen, dass der fieberhafte Infections-Icterus eine specifische Krankheit sej, dass derselbe wenigstens mit Abdominaltyphus und Recurrens nichts gemein habe. Eine gewisse Uebereinstimmung des Symptomencomplexes mit demjenigen der acuten gelben Leberatrophie und des Gelbfiebers musste indessen, wie schon von Weil, so auch.von manchen späteren Beobachtern zugegeben werden, und wenn Weil selbst gegen die Uebereinstimmung mit Gelbfieber das sporadische Auftreten der von ihm beobachteten Fälle anführt, so wurden späterhin in Deutschland und Frankreich auch kleinere Epidemieen beobachtet, welche unbedingt und ausschliesslich zu dem von Weil beschriebenen Symptomencomplex gehörten, sich aber weder als Abdominaltyphus mit Icterus, noch als Recurrens deuten lassen wollten. ${ }^{\mathbf{I}}$

So ist es der klinischen Beobachtung noch nicht gelungen, die Frage zu entscheiden, ob der ron Weil erstmals beschriebene Symptomencomplex einer bis dahin unbekannten - bezw. umbeachtet gebliebenen Krankheit angehürt, oder ob es sich etwa um Fïlle der acuten Leberatrophie oder des Gelbfiebers handle.

Auch die pathologisch-anatomischen Befunde haben bis jetzt eine

\footnotetext{
${ }^{1}$ Einen interessanten Beitrag zn den Beobachtungen solch epidemischen Auftretens der in Rede steheuden Krankheit liefern folgende nach Abschluss vorliegender Arbeit mir durch den Leibarzt Sr. Majestät des Königs von Württemberg, Herrn Oberstabsarzt I. Cl, à la suite, Ober-Medicinalrath Dr. von Fetzer, aus seinem damaligen garnisonärztlichen Bericht für Sommer 1882 gütigst gemachten Mittheilungen. Vom 23. bis 27. August 1882 erkrankten vom Ulanen-Regiment Nr. 19 drei Mann, am 15. September ein vierter, sämmtliche mit sehr hohem Fieber, welches rasch zur Norm oder darunter abfiel, um dann wieder von Neuem mässiger anzusteigen, ferner mit Erbrechen und Diarrhöe, bochgradigem Ikterus, Petechien, Brouchohämorrhagieen und Albuminurie. Den Erkrankungen war in den Monaten Februar bis Juni (30.) desselben Jahres eine Epidemie von katarrbalischem Ikterus vorausgegangen; auch waren während des Sommers mebrere Fälle von Abdominaltyphus vorgekommen. In sämmtlichen Zimmern, in welchen die vier von der schweren Erkrankung im Herbst Betroffenen gelegen hatten, waren im Frühjahr Gelbsuchterkrankungen vorgekommen. Einer der im August Erkrankten war schon im April an katarrhalischer Gelbsucht krank gelegen. Der garnisonärztliche Bericht schliesst in eingehender kritischer Besprechnng des eigenartig neuen Krankheitsbildes katarrhalischen Ikterus, biliöse Pneumonie, Phosphorvergiftung und Iyphus aus und gelangt so zu der Diagnose: biliöses Typhoid (Griesinger).
} 
Aufklärung über die Natur der in Rede stehenden Infectionskrankheit noch nicht bringen können, weil zu Obductionen noch selten Gelegenheit war.

Die Frage, ob das in Rede stehende Krankheitsbild Anspruch machen kann, als eine gesonderte, wohl charakterisirte, specifische Infectionskrankheit anerkannt zu werden, kann nur durch die Erforschung der Aetiologie entschieden werden, und die Untersuchung in dieser Richtung wird naturgemäss eine bakteriologische sein, aber anch einer solchen hat sich bisher die mangelnde Gelegenheit zu Sectionen hindernd in den Weg gestellt.

In meiner bisherigen Garnison Ulm, woselbst die „Weil'sche Krankheit" schon seit einer Reihe von Jahren ziemlich häufig beobachtet wird, ${ }^{1}$ bin ich in die Lage gekommen, zur Ausfüllung dieser Lücke beizutragen, und mich mit der Erforschung der Aetiologie dieser Krankheit zu beschäftigen. ${ }^{2}$

Als Material zu meinen Untersuchungen dienten die Organe von zwei der Krankheit erlegenen Patienten, ausserdem wurden in sechs Fällen das Blut und der Harn mikroskopiseh und bakteriologisch untersucht.

Der erste Fall, von welchem meine ganzen Untersuchungen ihren Ausgang nahmen, ist der inzwischen von $\mathrm{H} \ddot{\mathrm{ueber}}{ }^{3}$ schon mitgetheilte Fall. Soweit als es zum Verständniss des Nachfolgenden erforderlich ist, bin ich genöthigt, das Wesentlichste über Krankheitsverlauf und Obductionsbestand hier ganz kurz zu wiederholen.

\section{Fall I.}

Sergeant M., Pionierbataillon Nr. 13, erkrankte ganz plötzlich auf Wache am Wasserübungsplatz dicht an der Donau mit Kopfschmerzen, heftigem Erbrechen und profuser Diarrhoe, Temperatur 40.0 . In den folgenden Tagen bei niedriger Temperatur grosse Prostration, Erbrechen, Diarrhoe, am vierten Tage Icterus, welcher in den folgenden Tagen sehr zunahm und ein grünliches Colorit annahm, Schwindelgefühl, Lichtscheu. Am achten Tage Blasenblutung; im Harn viel Eiweiss, rothe Blutkörperchen und Tyrosinkrystalle. Am neunten Tage zeitweise Delirien und Zuckungen der Gliedmassen bei $36 \cdot 0^{\circ}$ Körpertemperatur. Abends $7 \mathrm{Uhr}$ unter krampfhaften Zuckungen plötzlicher Tod.

${ }^{1}$ Hüeber, Die neue Infectionskrankheit Weil's in der Armee. Deutsche militär-ärztliche Zeitschrift. 1888.

${ }^{2}$ Einen Theil der diese Untersuchungen betreffenden Präparate habe ich beim internat. med. Congress in Berlin 1890 in der hygien. Section demonstrirt.

${ }^{3}$ H $\mathrm{u}$ eber, Weitere Beiträge zu Weil's fieberhafter Gelbsucht. Deutsche militär ärztliche Zeitschrift. 1890. 
Obduction 14 Stunden p. m. Intensiv gelb-grünliche Verfärbung der Körperoberfläche; an den Lippen und Nasenöffnung Borken: Herpes. In den Bindehäuten beiderseits Blutergüsee. Grosses Netz mit mehreren 10-Pfennigstück-grossen Hämorrhagieen durchsetzt. Milz 14:9 $\mathrm{cm}$ gross, Follikel bedeutend geschwollen. Beide Nieren stark vergrössert, auf der Oberfläche zahlreiche grössere und kleinere Blutaustritte zeigend. Die Rindensubstanz reichlich $1 \mathrm{~cm}$ breit stark injicirt. Leber auffallend blass, von normaler Grösse; die acinöse Zeichnung in einzelnen Partieen undeutlich und verschwommen. Mikroskopisch erscheint der acinöse Bau in solchen Partieen fast gänzlich verwischt, die Leberzellen mit grossen Fettropfen infiltrirt. In Schnitten aus Milz, Leber und Niere fanden sich Herde kleinzelliger Infiltration, sowie gelbe, amorphe Pigmentschollen (icterische Körner). Im ganzen Darmcanal keine merkliche Abweichung von der Norm; nur die Dünndarmschleimhaut leicht injicirt, aber ohne Ecchymosen oder Hämorrhagieen. Solitärfollikel und Peyer'sche Plaques weder geschwellt noch sonstwie krankhaft veründert. Beide Brusthöhlen leer, Lungen überall lufthaltig, überaus blutreich; Herz auffallend gross; im rechten Ventriliel ein blasses gelbliches Gerinnsel.

Behufs Untersuchung auf Bakterien wurden zunächst schon bei der Section einige Ausstriche auf Deckgläser aus dem Gewebssaft von Lunge. Leber, Milz und Nieren hergestellt und diese mit rerschiedenen Anilinfarben: wässeriger Gentianaviolettlösung, mit Ziehl'schem Carbolfuchsin und mit Löffler's Methylenblau gefärbt. In diesen Gewebsausstrichen konnten aber Mikroorganismen, wenigstens mit Sicherheit, nicht nachgewiesen werden.

Zur weiteren Untersuchung in Gewebsschnitteu wurden Stïcke der Leber, Milz und Nieren in absolutem Alkohol gehärtet, alsdann mit dem Mikrotom geschnitten und auf die verschiedenste Weise gefärbt. Die ersten Schnittfärbeversuche wurden auf die gewöhnlichste Art angestellt; Färbung mit wässerigem Gentianaviolett, Entfärben mit Essigsäure, alsdann absoluter Alkohol, Cedernöl, Canadabalsam. Auf diese Weise konnte ich trotz Untersuchung sehr vieler Schnitte gar kein Resultat erlangen. Ebenso erfolglos erwies sich stets die Gram'sche Methode. Die Verwendung von Löffler's Methylenblau mit kurzem, wie mit stundenlangem Einlegen der Schnitte, sowie die Weiterbehandlung mit Oxalsäure nach Löffler's Vorschriften für die Färbung der Rotzbacillen blieb gleichfalls ohne Erfolg. Alsdann versuchte ich Färbung mit Carbolfuchsin, Entfärbung in Essigsäure - Alcohol absol.- Cedernöl; hier hatte es in manchen Schnitten den Anschein, als ob kurze Bacillen zu sehen wären, aber die verschiedene' Grösse der als Mikroorganismen sich präsentirenden Ge- 
bilde, die theilweise bis zur Kokkenform gekürzt erscheinenden Glieder und die bei Carbolfuchsin so häufig zu intensive Färbung des Gewebes liessen bis jetzt eine bestimmte Beurtheilung noch nicht zu. Die ersten positiven Resultate erhielt ich mit Kühne's Methylenblaumethode und zwar besonders dann, wenn ich gar keinen Alkohol bei der Entwässerung verwendete, sondern nach Kühne's Vorschrift den in Salzsäurewasser behandelten Schnitt auf dem Deckglas auffing, mit Fliesspapier abtrocknete und dann unter Benutzung der Kühne'schen Pincette die weitere Entfärbung mit Anilinöl vornahm. Auf diese Weise gelang es, zunächst in Milzschnitten sehr distinct gefärbte Bacillen - wenn auch sehr vereinzelt liegend - aufzufinden; oft fanden sich in einem Schnitte nur zwei bis drei, ja manchmal nur ein einziger Bacillus. Liess ich die Schnitte so kurz wie möglich in dem $\mathrm{ClH}$-Wasser und in gewöhnlichem Wasser, und überliess die Entfärbung vorwiegend dem Anilinöl, so konnte ich etwas mehr Bacillen und diese besser gefärbt erkennen. Die $\mathrm{Ba}$ cillen erschienen als Kurzstäbchen, welche sich durch einen besonderen Ton im Blau, durch etwas intensiver gefärbte abgerundete Enden, eine meist leichte Krümmung und endlich durch eine eigenthümliche Transparenz auszeichneten, welch' letztere auf ihre schlechte Empfänglichkeit für die Anilinfarben, bezw. auf ihre geringe Tenacität für dieselben zurückzuführen sein wird, und welche ich sonst bei Bakterien noch niemals in ähnlicher Weise beobachtet habe. Gleichwohl hat aber auch die Färbung nach Kühne keine vollkommen befriedigenden Bilder geliefert, denn das sehr spärliche Auffinden sehr schwach gefärbter Bacillen musste klar machen, dass die Methode noch nicht die richtige sei, um alle Mikroorganismen, welche sich in dem. Gewebe fanden, zur Anschaunng zu bringen. So kehrte ich denn zur einfacheren Methode der Färbung mit Carbolfuchsin, Entfärbung in Essigsäure und Entwässerung in Alkohol zurück und fand bald, dass, wenn man die ganze Färbungsprocedur ziemlich rasch von Statten gehen liess, man völlig befriedigende Resultate erhalten konnte. Schon in der Farbflüssigkeit dürfen die Schnitte nicht zu lange (nicht länger als 3 bis 5 Minuten) bleiben, da sonst die zur Entfärbung des Zellenprotoplasma nothwendige Behandlung mit Essigsäure und Alkohol so lange Zeit in Anspruch nimmt, dass mit dem Protoplasma sich auch die Bakterien wieder entfärben.

Behandelt man also die Schnitte so lange wie angegeben mit Carbolfuchsin, bringt sie hierauf in nicht zu starke Essigsäure (ein Tropfen auf 30 ecm Wasser), bis der Schnitt keine starken Farbewolken mehr loslässt und sodann nur so lange in absoluten Alkohol, als zur Entwässerung unbedingt erforderlich' ist, so findet man die Bacillen intensiv gefärbt, so Zeitschr. f. Hygiene. XII. 
dass sie sich von den ebenso gefärbten Kernen mit befriedigender Deutlichkeit abheben. Sie erhalten bei dieser Methode gleichfalls das transparente Aussehen wie bei der Färbung nach $K u ̈ h n e$, dabei nehmen sie einen mehr gelblich-rothen Farbenton an, welcher sie von dem Bläulichroth des Gewebes unterscheidet. Die Pole derselben sind intensiv gefärbt. Mit diesem Färbeverfahren konnten die Bacillen in allen untersuchten Organen: Leber, Milz und Nieren aufgefunden werden, allerdings in den beiden erstgenannten auch nur sehr spärlich, um so reichlicher dagegen in den Nierenschnitten. Hier finden sie sich in dichten Haufen beisammenliegend, ähnlich wie die Herde der Typhusbacillen in der Milz gcfunden werden. Die Bacillen sind hier meist ziemlich lang und von sehr beträchtlicher Dicke, so dass sie den Milzbrandbàcillen an Grösse mindestens gleichkommen, ja dieselben an Dicke eher übertreffen; ihre oft stark gekrümmte Form, ihr gewölbtes, intensiv gefärbtes Ende und das Fehlen von Absätzen zwischen den Gliedern unterscheiden sie aber sehr wesentlich von diesen. Noch eine weitere Eigenthümlichkeit besitzen diese Bacillen, welche in besonders gut gefärbten Präparaten zu Tage tritt: jeder einzelne Bacillus trägt an seinen beiden Langseiten borstenförmige Ansätze, welche demselben ein sehr eigenthümliches Aussehen verleihen. Betrachtet man einen solchen Bacillenhaufen, so erblickt man ein Gewirr feinster ungefärbter Fäden zwischen den einzelnen Bacillen Fäden, welche wohl einer Gallert- (Kapsel-?) Bildung ron Seiten der Bakterien zuzuschreiben sein dürften. Ob die „Borsten" dieser Gallertbildung ihre Entstehung verdanken oder ob es sich um abgebrochene Ansätze von Geisselfäden handelt, lässt sich am Präparate nicht entscheiden, doch scheint mir diese Frage dadurch entschieden zu sein, dass ich an den später zu beschreibenden, durch das Culturverfahren gewonnenen Bakterien Geisselfäden gefunden habe, deren Ansatz mit demjenigen dieser Borsten völlig übereinstimmt. Taf. II, Fig. 1 zeigt einen Nierenschnitt, welcher aus meinem ersten Falle gewonnen ist und die soeben geschilderten Verhältnisse erkennen lässt. $\mathrm{Ob}$ die Bacillen in den Blutgefässen, und ob sie nur ausschliesslich in diesen liegen, lässt sich an diesem Schnitte nicht entscheiden, auch die übrigen von diesem Falle gewonnenen geben hierüber keinen Aufschluss, wohl aber Schnitte, welche ich aus dem Falle IX erhalten habe, und in welchem die Bakterien in weit reichlicherer Menge in allen Organen sich finden. Hier findet man Stellen, wo ganze Gefässe mit den Bacillen vollgestopft sind, daneben finden sich diese aber auch durch das ganze Gewebe hin regellos zerstreut; so ist hier das Verhalten übereinstimmend in allen Organen. Sehr auffällig bleibt noch in diesen sämmtlichen Schnitten, dass man neben den oben geschilderten Bacillenformen auch noch da und dort kürzere Glieder bis zu eigentlichen Kokkenformen an- 
trifft, ja dass.auch die Dicke dieser Glieder so sehr wechselt, dass man glauben möchte, verschiedene Bakterienarten in einem und demselben Schnitte vor sich zu haben, fünden sich nicht von diesen kleinen Kurzstäbchen und scheinbaren Mikrokokken alle Uebergangsformen bis zu den geschilderten grossen, zuweilen mit Borsten besetzten Bacillen. Häufig findet man in der Nähe der Bacillenhaufen oder in diesen selbst icterische Körner und Pigmentschollen, sowie ausgetretene Blutkörperchen, so dass es den Anschein gewinnt, dass diese Bacillenhaufen ein Gefäss, welches sie vollgestopft hatten, zum Bersten gebracht haben, ähnlich, wie dies bei Milzbrand in den Glomerulis der Niere beobachtet werden kann. Die mit Methylenblau gefärbten Bacillen erscheinen durchweg erheblich schlanker als die mit Carbolfuchsin gefärbten, auch fehlt hier der Borstenbesatz. Bei beiden F'ärbungsverfahren sieht man aber, wenn man die Blende verwendet, die Bacillen mit einem lichtglänzenden Hofe (Gallertkapsel?) umgeben, doch ist mir eine Färbung derselben nicht gelungen.

Für die Untersuchung mittels des bakteriologischen Culturverfahrens wurden gewählt: Leber, Milz, Niere und verlängertes Mark; das letzgenannte Organ deshalb, weil schon während des Lebens Störungen von Seiten der nerrösen Centralorgane bestanden hatten, sowie weil der Tod unter krampfhaften Zuckungen und ganz plötzlicher Lähmung der Respirations- und Circulationscentren erfolgt war. Aus den genannten Organen wurden Culturen angelegt in folgender Weise:

1. Auf Glycerin-Agar; Gewebspartikelchen auf in den Röhrchen schräg erstarrte Flächen gestrichen und in den Brütschrank gebracht: aus Milz, Leber, Nieren und Medulla oblongata.

2. Auf Gelatine; Platten mit den üblichen Verdünnungen bei Zimmertemperatur gehalten: aus Milz.

3. In Bouillon unmittelbar geimpft und diese im Brütschrank gehalten: aus Milz und Leber.

Auf den Glycerin-Agarröhren, welche im Brütschrank gehalten waren, wuchsen aus Leber, Niere und Medulla oblongata innerhalb zwei Tagen dicke weisse Colonieen, welche im unteren Theile des Glases confluirten und im Condenswasser einen dicken weissen Bodensatz bildeten. Bei der mikroskopischen Untersuchung der einzeln abgegrenzt gebliebenen Colonieen höher oben in der Röhre, welche trockener waren, fanden sich anscheinend ausschliesslich Mikrokokken; untersuchte man aber den feuchteren Belag weiter unten oder das Condenswasser, so fanden sich zwischen den runden Gebilden auch zahlreiche ausgesprochene Bacillen, so dass es den Anschein hatte, es seien hier in Folge des Zusammenfliessens der Colonieen Bacillen und Mikrokokken mit einander vermischt. In den 
Glycerin-Agarculturen aus Leber konnten nur Mikrokokkenformen aufgefunden werden, dagegen fandeu sich in den Culturen aus Niere in einigen Colonieen die Bacillen rein, in anderen (nicht durch Confluiren veränderten) gleichfalls mit Kokken vermischt. Ein mehrfaches Weiterzüchten durch Ausstreichen auf schräg erstarrtem Glycerin-Agar mit Anlegen von Verdünnungen sowohl der aus den Nieren erhaltenen reinen Bacillenculturen, als auch der übrigen anscheinend durch Mikrokokken verunreinigten Colonieen ergab aber in allen Fällen fortdauernd dasselbe Resultat, nämlich dass in völlig isolirt liegenden Colonieen stets Bacillenmit Kokkenformen gepaart vorkamen. Es ging daraus mit Sicherheit hervor, dass es sich nicht um zwei verschiedene Arten von Mikroorganismen handelt, sondern dass die so gewonnenen Bakterien in einer kürzeren und längeren Wuchsform neben einander vorkamen.

In den zwei - selbstverständlich unter peinlichster Beobachtung aller Cautelen angelegten - Culturen unmittelbar in Bouillon fanden sich dieselben Verhältnisse: Die Bouillon war nach zwei Tagen stark getrübt, ohne nennenswerthen Geruch. Sie schien eine Reincultur von Kokken zu enthalten; als aber zur Controle der Reinheit Gelatineplatten aus dieser Bouillon angelegt waren, entpuppten sich die scheinbaren Mikrokokken als eine Reincultur von ausgesprochenen Kurzstäbchen.

Auf den Gelatineplatten aus Milz und Leber wurden dieselben Verhältnisse angetroffen: Colonieen, welche in den ersten zwei Tagen die Gelatine nicht verflüssigten, sondern sich auf derselben in an Typhuscolonieen erinnernder Weise ausbreiteten und mikroskopisch anscheinend aus Kokken bestanden, dazwischen aber typische Bacillen, meist Kurzstäbchen von der Form des Bacillus prodigiosus, erkennen liessen.

Es konnte somit durch das Culturverfahren auf den verschiedenen Nährsubstraten und aus den verschiedenen Organen eine Bacillenart isolirt werden, welche in den verschiedenen Culturen zunächst das Uebereinstimmende bot, dass sich eine auffallende Mannigfaltigkeit der äusseren Form, ein Wechsel zwischen Kokkenformen und Kurzstäbchen bis zu Scheinfäden vorfand.

Von den hier gewonnenen Culturen wurde nunmehr eine solche Colonie, in welcher die Organismen am reichlichsten im Stïbchentypus vorkamen, auf Gelatineplatten gebracht- und das Plattenverfahren viele Monate hindurch oftmals wiederholt, ja auch in den letztrerflossenen Wonaten noch öfters durch neue Aussaat die früheren Befunde nachgeprüft. Ich gebe daher im Folgenden die genaue Beschreibung der in diesem ersten Falle isolierten Bakterien, wie sich dieselben bei diesen lange fortgesetzten Untersuchungen dargestellt haben.

Schon bei der ersten Untersuchung war es aufgefallen, dass die bei 
hoher Zimmertemperatur (20 bis $25^{\circ} \mathrm{C}$. den Tag über) sehr rasch wachsenden Colonieen zwar anfänglich die Gelatine nicht verflüssigten, dass aber am Ende des zweiten oder am dritten Tage, zuweilen auch später, ein Theil der Colonieen in der Mitte einzusinken und die Gelatine zu verflüssigen begann. Das erste Mal, als ich noch die runden Glieder für Kokken und damit meine Culturen für unrein hielt, erwartete ich nicht anders, als dass ich nunmebr in den verflüssigenden Colonieen die Bacillen, in den nicht verflüssigenden die Kokken finden werde oder umgekehrt; das war aber nicht der Fall: zu meinem Erstaunen fanden sich sowohl unter den verflüssigenden als unter den nicht verflüssigenden Colonieen stets beide Formen der Mikroorganismen bunt durch einander gemischt vor und diese Erscheinung wiederholte sich immer wieder, so oft auch später neue Plattenaussaaten gemacht wurden.

Es stand somit fest, dass beide Formen derselben Art angehören, und dass der hier anfgefundene Organismus sowohl verschiedene Wuchsformen in seinem Entwickelungsgange durchmacht, als auch, dass seine Culturen in der Fähigkeit, den Nährboden zu peptonisiren, wechseln. Um in dieser Beobachtung noch weiter sicher zu gehen, wurden von Beginn der Versuche bis auf den heutigen Tag zwei Culturen aus jenen Platten angelegt und neben einander fortgezüchtet, deren eine von einer auf der Platte verflüssigenden, die andere von einer nicht verflüssigenden Colonie stammte. Diese zwei Culturen, welche als ,,verflüssigende“ und als ,nicht verflüssigende" bezeichnet sind, verflüssigen in der Stichcultur beide die Gelatine, bringt man sie aber auf Platten, so finden sich jedes Mal wieder neben den rasch und energisch verflüssigenden Colonieen solche, welche lange Zeit gar keine Verflüssigung hervorbringen. Das Aussehen dieser verschiedenen Typen von Colonieen werde ich unten genauer beschreiben. Bekanntlich hat R. Pfeiffer ${ }^{1}$ bei Untersuchung des Vibrio Metschnikoff ganz ähnliche Beobachtungen hinsichtlich des Peptonisirungsvermögens dieser Bakterien gemacht.

Die typischsten Bilder der Mikroorganismen selbst erhält man von jungen, 2 bis 3 Tage alten, bei 18 bis $20^{\circ} \mathrm{C}$. gewachsenen Gelatineplatten-Colonieen. In solchen findet man die Bacillen kurz, dick, mit abgerundeten Enden, meist zu zweien an einander gelagert, mit einem je nach der Intensität der Färbung mehr oder weniger bemerkbaren Zwischenraum; ist die Tinction sehr intensit, und liegen mehrmals zwei Glieder an einander, so kommen gekrümmte Stäbchen zu Stande, ähnlich den Finkler'schen Vibrionen, auch kommt Aneinanderlagerung von mehr

${ }^{1}$ R. Pfeiffer, Ueber den Vibrio Metschnikoff und sein Verhältniss zur Cholera asiatica. Diese Zeitschrift. Bd. VII. 
als zwei Gliedern, die Bildung kurzer Scheinfäden vor, welche zusammen eine einfach, zuweilen auch mehrfach gekrümmte Linie bilden: Die Färbung gelingt 2 war mit wässerigem Gentianaviolett, ist aber wenig intensiv, viele Individuen bleiben dabei sehr blass; ziemlich intensiv wird sie mit Löffler's Methylenblau. Bei kurz dauernder Färbung mit Carbolfuchsin färben sich die Enden der Bacillen sehr intensiv, wogegen die Mitte eine völlig ungefärbt bleibende Lücke aufweist; hierbei entstehen häufig die wunderlichsten Zerrbilder, so dass diese Färbemethode sich schlecht eignet. Dagegen hat sich mir das Carbolfuchsin, wenn es anf dem Deckglas erwärmt wurde, als das beste Fürbeverfahren, welches auch die Bacillen in der charakteristischsten Weise zur Anschanung bringt, bewährt. Bei dieser Behandlung der Ausstriche aus den Reinculturen erkennt man die Bakterien in völliger morphologischer Uebereinstimmung mit den in den Gewebsschnitten gefundenen: sie haben alsdann dieselbe Grösse, dieselben gekrümmten Formen, auch die Transparenz ist bei nicht zu intensiver Färbung wahrzunehmen; dieselbe kommt durch die geringere Aufnahmefähigkeit des Mittelstückes der Bacillen für die Anilinfarben zu Stande. Bei allen weniger intensiven Färbemethoden erscheinen die Bakterien erheblich kleiner und zwar in überaus wechselnden Dimensionen. Bei Anwendung der Gram'schen Methode tritt Entfärbung ein. Das Photogramm auf Taf. II, Fig. 2 zeigt ein mit Gentianaviolett gefärbtes Ausstrichpräparat; auf demselben erscheinen die Bakterien erheblich kleiner als im vorigen Schnittpräparate, doch finden sich auch hier häufig Bacillen, welche an Dicke jenen nichts nachgeben. Dieser gewaltige Wechsel in der Grösse der einzelnen Individuen in einer und derselben Cultur lässt sich besonders gut auch in dem Klatschpräparat Taf. III, Fig. 1 erkennen. Bei der Untersuchung auf Geisselfäden nach Löffler's Vorschrift findet man den Bacillen einen ganzen Schwarm ron Geisselfäden zu beiden Langseiten anhängen, in derselben Weise, wie bei Proteus vulgaris.

Wie aus dem Besitze solch' stattlicher Bewegungsorgane schon zu erwarten ist, sind die Bakterien sehr lebhaft beweglich; besonders wenn sie als Einzelglieder, nicht in Verbänden auftreten, erinnert ihre Beweglichkeit sehr an diejenige der Cholerabacillen, doch ist ihre Bewegung vielleicht um Weniges langsamer als diese. Längere Verbände, Scheinfäden, sind im hängenden Tropfen häufig zu beobachten; an diesen ist die Bewegung entsprechend langsamer und ähnelt dann mehr derjenigen der Typhusbacillen. Unter den kurzen. Formen, kokkenähnlichen und doppelg]iederigen Kurzstäbchen, zeigen manche eine ganz besondere Lebendigkeit: sie schiessen wie Pfeile hin und her, machen manchmal kreisformige und 8-förmige Wege, drehen sich dann wieder, besonders wenn sie mit einem Pole irgendwo hängen geblieben sind, fortwährend 
um sich selbst; häufig beobachtet man auch eine um die verticale Axe oscillirende Fortbewegung der Bacillen. Besonders auffällig ist ein die Bakterien hauptsächlich an den beiden Langseiten umgebender glänzender Lichthof.

Auf der Gelatineplatte sieht man anfänglich - und zwar je nach der Temperatur schon nach 24 bis 36 Stunden oder auch erst am vierten Tage - mit blossem Auge feine wasserhelle Tröpfchen, mit welchen die Platte wie besprengt ist. Bei schwacher Vergrösserung erscheinen sie rund, hellgelb, schwach granulirt und scharf contourirt. Etwas später wird die Contour häufig etwas gebuchtet; sind sodann die Colonieen noch etwas älter geworden, so beginnen sie aus der Tiefe heraus ihr Verflüssigungswerk; die Gelatine sinkt dann kraterartig ein und es entsteht ein Bild concentrischer Schichtung wie bei den Choleracolonieen, wobei sie sich von diesen jedoch durch das Fehlen des ,ausgeschlagenen Randes" wesentlich unterscheiden. Dies ist das Bild der noch geschlossen in der Gelatine liegenden Colonieen (Taf. I, Fig. 1). Bei fortschreitendem Wachsthum verblasst die concentrische Schichtung, die Contour wird unregelmässig gebuchtet, schliesslich brechen solche Colonieen nach der Oberfläche durch und erhalten hier sodann meist eine pallissadenartige Randzone aus radiär gestellten Härchen. Alsdann zerfällt die Colonie allmählich, wobei sie zunächst ein an Milzbrandcolonieen in fortgeschrittener Entwickelung erinnerndes Aussehen annimmt; hiermit beginnt eine Zerklüftung der Colonie, wobei einzelne trübe Brocken in der verflüssigten Gelatine schwimmen und der Anblick das Charakteristische verliert.

Ganz anders verhalten sich ursprünglich schon weit oben liegende Colonieen: während im ersten Beginn der Entwickelung dieselben nur wie feine runde Tröpfchen der Gelatine aufsitzen, beginnen sie bald, sich in feinem Belage mit zierlicher Linienzeichnung auf der Oberfläche auszubreiten; dieser Belag würde genau wie eine Typhuscolonie aussehen, wäre nicht in der Mitte ein dicker weisser, bei schwacher Vergrösserung ziemlich dunkelgelber Klumpen. So erreichen diese Colonieen (wenn sie gut isolirt liegen) eine beträchtliche Grösse ( 1 bis $3^{\mathrm{mm}}$ Durchmesser). Dann sinkt die ganze Colonie dellenförmig ein; sie behält dabei zunächst ihr bisheriges Aussehen, zeigt aber bei schwacher Vergrösserung am Rande einen Lichthof; jenseits des letzteren sieht man noch zarte, verschwommene, blassgraue Schlieren, die Reste des ersten nicht verflüssigenden Stadiums (Taf. I, Fig. 2). Diese Schlieren erinnern häufig an das hübsche Bild, welches wohlentwickelte Milzbrandcolonieen darbieten; bei günstigen Temperatur- und Ernährungsverhältnissen kommen aber völlig charakteristische Proteus-Figuren, abenteuerliche Schnörkel und abgeschnürte selbstständige Inseln zu Stande (Taf. III, Fig. 1). 
In Folge des Eintrittes der Verflüssigung vollzieht sich eine für die Gestalt der Bakterien selbst bedeutungsvolle Veränderung: sind die Bacillen bisher auf der Oberfläche fortwuchernd zu langen Scheinfäden ausgewachsen, so beginnt mit der Verflüssigung ein Zerfall der lebhaft beweglichen Kurzstäbchen in ihre Einzelglieder. Die Taf. III, Fig. 1 veranschaulicht diese Verhältnisse: man sieht hier einen noch nicht verflüssigenden Bezirk unmittelbar in einen verflüssigenden übergehen und hier die zum Theil überaus mächtigen Scheinfäden in unscheinbare Kurzstäbchen zerfallen. Ist bei diesen Oberflächencolonieen dieser Entwickelungszustand erreicht, so gehen diese Bilder und diejenigen der zuvor geschilderten geschlossenen Colonieen mehr und mehr in einander über.

Mit dieser Schilderung soll jedoch nicht die Anschauung erweckt werden, als ob dieser erst secundäre Eintritt der Verflüssigung der Oberflächencolonieen eine Regel ohne Ausnahme bilde, im Gegentheil: man sieht auch die der Oberfläche aufsitzenden ursprünglichen wasserhellen Tröpfchen nicht selten sofort einen scharfen Verflüssigungskrater bilden, wobei dann von flächenhaft ausgebreiteten Randpartieen nirgends etwas zu bemerken ist; auf einer und derselben Platte kann man aber gleichzeitig alle diese Typen finden. Sind die aus dem erstbeimpften Gelatineröhrchen hergestellten Originalplatten sehr dicht mit Colonieen besetzt und sind diese bei etwas kühler Zimmertemperatur herangewachsen, so geht die Verflüssigung der Colonieen ziemlich langsam vor sich und man erhält alsdann genau das Bild, wie es die Choleraplatten darbieten: das eigenthümlich zerfressene Aussehen der Platten. Bei noch kühlerer und, wie es scheint, besonders bei stark wechselnder Temperatur, hört die Verflüssigung dann überhaupt auf, um, wenn die Platte wieder bei höheren Wärmegraden gehalten wird, vielleicht von Neuem zu beginnen, oder die Abkühlung vermag auch die Verflüssigung nur hinauszuschieben, nicht ganz fernzuhalten. Häufig genug aber habe ich es auch beobachtet, dass die Verflüssigung trotz kühler Temperatur doch eintrat und dagegen in der Wärme ausblieb, ja sogar, dass z. B. die Originalplatte ohne Verflüssigung blieb, während auf der ersten und zweiten Verdünnungsplatte alle Colonieen verflüssigten.

Das Verhalten auf der Gelatineplatte ist somit ein sehr vielgestaltiges, wie auch schon die Beobachtung der Bacillen selbst im gefärbten Präparate einen bedeutenden Wechsel der Form und Grössenverhältnisse ergeben hatte.

In der Stichcultur werden diese Dinge noch auffallender: hier entwickelt sich zunächst an der Oberfläche ein mässig grosser Belag; alsdann sinkt dieser (wie auf der Platte) dellenförmig ein und nun beginnt darunter sich unter langsamer Verflüssigung eine Luftblase zu entwickeln, 
welche der Cultur genau die Gestalt einer Choleracultur verleiht (Taf. I, Fig. 3). Dabei beginnt aber die Gelatine eine grünliche Fluorescenz anzunehmen, welche in manchen Culturen sehr intensiv werden und einen prächtigen Farbeneffect liefern kann. Im weiteren Verlaufe greift die Verflüssigung dem Stich entlang tiefer, wobei sie allmählich bis auf den Boden des Glases fortschreitet oder auch schon höhẹr oben aufhört und einen. Theil des Stiches unverflüssigt lässt. Der choleraähnliche Verflüssigungskrater entwickelt sich aber nur dann, wenn das Wachsthum der Cultur nicht allzu rasch von Statten geht, andernfalls bildet der Verflüssigungskrater die „Strumpfform" wie bei den Finkler'schen Bacillen. Späterhin sinkt die verflüssigte Cultur zu Boden in dichten wolkigen Massen, welche eine weissliche Farbe haben; seltsamer Weise findet sich hier manchmal eine dunkelgrau-schwarze Verfärbung in dieser Masse. Bleibt der untere Theil des Stiches von Verflüssigung frei, so nimmt er mit der Zeit einen mehr und mehr dunkelgelben ja bis braunrothen Ton an. An der Oberfläche bleibt ein Häutchen von sehr wechselnder Dicke, manchmal sehr derb und weiss, manchmal mehr grau, überaus zart und am Rande zierlich gekräuselt, zurück. Ist die Haut dick, so ist ihre Masse fadenziehend. Die Bildung einer mässig starken Haut ist zwar die Regel, doch kann sie über mehrere Generationen hin wieder beinahe ausbleiben. Bei ruhigem Stehenlassen der Cultur beobachtet man in den oberen Theilen der Gelatine (ähnlich wie bei Cholera) eine getrübte Zone (die beweglichen Bacillen), darunter eine klare und am Boden die abgesetzten nicht mehr bewegungsfähigen Bakterienvegetationen.

Auf Agar bei Brüttemperatur $\left(37.5^{\circ} \mathrm{C}\right.$.) wachsen die Bakterien schon in 24 Stunden zu feinen wasserklaren Tröpfchen und nach 48 Stunden zu einem dicken gelblich-weissen Belage heran, weleher dem Nährsubstrat eine grüne Fluorescenz verleiht und im Condenswasser dichte Flocken bildet. Zuweilen - aber nicht regelmässig - finden sich in der Substanz des Agar Gasblasen; auch in den Gelatine-Stichculturen kommt es manchmal zur Gasentwickelung.

In 1 procent. Peptonbouillon im Brütschrank findet gleichfalls schon nach 24 Stunden mässige, nach 48 Stunden intensive diffuse Trübung statt. Bildung eines Häutchens wird hier und da beobachtet, ist aber hier niemals sehr stark.

Auf Kartoffeln bei Zimmertemperatur bilden die Bacillen einen dicken, schmierigen, Anfangs blassgelben, später meist dunkelbraunen Belag, wie die Culturen der Rotzbacillen. Das am meisten Charakteristische des Wachsthums auf Kartoffeln ist die bleigraue Verfärbung der Kartoffel selbst in ihrer ganzen Substanz (Taf. I, Fig. 4abc); diese Farbe geht nach etwa 14 Tagen in ein schmutziges Rothbraun über. 
An der grossen Variabilität der Culturen nimmt aber noch das Verhalten auf der Katoffel Antheil, so dass ich das oben geschilderte Wachsthum nicht als ausnahmslos zu beobachten bezeichnen möchte; immerhin ist die graublaue Verfärbung der Kartoffel ziemlich constant und bietet ein recht charakteristisches Merkmal.

Sporenbildung habe ich an meinen Bakterien niemals wahrgenommen; dagegen habe ich einmal, als ich eine längst eingetrocknete, acht Monate alte Agarcultur auf Gelatineplatten brachte, noch reichliche Entwickelung der typischen Colonieen stattfinden sehen. Ueber weitere biologische Eigenschaften der in Rede stehenden Bakterien konnte ich meine Untersuchungen noch nicht zum Abschluss bringen und muss diesbezügliche weitere Mittheilungen mir noch vorbehalten.

Es war nun das Nächstliegende, die gewonnenen Bakterien auf ihre Pathogenität zu prüfen und zutreffenden Falles die beim Thierversuch sich ergebenden pathologischen Veränderungen mit denjenigen der fieberhaften Gelbsucht zu vergleichen. Noch zuvor aber war es von Werth zu versuchen, $a b$ sich unmittelbar vermittelst der frischen Organe des letal verlaufenen Krankheitsfalles eine Thierinfection herbeiführen lasse. Aber in dieser Richtung waren die äusseren Umstände sehr kläglich. Bei Beginn meiner Untersuchungen eben erst mit meiner bakteriologischen Einrichtung am Orte beschäftigt, war ich noch nicht im Besitze von irgend welchen Versuchsthieren, und so dauerte es trotz aller Bemühungen sieben Tage, bis ich endlich die bescheidene Zahl von drei grauen Hausmäusen erhalten konnte. Ein mit geglühten Instrumenten ausgeschnittenes Leberstück war in sterilisirter Glasschale während dieser Zeit auf Eis gehalten worden und hatte sich anscheinend ziemlich gut conservirt. Von den drei Mäusen erhielt die erste ein Stück der aufbewahrten Leber unter die Haut an der Schwanzwurzel, die zwei anderen wurden mit der inzwischen gezüchteten soeben beschriebenen Bacillenart in derselben Weise geimpft. Die mit dem Organstück unmittelbar geimpfte Waus und die eine der mit Cultur geimpften Mäuse blieben am Leben und gesund, die andere der mit der Bacillenreincultur geimpften Mäuse dagegen starb nach 13 Tagen. Bei der Obduction derselben fand sich makroskopisch nichts Abnormes; mikroskopisch dagegen reichliche Fettinfiltration der Leber- und der Nierenepithelien. In Ausstrichen der Leber fanden sich relativ reichlich dicke, etwas gekrümmte Bacillen mit abgerundeten Enden vor, welche den inzwischen in den Culturen gefundenen morphologisch glichen. Dieselben Bacillen waren auch in den Nieren und der Milz zu finden; in diesen Organen jedoch etwas spärlicher. Aus der Leber dieser Maus wurden Gelatineplatten angelegt. Nach drei Tagen waren auf diesen Platten Colonieen gewachsen, 
von welchen ein Theil die Gelatine $z u$ verflüssigen schien, ein anderer nicht, obwohl sie sonst den Findruck machten, dass es sich um eine einzige Art handle, und die Ausstrichpräparate aus beiden Colonieenarten genau dieselben Doppelstäbchen, dazwischen kurze kokkenähnliche Formen und längere gekrümmte Fädchen ergaben. Auch das gesammte Verhalten gegen die verschiedenen Anilinfarben, sowie die Unempfänglichkeit für die Gram'sche Färbung wurde bei beiden übereinstimmend beobachtet; desgleichen die lebhafte Beweglichkeit. Auch hier wurden, wie bei den ursprünglichen Bakterien, zwei Culturen neben einander gezüchtet, von welchen die eine als „, bezeichnet wurde. Auch das weitere Verhalten sowohl auf der Platte als im Gelatinestich erwies diese Culturen als nit den vorigen identisch; insbesondere die Bildung von Colonieen, welche in einem gewissen Stadium lebhaft an Choleracolonieen erinnern, ferner die gleichfalls choleraähnliche Entwickelung des Verflüssigungskraters im Gelatinestich und schliesslich die grünliche Fluorescenz. Der Wechsel in der Verflüssigungs,wirkung auf die Nährgelatine hatte stets etwas so Ueberraschendes, dass man oft an eine Spielart denken konnte. Fast immer aber trat sowohl bei den ursprünglichen als bei den aus dieser Maus erhaltenen Culturen später noch, und zwar ganz besonders in den Stichculturen, Verflüssigung ein. Doch besass ich auch schon Stichculturen, welche aus den von „verflüssigend" angelegten Platten abgeimpft waren und es dauernd nicht zur Verflüssigung brachten.

Im Laufe der seit Gewinnung dieser Culturen verflossenen $2 \frac{1}{2}$ Jahre hat die eine derselben, und zwar die als "Nicht verflüssigend" bezeichnete, ihre Fluorescenz verloren und wächst (bei genügend hoher Zimmertemperatur) exquisit wie Proteus vulgaris unter rapider Verfüssigung. Lässt man aber die Platten bei kühler Temperatur langsam wachsen, so verschwindet die Bildung der Proteusfiguren wieder vollständig, um so charakteristischer entwickeln sich alsdann wieder die Colonieen vom Choleratypus und eine Stichcultur aus einer solchen bei kühler Temperatur gewachsenen Platte hat noch nach 4 Tagen keine Verflüssigung gezeigt, obgleich Sticheanal und Oberfläche kräftiges Wachsthum hatten erkennen lassen. Alsdann begann sich hier ein choleraähnlicher Verfüssigungskrater langsam zu entwickeln.

Die hier aus dem letal verlaufenen Falle eines Infectionsicterus erhaltenen und durch das Thierexperiment reproducirten Culturen hatten in mir den Verdacht erregt, ob es sich nicht bier um eine dem Vibrio Metschnikoff nahe verwandte Art, vielleicht gar um diese Bakterien selbst, handle; nach Pfeiffer wird Verfettung der Leber bei Tauben beobachtet, welche mit sterilisirten Culturen dieses. Vibrio vergiftet wurden. Lag 
schon hierin eine gewisse Uebereinstimmung mit den beim fieberhaften Icterus und bei meinem Versuchsthiere gefundenen Veränderungen, so war das an Cholerculturen erinnernde Verhalten meiner Bakterien sowohl auf der Platte als im Gelatinestich, sowie die Eigenschaft, die Gelatine in wechselndem Grade zu peptonisiren, besonders geeignet, den genannten Verdacht $\mathrm{zu}$ erwecken. Theilweise geleitet durch diese Erwägung, theils auch unbefriedigt von dem verspäteten Verenden der Versuchsmaus beschloss ich daher, weitere Versuche an Tauben anzustellen, welche ja auf Vibrio Metschnikoff überaus leicht reagiren. Ich injicirte also zweien Tauben je $0.5^{\mathrm{cm}}$ einer. neun Tage alten verflüssigten Gelatinecultur meiner Bakterien mittels Koch'scher Spritze in den rechten Brustmuskel und zwar erhielt die eine Taube eine Cultur, welche noch nicht durch ein Thier gegangen war, die andere wurde mit einer aus der Versuchsmaus erhaltenen Cultur inficirt. Die erstere blieb am Leben, die letztere starb 16 Stunden nach der Infection. Ich muss hier erwähnen, dass diese Versuche erst sieben Monate nach Beginn der Untersuchungen ausgeführt werden konnten, dass also ein Verlust der Virulenz der ursprünglichen Culturen schon von vornherein sehr zu befürchten war. Das Sectionsergebniss der mit der virulenteren Cultur inficirten Taube war folgendes: Rechter Brustmuskel erheblich dicker als der linke. Beim Einschneiden zeigt sich der rechte Brustmuskel mehr gelblich gegenüber dem linken und mit blassgelblicher Oedemflüssigkeit durchtränkt; der linke Brustmuskel dünn und sehr trocken. Im Ausstrich aus dem Oedem des rechten Brustmuskels sind die Bakterien in überreichem Maasse vorhanden; in Ausstrichen aus dem linken Brustmuskel, im Herzblut, Leber und Darm fehlen dieselben; dagegen sind sie sehr reichlich vorhanden in den Lungen. Frische, mittels Gefriermethode gefertigte Leberschnitte ergeben Folgendes: Die Zeichnung der Leberläppchen ist nur noch an wenigen Stellen zu erkennen, auch die Leberzellen sehr undeutlich; sie sind reichlich mit grossen bis kleinsten Fetttropfen gefüllt, was durch Zusatz von 3 Procent $\mathrm{KOH}$ besonders deutlich wird.

In Schnitten aus der gehärteten Milz wurden die grossen leicht gekrümmten Stäbchen in spärlicher Anzahl aufgefunden. Aus Brustmuskel und Lunge wurden Gelatineplatten angelegt. Am dritten Tage waren auf denselben Colonieen in Gestalt der feinen Tröpfchen zu sehen. Das nächste, was sodann auffiel, war wiederum die Neigung, verflüssigende und. nicht verflüssigende Colonieen zu bilden; des Weiteren entwickelten sich dieselben genau wie die bisher beschriebenen, so dass ich dieser Beschreibung hier nichts hinzazufügen habe. Mit einer der so erhaltenen Culturen, und zwar aus der Lunge, wurde drei Wochen später eine weitere Taube in derselben Weise inficirt wie die erste: $0.5^{\mathrm{com}}$ ver- 
flüssigter Gelatinecultur in den rechten Brustmuskel. Dieselbe zeigte sich von der Impfung ab mehrere Tage sichtlich krank; sträubte die Federn, frass schlecht, sass in der Ecke und liess sich kaum wegtreiben; die Bewegungen waren langsam und matt. Die Ausleerungen waren dünn, gelblich, wässerig. Dann erholte sie sich anscheinend, ging aber 10 Tage nach der Infection ein. Bei der Section fand sich im geimpften rechten Brustmuskel ein 10-Pfennigstück-grosser nekrotischer Herd, welcher sich auf das intermusculäre Bindegewebe des rechten und linken Brustmuskels weiter erstreckte. Der untere Theil des Dünndarmes war entzündet und mit röthlich-gelber wässeriger Flüssigkeit gefüllt. Diese enthielt die gekrümmten Bacillen in grosser Menge. Die Leber erschien blassgelb gefärbt und erschien bei mikroskopischer Untersuchung im frischen Schnitt hochgradig fettig degenerirt. In Ausstrichen konnten ausser im Darm die Bakterien auch in der Milz, nicht aber in Lungen, Leber und Nieren gefunden werden; auch im Nekrosenherd des Brustmuskels wurden sie im Ausstrich und Schnitt vermisst und konnten hier nur durch das Culturverfahren nachgewiesen werden. In den Ausstrichen erscheinen bei den Tauben die Bakterien fast ausschliesslich in Kokkenform, wie dies auch R. Pfeiffer bezüglich des Vibrio Metschnikoff beobachtet hat. Das Culturverfahren wies die Bakterien nach im Brustmuskel, Darm, Niere, sowie (vereinzelte Colonieen) im Herzblut. Die Platten aus Milz, Lunge und Leber blieben steril.

Gleichzeitig mit der Aussaat der Organe dieser Taube wurde eine Aussaat einer von Hrn. Privatdocent Dr. R. Pfeiffer aus dem Berliner hygienischen Institut mir freundlichst übermittelten Cultur des Vibrio Metschnikoff auf Platten vorgenommen und zudem auch die früheren Culturen wieder auf Platten gebracht, um feststellen zu können, ob meine Culturen mit Vibrio Metschnikoff identisch seien. Diese Untersuchungen ergaben zunächst für Vibrio Metschnikoff und meine Culturen viel Uebereinstimmendes im Beginn der Entwickelung der Plattenculturen: die wie kleine Perlen glänzenden, stecknadelkopfgrossen, eingesunkenen, verflüssigenden Colonieen, den feinen Strahlenkranz um die grösseren, sowie den durch das scharfrandige Einsinken der Colonieen bedingten Lichteindruck. Andererseits besitzt Vibrio Metschnikoff eine weit grössere Choleraähnlichkeit als meine sämmtlichen bisherigen Culturen, auch zeigen die Platten von Metschnikoff entfernt nicht so viele Variationen wie die meinigen. In gefärbten Deckglas-Ausstrichen findet man bei Vibrio Metschnikoff ebenso vielerlei Formen aus einer und derselben Colonie, wie bei meinen Culturen, aber bei Metschnik off kommen ausgebildete Spirillen, wogegen ich meine Organismen trotz der auftretenden gekrümmten Formen zu den Bacillen glaube rechnen zu müssen, auch behält Vibrio Metschnikoff 
im Klatschpräparat streng seine kleinen gekrümmten Stäbchen bei, während bei den Culturen meiner Bakterien Form- und Grössenverhältnisse weit bedeutenderen Schwankungen unterliegen.

Das Verhalten im hängenden Tropfen ist für Vibrio Metschnikoff und meine Bakterien nicht zu unterscheiden. Noch weitere wesentliche Unterschiede sind die, dass Vibrio Metschnikoff erheblich langsamer wächst, dass er keine Proteusformen annimmt, und schliesslich dass er für Mäuse nur sehr wenig pathogen ist, wogegen sich meine Bakterien bei den noch z" beschreibenden späteren Untersuchungen für diese Thiere ziemlich infectiös erwiesen haben. Eine zur Vergleichung mit meinen Befunden mit Vibrio Metschnikoff geimpfte Taube starb nach 16 Stunden. Sie bot die von Pfeiffer geschilderten Befunde; in den Gewebsausstrichen erschienen die kokkenförmigen kurzen Vibrionen meinen Bakterien besonders ähnlich, auch das Bild der fettigen Degeneration war dasselbe wie in meinen Versuchen; gleichwohl muss ich auf Grund der oben erwähnten Onterschiede die Identität meiner Bakterien mit Vibrio Metschnikoff verneinen, hatte jedoch diese zwei Bakterienarten für ziemlich nahe mit einander verwandt.

Weitere, sowohl Impf- als Fütterungsversuche an grauen Mäusen waren mir bei meinen in dieser Richtung sehr prekären Hülfsmitteln durch verschiedentliches Jissgeschick fehlgeschllagen, ich übergehe dieselben daher. Erst im December 1890, also neun Monate nach den letzten Thierversuchen, kam ich in den Besitz einer Zucht weisser Mäuse, auf welche ich nun die bisher erhaltenen Culturen theils durch subcutane Infection an der Schwanzwurzel verimpfte, theils in Form von Bouillonculturen verfütterte. Diese Versuche fielen negativ aus. Ich musste mich daher zur Infection in die Bauchhöhle entschliessen. Hierzu verwendete ich, in Bouillonaufschwemmung, eine Mischung einer vier Wochen alten GlycerinAgar- mit einer frischen Gelatine-Cultur, welche beide im Brütschrank gewachsen waren, und injicirte drei weissen Mäusen je $0.1 \mathrm{~cm}$ hiervon in die Bauchhöhle; die erste Maus (A) wurde mit der seit $1 \frac{1}{2}$ Jahren auf Gelatine fortgezüchteten, noch niemals durch den Thierkörper gegangenen Cultur inficirt; bei der zweiten (B) kam die Cultur, welche vor $1 \frac{1}{2}$ Jahren eine Maus passirt hatte, und bei der dritten (C) die Cultur, welche auch noch vor 10, bezw. 9 Monaten zwei Tauben getödtet hatte, zur Verwendung. Die mit jener ersten Cultur inficirte Maus A blieb am Leben, zeigte sich auch trotz des nicht unbedeutenden Eingriffs fortwährend völlig munter. Maus B starb nach 20, Maus C nach 9 Stunden. Die Section von Maus C ergab: Cutisgefässe stark injicirt; in der Bauchhöhle sehr spärliche, schwach gelb-röthlich gefärbte Flüssigkeit; Leber von normalem Ausseben; ziemlich dunkel. Milz beträchtlich vergrössert. Nieren auffallend gross. Am Darm nichts Abnormes. In Ausstrichen aus der As- 
citesflüssigkeit und aus der Milz sehr zahlreiche, aus den Nieren spärliche Bacillen, in der Leber nicht deutlich, im Herzblut keine zu finden; durch das Plattenverfabren wurden die Bacillen aber auch im Herzblut nachgewiesen.

Section von Maus B. Cutisgefässe injicirt. Axillardrüsen hämorrhagisch. In der Bauchhöhle keine Flüssigkeit, keine Reizerscheinungen. Die Einstichöffnung ist nicht-mehr zu finden. Am oberen Dünndarm vier eigenthümliche Plaques zu sehen von ca. $1^{\mathrm{mm}}$ Durchmesser; ausserdem punktförmige Hämorrhagieen. Milz stark vergrössert. Lungen normal. Mikroskopisch: Leberverfettung sehr deutlich, aber noch im 'Beginn. Bakterien nur in der Bauchhöhle nachweisbar; hier ziemlich zahlreich. Durch Cultur konnten die Bakterien gleichfalls nur aus der Bauchhöhle gezüchtet werden; die Platten von Milz und Niere blieben steril.

\section{Fall II.}

Unteroffizier L., Pionnierbataillon Nr.13. Die Krankengeschichte dieses ist kurz folgende: Erkrankte am 18. Juni 1890 mit Fiebersymptomen, Schlingbeschwerden und Wadenschmerzen. Aufnahme in's Garnisonlazareth am 22. Juni. Angeblich in den letzten Tagen schlechter Appetit und Durchfall. Angebliche Ursache: Erkältung. Hat an 2. und 6. d. M. in der Donau gebadet. Temperatur bei der Aufnahme $40^{\circ} 0^{\circ}$; Milz wenig vergrössert, hintere Rachenwand stark geröthet, Mandeln nicht geschwollen, ohne Belag. Waden auf Berihrung sehr empfindlich. 23. Juni (fünfter Krankheitstag): Icterus. Leberdämpfung nicht vergrössert. Harn enthält Gallenfarbstoff und Eiweiss. 24. Juni Temperatur zwischen 39.0 und $40 \cdot 0^{\circ}$. Schmerzen in einigen Gelenken und im rechten Vorderarm. Grosse Lichtempfindlichkeit. Ueber beiden Lungen hinten unten Reiben. Urinsecretion spärlich. Stuhl grau, von mittlerer Consistenz. Icterus (in's Grünliche spielend) verstärkt. Bis zum 26. Juni hat der Icterus seinen Höhepunkt erreicht, Petechien fehlen, die Temperatur beträgt $38 \cdot 7^{\circ}$, es besteht grosse Apathie, Brechneigung; Pupillen ausserordentlich eng. Leber eher verkleinert wie vergrössert. Stuhl angehalten. Vom 28. Juni ab normale Temperatur, vom 30. Juni ab lässt der Icterus nach; vom 4. Juli ab stellt sich aber unter erneutem mässigem Fieber $\left(38.4^{0}\right.$ bis $\left.38.8^{\circ}\right)$ wieder Diarrhoe ein, welche $z$ war bald wieder verschwindet, doch verläuft die Reconvalescenz überaus langsam und erst am 9. September kann Patient geheilt entlassen werden.

Bei diesem zweiten Falle wurde versucht, aus dem Blute oder dem Harn während des Verlaufes der Krankheit die supponirten Erreger aufzufinden. Blutproben wurden durch Stich mit geglühter Nadel in die Fingerkuppe des rechten Mittelfingers nach vorheriger sorgfältiger Desinfection mit Sublimat, sodann Abwaschung mit sterilisirtem destillirten Wasser und sterilisirter Watte entnommen und theils in flüssig gemachter Gela- 
tine vertheilt, theils auf schräg erstarrtem Glycerin-Agar (unter Anlegen von Verdünnungen) ausgestrichen. Die Gelatineröhren wurden auf Platten ausgegossen, die Glycerin-Agar-Röhren kamen in den Brütschrank. Alle diese Blutculturen blieben steril. Der Versuch der Auffindung der Erreger im Harn schien wegen der bei Weil'scher Krankheit regelmässig beobachteten und auch im vorliegenden Falle vorhandenen heftigen $\mathrm{Ne}$ phritis Erfolg zu versprechen. Der Harn zur mikroskopischen und bakteriologischen Untersuchung wurde in sterilisirten Erlenmeyer'schen Kölbchen nach vorausgegangener Desinfection der Glans penis und insbesondere der Fósa navicularis aufgefangen ${ }^{1}$ und sofort im Laboratorium verarbeitet. Die mikroskopische Untersuchung dieses Harns ergab ein reichliches Sediment, bestehend aus Blutkörperchen, Nierenepithelien, granulirten Cylindern, sowie einer reichlichen Menge ziemlich grosser Bacillen mit abgerundeten Enden.

Auf Taf. I, Fig. 5 sind dieselben abgebildet: sie sind theils gekrümmt, theils gerade gestreckt, manche liegen in Haufen beisammen, andere mehr einzeln zerstreut, mit Vorliebe aber in zweigliederigen Verbänden angeordnet. Sie liegen nicht in den Zellen, wohl aber scheinen sie manchmal zwischen diese hineingeschoben, jedenfalls finden sie sich im Ausstrichpräparat überall da besonders reichlich, wo Gewebselemente liegen. Die grosse Zahl dieser Bacillen in dem frisch gelassenen und unter den angeführten Cautelen aufgefangenen Harn macht es an sich schon wahrscheiulich, dass es sich hier nicht um Zufälliges handelt. Aus diesem Harn wurden dann sofort Gelatineplatten angelegt und Ausstriche auf Glycerin-Agar gemacht, welch' letztere im Brütschrank gehalten wurden. Auf den Gelatineplatten hatten sich bei der hohen Sommertemperatur schon nach zwei Tagen charakteristische Colonieen in grosser Zahl entwickelt. Auf allen Platten fand sich eine verflüssigende und eine nicht verflüssigende Form stets neben einander. Die Colonieen zeigten alle früher beschriebene Typen: concentrische (choleraähnliche) Schichtung bei den jungen Colonieen, ferner runde, mehr opake Colonieen, zuweilen mit Einbuchtung, häufig mit einem durch das Einsinken hervorgerufenen Lichthof oder auch mit nicht verflüssigenden proteusähnlichen Ausläufern. Bei weiter fortgesetzten Untersuchungen fand ich bis auf den heutigen Tag noch folgende Verhältnisse sich stets wiederholen: auch die Oberflächencolonieen treten in zwei verschiedenen Typen auf; sie breiten sich zunächst alle flächenhaft aus, wobei sie eine schöne wellige Zeichnung erbalten; jetzt unterscheiden sie sich dadurch, dass die einen an der Peri-

1 Entnahme grösserer Blutproben auf eingreifendere Art, sowie Entleerung des Harns mittels sterilisirten Katheters erschien in diesem wie in den späteren Fällen wegen der Rücksicht auf unsere Kranken nicht thunlich. 
pherie ein mehr gelapptes Ansehen gewinnen, so dass vielfach kleine nicht rom Bakterienrasen überwachsene Gelatine-Inseln stehen bleiben und dass sie sehr op ak und gelbbraun gefarbt werden (vgl. Taf. I, Fig. 6), wogegen die anderen einen zarten, perlmutterglänzenden Belag bilden und bei schwacher Vergrösserung ganz und gar wie Typhuscolonieen aussehen. Finden die letzteren jetzt genürsend Platz, so nehmen sie einen Durchmesser bis $0.5^{\mathrm{cm}}$ an und behalten ihre Zartheit ohne zu verflüssigen. Die anderen Colonieen jedoch fangen 1 bis 2 Tage später an dellenförmig einzusinken, nun wird der bisher gelappte Rand gelockert, es treten feine Härchen an demselben hervor, der Verflüssigungstrichter wird mehr und mehr kreisrund, die Bakterien der Randzone stellen sich radiär, pallissadenförmig oder sie legen sich mehr nach der einen oder anderen Seite oder endlich sie stehen struppig durch einander wie bei einer ïberreifen Milzbrandcolonie. Die geschlossenen Colonieen pflegen von der Tiefe aus unmittelbar durch Verflüssigung ihres Nährsubstrates an die Oberfläche zu dringen oder sie bleiben als geschlossene kleine Colonieen auf einem jugendlichen Stadium stehen. Impft man von der einen oder anderen Art der geschilderten Colonieen in eine Gelatineröhre mittels Stich ab, so ist man nicht im Stande vorher zu sagen, ob die nun wachsende Cultur verflüssigen wird; wenigstens ist mir oftmals der aus einer ganz verflüssigten Colonie angelegte Stich nicht verflüssigend gewachsen oder hat nach wenigen Umzüchtungen sein Peptonisirungsvermögen wieder eingebüsst. Sticht man andererseits eine nicht verflüssigende Colonie auf eine Gelatineröhre ab, so wird sie meist auch sich als nicht verflüssigend fortzüchten lassen; will man aber aus dieser Cultur die verflüssigende wieder erhalten, so braucht man sie nur auf Platten zu bringen und kann sicher sein, auf diesen die verflüssigende und die nicht verflüssigende Spielart wieder anzutreffen. Ebenso habe ich es bei diesen und bei anderen meiner Culturen schon öfters erlebt, dass die mit Colonieen dicht übersäte Originalplatte von aller Verflüssigung rerschont blieb und bis zur völligen Eintrocknung aufbewahrt werden konnte, während auf den Verdünnungsplatten fast ausschliesslich verflüssigende Colonieen zu finden waren; aber auch den umgekehrten Fall habe ich nicht seltener beobachtet. Diesem capriciösen Verhalten der Plattenculturen entspricht nun auch die Entwickelung der Stichcultur. Tritt Verflüssigung ein, so entwickelt sich eine trichterförmige Luftblase wie bei den Choleraculturen, bleibt sie aus, so entsteht auf der Oberfläche der Gelatine eine höchst zierliche baumförmige Verästelung, wie sie mir von keiner anderen Bakteriencultur bekannt ist (vgl. Taf. I, Fig. 7). Wie bei den früheren Culturen habe ich auch hier von Anfang an eine als "verflüssigend" und eine als "nicht verflüssigend" bezeichnete fortgezüchtet und dieselben, so oft beide auch auf 
Platten gebracht und aus diesen wieder aufgefrischt wurden, doch stets getrennt gehalten. So habe ich denn schliesslich doch gewisse, etwas constant bleibende Eigenthümlichkeiten bei diesen zwei Culturen erhalten: während früher beide eine schwach grünliche Fluorescenz (wie meine ursprünglichen von Fall I gewonnenen Culturen) besessen hatten, hat sich diese bei der als "nicht verflüssigend" bezeichneten Art immer schöner entwickelt, so dass diese das Bild der Fluorescenz auf's prächtigste bietet (vgl. Taf. I, Fig. 8), wogegen die ,verflüssigende" manchmal ganz ungefärbt erscheint, manchmal einen Stich in's Röthliche annimmt. Auf Platten gehen die intensiv grün fluorescirenden Oberflächencolonieen, bei schwacher Vergrösserung gesehen, in äusserst zart gebuchtete, Lücken lassende Beläge über; an manchen Stellen kommt es bis zur Abschnürung einzelner Inseln: Proteustypus. In der Mitte sind die Colonieen meist ziemlich dicht, so dass hier ein förmlicher Klumpen sich bilden kaun. Die geschlossenen Colonieen sind kreisrund und haben den beschriebenen Choleratypus. Die Bacillen sind sehr lebhaft beweglich. Auf Kartoffeln bieten diese Cultureu das schon S. 537 geschilderte Aussehen.

Im gefärbten Deckglaspräparate finden sich die Kurzstäbchen mit abgerundeten Enden und meist stärker gefärbten Polen, vielfach zu zweien gelagert, ferner gekrümmte Stäbchen, vereinzelte kurze Scheinfāden und Kokkenformen, besonders bunt durch einander gemischt, wenu das Präparat aus einer Colonie stammt, in welcher die Verflüssigung bereits begonnen hat. Von den nicht verflüssigenden Colonieen gewinut man selrr lange und stattliche Scheinfäden; lommt es alsdann noch zur Verflüssigung, so fallen diese zum grössten Theil zu Kokkenformeu auseinander.

Die hier erhaltenen Culturen zum Thierexperiment zu verwenden war mir erst gleichzeitig mit den auf S. 542 geschilderten Versuchen, d. h. sechs Monate nach Gewinnung der Culturen aus dem Harne, möglich. Damals wurde auch eine Maus in derselben Weise wie dort beschriebeu mit $0.1 \mathrm{com}$ einer gemischten alten Agar- und frischen Gelatinecultur in die Bauchhöhle inficirt. Das Thier zeigte aber keinerlei Krankheitserscheinungen.

\section{Fall III.}

Pionier K. Erkrankte am 30. August 1890 mit Fieber, Rücken- und Wadenschmerzen. Er glaubt, „dass die Donaubäder zu seiner Erkrankung beigetragen haben"; er hat am 23. Augustangeblich letztmals in der Donau gebadet, in der Zeit vorher eine Woche lang täglich. Aufnahme in's Lazareth: 1. September 1890. Temperatur: $39 \cdot 3^{0}$. Von einer Untersuchung der Lungen muss wegen sehr heftiger Rückenschmerzen abgesehen werden. Leichter beginnender Icterus (am dritten Krankheitstage); leichte Conjunctivitis. Rachen geröthet, auf der 
rechten Tonsille ein leichter graugelber Belag. Die Musculatur beider Waden bei leichtem Druck äusserst schmerzhaft; starker Durchfall; Stuhl wässerig, gelblich gefärbt, mit reichlichen Schleimflocken. Im Harn geringe Menge von Gallenfarbstoff, Spuren von Eiweiss. 3. September Icterus beträchtlich stärker, dabei Stich in's Grüne. Temperatur Abends: 39.9 ${ }^{\circ}$; starke Kopfschmerzen; sehr grosses Mattigkeitsgefühl. 4. September am Rumpf kleine, unregelmässige, roth gefärbte Flecken, welche theilweise confluiren. 5. September Milzvergrösserung. Temperatur Abends: $38 \cdot 5^{\circ}$. 6. September Fieberabfall: Morgens $37 \cdot 4^{0}$, Abends $37 \cdot 8^{\circ}$. Von da ab normale Temperatur und leidliches Wohlbefinden, aber Icterus und Wadenschmerzen, sowie Eiweissund Gallenfarbstoffgehalt des Harns bestehen fort. Vom 14. September ab steigt die Temperatur wieder staffelförmig an, um am 19. Sept. die Höhe von $40 \cdot 2^{\circ} \mathrm{zu}$ erreichen und alsdann wieder ebenfalls staffelförmig abzufallen. Gleichzeitig mit diesem Anstieg der Temperatur treten wieder Kopfschmerzen auf; die Wadenschmerzen werden stärker; Mattigkeitsgefühl; von Neuem Milzvergrösserung. Nur sehr langsame Reconvalescenz; noch am 7. October leichte Spur von Eiweiss im Harn. Am 19. November geheilt in zweiwöchentlichen Erholungsurlaub entlassen.

Ton diesem Falle erhielt ich am 3. September Kenntniss und entnahm an demselben Tage Blutproben sowie Harn; beides in der bei Fall II (S. 543) angegebenen Weise. Die milkroskopische Untersuchung des Harnsedimentes ergab zahlreiche grosse Drusen von Tyrosinkrystallen, ferner Cylinder und zahlreiche Nierenepithelien. Dazwischen fanden sich haufenweise meist doppelgliedrige Kurzstäbchen mit stark gefärbten Polen und transparentem Zellleibe (die letztere Erscheinung hier besonders markant), allerdings waren die Organismen auffallend klein, rgl. Taf. III, Fig. 2. Aussaat wurde aus Blut auf Glycerin-Agar (Brütschranli) und auf Gelatine (Zimmer) vorgenommen. Aus dem Harn wurden nach Absetzen aus dem Sediment Gelatineplatten angelegt. Am 7. September wurde abermals eine Harnprobe entnommen und auf Gelatine gebracht. Sämmtliche am 3. September angelegten Culturplatten blieben steril.

Es ist hier also der Versuch, die Mikroorganismen aus dem Harn zu züchten, fehlgeschlagen, obgleich dieser dieselben reichlich enthielt. Soweit indessen das morphologische Verhalten einen Schluss gestattet, bin ich geneigt, die im Harn gesehenen Organismen für identisch mit den in den zwei ersten Fällen auch durch das Culturverfahren gewonnenen anzusehen; dieselben scheinen aber im Harn zur Zeit der Culturversuche schon abgestorben gewesen zu sein.

In demselben Sommer 1890, in welchem die Erkrankungsfälle II und III zur Beobachtung lamen, traten noch zwei weitere auf, wovon der eine tödtlich endete. Leider entging mir die Möglichkeit, diese beiden Fälle in Untersuchung zu nehmen, da ich während ihres Verlauf'es von Ulm 
abwesend beim internationalen medicinischen Congress in Berlin war. Durch einen bedauerlichen Irrthum wurden auch die zur späteren Untersuchung bestimmten aufbewahrten Organtheile vor meiner Rückkehr vernichtet. Der Vollständigkeit wegen mögen aber wenigstens die Krankengeschichten und besonders das Sectionsergebniss hier mitgetheilt werden.

\section{Fall IV.}

Fussartillerist Br. Erkrankte am 2. August 1890 plötzlich mit heftigem Frost und Hitze, Husten und Erbrechen. Als Ursache giebt er Erkältung bei einem Bivak (Belagerungsübung?) an; in der Donau will er nur einmal, und zwar vor drei Wochen gebadet haben. Am 3. August Aufnahme in's Lazareth. Temperatur $40 \cdot 3^{\circ}$. Heftiger Schüttelfrost; Halsschmerzen; Gaumenbögen stark geröthet, Tonsillen geschwollen. 4. August Temperatur $39 \cdot 2^{\circ}$. Kopfschmerzen, Brechneigung, pleuritisches Reiben rechts. 5. August Temperatur $39 \cdot 4^{\circ}$. Urin eiweisshaltig. Sputum

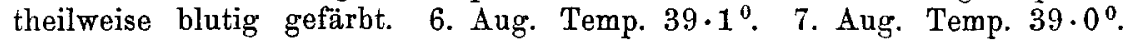
Schmerzen auf der Brust, in den Schultern und Knieen, Druckempfindlichkeit in beiden Waden. Leichter Icterus (am vierten Tage). 8. August Temp. 38. $7^{\circ}$. Starkes Mattigkeitsgefühl, heftige Schmerzen in beiden Waden. Milz beträchtlich vergrössert. Der Urin enthält Gallenfarbstoff, Eiweiss, Cylinder. Stuhl geformt, entfürbt. 10. Aug. Fieberabfall. 11. Aug. Etwas Diarrhoe. 14. Aug. Ieterus im Rückgang; noch deutlicher Milztumor. Von da ab langsame Reconvalescenz. 19. September geheilt entlassen.

\section{F all V.}

Pionier L. Erkrankte am 4. August 1890 an Frost, Hitze und Kopfschmerzen. Aufnahme in's Lazareth an demselben Tage. Weiss keine Ursache anzugeben; hat in letzter Zeit täglich in der Schwimmschule gebadet. Temperatur $40 \cdot 0^{\circ}$. Gaumenbögen leicht geröthet, Tonsillen geschwollen, ohne Belag. 5. Aug. Temperatur $39 \cdot 6^{\circ}$. Sehmerzen in beiden Kniegelenken. 6. Aug. Temperatur 38.10. Starkes Nasenbluten. Kein Milztumor. 7. Aug. Temperatur 39.3\%. Wiederholtes Nasenbluten. Druckempfindlichkeit beider Waden. Icterus. Lebergegend nicht druckempfindlich. Leber nicht vergrössert. 8. Aug. Milz wenig vergrössert. Urin stark eiweisshaltig. 9. Aug. Temperatur $37 \cdot 7^{\circ}$. Icterus stärker, Stuhl grau. Schmerzhaftigkeit der Waden, besonders beim Beklopfen. Kein Nasenbluten mehr; Nacht ruhig, Puls kräftiger. Mittags 1 Uhr plötzlicher Collaps und Tod.

Obductionsbefund: Haut ausgesprochen icterisch, besonders die Conjunctiva, Leber nicht vergrössert, auf dem Durchschnitt von braunrother Farbe, auffallend speckigem Glanz, blutarm, der acinöse Bau kaum erkennbar. Milz vergrössert $\left(10: 16^{\mathrm{cr}}\right)$. Die Nierenkapsel beiderseits fast überall mit der Niere selbst verwachsen. Beide Nieren bedeutend vergrössert. Beim Durchschnitt zeigt sich die Rindensubstanz sehr stark verbreitert und geschwollen. Die Pyramiden braunroth, in einer Pyramide der linken Niere 
ein umfangreiches Blutextravasat. Dünn- und Dickdarm, sowie Magen stark mit Gasen gefüllt, die Serosa glatt, keine Auflagerungen; Magen- und Darmschleimhaut überall normal, keine Schwellung der Mesenterialdrüsen oder Peyer'schen Plaques.

In den folgenden im Sommer 1891 aufgetretenen Fällen wurden wiederum bakteriologische Untersuchungen von Blut und Harn ausgeführt und Fall IX, welcher tödtlich rerlief, konnte einer systematischen bakteriologischen Verarbeitung unterworfen werden.

\section{Fall VI.}

Grenadier B. Erkrankte am 11. Juli 1890 mit Kopfschmerz, Schwindel, Mattigkeit und Gliederschmerzen. Aufnahme in's Lazareth am 12. Juli 1891. Temperatur $38.7^{\circ}$. Ursache unbekannt; hat rom 28. Juni bis 2. Juli dreimal in der Donau gebadet, nachher nicht mehr. Civilberuf: Metzger. Hochgradiges Schwindelgefühl; Patient schwankt beim Aufsitzen im Bett. Die Leberdämpfung überragt den freien Rippenrand in der Mammillarlinie um zwei Fingerbreiten. Milz scheint etwas vergrössert. 16. Juli Temperatur $40 \cdot 1^{\circ}$. Icterus. 17. Juli Temperatur $37 \cdot 8^{\circ}$. Icterus bedeutend stärker. Stuhl fast völlig entfärbt. Im Harn Gallenfarbstoff aber kein Eiweiss. Fieberabfall. Langsame Reconvalescenz; der Harn bleibt dauernd frei von Eiweiss.

In diesem Falle entnahm ich am 18. Juli Blutproben aus der Fingerkuppe und beschickte damit schräg erstarrtes Glycerin-Ägar (Brütschrank) und Gelatineplatten (Zimmer). Desgleichen fing ich Harn in sterilem Erlenmeier'schen Kölbchen auf und machte von demselben gleichfalls Aussaaten auf Glycerin-Agar und Gelatine. Auf den mit Blut beschickten Agarflächen wuchsen nur in einem Röhrchen einige Colonieen von Diplokokken, welche gegen einander abgeplattet erschienen, offenbar eine Verunreinigung, in den Glycerin-Agar-Culturen aus Harn dagegen waren bei Brüttemperatur schon nach 24 Stunden die Culturflächen mit zarten Colonieen bedeckt. Dieselben erwiesen sich als aus lebhaft beweglichen meist zu zweien gelagerten Bacillen bestehend, welche in der Mitte eine helle Lücke aufwiesen und an den Enden abgerundet waren. Sie färbten sich schlecht mit Gentiana, gut dagegen mit Löffler's Methylenblau unter Erwärmen, doch erschienen sie hierbei ziemlich klein; grösser sah man sie bei Färbung mit Carbolfuchsin mit Erwärmen; hierbei verschwand auch die Lücke. Die Form der Bacillen erschien häufig beinahe völlig kreisrund, sodass man auf den ersten Blick sehr geneigt sein konnte, dieselben für Kokken anzusehen, doch fanden sich in Klatsehpräparaten ganz unzweifelhafte Bacillen oft mitten zwischen die scheinbaren Kokken eingelagert, wie dies aus dem in Taf. IV, Fig. 1 abgebildeten Klatschpräparate $z \mathfrak{u}$ ersehen ist. 
Auf den Gelatineplatten fanden sich anfänglich Colouieen vom Aussehen wasserheller Tröpfchen, welche bei schwacher Vergrössernng kreisrund und dunkelgelb erschienen, zuweilen mit concentrischer Schichtung (Choleratypus), zuweilen auch unregelmässig eingebuchtet; nach 2 Tagen war zwar keine eigentliche Verflïssigung von den Colonieen aus eingetreten, dagegen. war die ganze Gelatine zähflüssig geworden und von den festen Colonieen aus hatten sich zahllose kleinste Schwärminseln über die ganze Gelatinefläche verbreitet. Die Oberflächencolonieen zeigten zarten, stark gebuchteten Belag und gingen zum Theil in den erwähnten Proteustypus über. Vielfach waren die Formen der Bacillen fast sämmtlich von kokkenförmiger Kürze, doch verriethen stets einzelne in den Colonieen liegende derbe Bacillen die eigentliche Natur der Orgalnismen.

In diesem Falle war ich endlich in der Lage, die gewonuene Cultur sofort auf eine weisse Mlans zu verimpfen und zwar benutzte ich hierzu eine im Brütschrank gewachsene Glycerin-Agarcultur; ich impfte eine Platinöse voll unter die Haut an der Schwanzwurzel. Nach etwa 20 Stunden war die Maus sichtlich krank: sie sass zusammengekauert, stellte die Haare, frass nicht, das rechte Auge war rerklebt. Nach weiteren 24 Stunden Morgens war sie schwer krank; sie fiel um, weun das Glas geneigt wurde, in welchem sie sass; beide Augen fest verklebt mit gelblichem Secret. Am Abend desselben Tages begann sie sich zu erholen, sie frass wieder und konnte sich etwas kräftiger auf den Beinen halten; die Augen waren noch verklebt. Am folgenden Morgen, also am dritten Tage nach der Impfung, war nur noch das rechte Auge rerklebt und das Thier frass mit grosser Gier. Bei dem sichtlichen schweren Krankheitszustand, aber der offenbar bevorstehenden Heilung entschloss ich mich, die Maus durch Chloroform zu tödten. Obduction: Magen colossal gefüllt; Leber ganz auffallend blassgelblich. Nilz sehr bedeutend vergrössert. Verfettung in der Leber nicht sehr dentlich, in der Niere dagegen sehr ausgesprochen. Die rechte Niere zeigt einen die Hälfte derselben einnehmenden gelben Herd (Infarkt?). In diesem massenhaft Bacillen und zwar ausgesprochen lange und gekrümmte Stäbchen; auch hier nicht sehr gross. In Milz, Lunge, Leber und Herzblut unsicherer Befund. Aus der erkrankten Niere war im Brütschrank auf Glycerin-Agar eine üppige Cultur sehr lebhaft (wie ein Mückenschwarm) beweglicher Bacillen gewachsen. Im gefärbten Präparat aus isolirter Colonie wurden kurze und lange, dickere und dünnere Bacillenformen, auch etwas geschlängelte, bunt durch einander vorgefunden. Schon die Glycerin-Agarcultur zeigte grünliche Fluorescenz: dieselbe Erscheinung trat auch bei den Gelatineplatten aus den Organen dieser Maus auf. Hier trat wieder 
im Anfang der Choleratypus der geschlossenen Colonieen auf, während die Oberflächencolonieen einen sehr zarten, aber stark zerklüfteten Belag bildeten. Auf der zweiten Verdünnungsplatte fanden sich Colonieen mit echten typischen Proteusschnörkeln. Die Bacillen erschienen theils lang, theils kurz bis zur Kokkenform; die längeren häufig gekrümmt; sie färbten sich nur mangelhaft mit Gentianaviolett und waren überaus lebhaft beweglich.

\section{Fall VII.}

Fussartillerist B. Erkrankte am 13. Juli 1891 plötzlich während des Dienstes mit Frieren, Kopfschmerz, Schwindel und Durchfall. Temperatur $40.0^{\circ}$.

An den folgenden Tagen niedrigere Temperaturen, doch bestand der Durchfall und grosse Mattigkeit fort. Am 19. Juli wurde Gelbfärbung der Haut bemerkt und Patient deshalb in's Lazareth geschickt. Ursache der Erkrankung unbekannt. Patient ist Schwimmer und hat bis 11 Tage vor dem Beginn seiner Erkrankung fleissig in der Donau gebadet. Temperatur am Tage der Aufnahme Abends $38.9^{\circ}$; von da ab jeden Tag niedrigere Temperatur, bis am dritten Tage die Norm erreicht ist. Milzvergrösserung war niemals nachweisbar, auch keine Vergrösserung oder Empfindlichkeit der Leber. Der Icterus nahm so lange, wie die erhöhte Körpertemperatur bestand, zu. Der Harn enthielt Gallenfarbstoff, aber niemals Eiweiss. Stuhl dünn und ziemlich stark entfärbt. Nach einmonatlichem Lazarethaufenthalt geheilt entlassen.

Man konnte bei diesem Fall sehr im Zweifel sein, ob man es mit der catarrhalischen Gelbsucht oder mit der Weil'schen Krankheit zu thun habe, da Milzschwellung und Nierenaffection fehlten, nervöse Symptome sehr wenig hervortraten und überhaupt der Krankheitsverlauf ein sehr leichter war. Andererseits spricht der plötzliche Beginn mit hohem Fieber, die Art des langsamen Fieberabfalls und das wenigstens im Beginn geklagte Schwindelgefühl für Weil'schen Icterus. Es war also hier von besonderem Interesse, ob sich die bei den bisher untersuchten Fällen aufgefundenen Bakterien nachweisen lassen. Die Blutuntersuchung fiel auch hier, wie bisher stets, negativ aus. Aus Harn dagegen wurde auf Glycerin-Agar im Brütschrank eine Cultur erhalten, bei welcher es zunächst aussah, als ob dieselbe nur aus Kokken bestehe; nach längerem Suchen fanden sich aber auch zwischen den Kokken vereinzelte kurze Stäbchen liegen. Ausserdem erwiesen sich die Barterien als unzweifelhaft beweglich. Die darauf folgende Untersuchung auf Gelatineplatten ergab ferner Folgendes: mit blossem Auge sieht man, besonders auf der zweiten Verdünnungsplatte, weit ausgebreitete, prächtig grün fluoreseirende Oberflächencolonieen; daneben kleine geschlossene, in der Tiefe liegende, über welchen die Gelatine einsinkt; sind solche weiter fortgeschritten, so bilden 
sie einen kreisrunden Verflüssigungskrater. Bei schwacher Vergrösserung zeigen die Oberflächencolonieen die feine Zeichnung wie Typhuscolonieen, unterscheiden sich aber von diesen durch ihre grünliche Farbe und den dichten Belag in der Mitte. Die kleineren geschlossenen Colonieen lassen die choleraähnliche concentrische Schichtung besonders deutlich erkennen. Die Bacillen besitzen die bisher als besonders charakteristisch geschilderte lebhafte Beweglichkeit, sie haben abgerundete Enden und aus einer und derselben Colonie findet man in jedem Ausstrichpräparate alle möglichen Form- und Grössenverhältnisse der Bakterien vor: besonders die Kokkenformen sind stark vertreten und zwar in den verflüssigenden Colonieen fast ausschliesslich; diese "Kokken" besonders können so klein werden, bezw. bei gewissen Färbungen (Methylenblau, Gentianaviolett) sich als so klein produciren, dass man es kaum für möglich halten sollte, dass sie dieselbe Abstammung besitzen wie neben ihnen liegende derbe, mehrfach gekrümmte Scheinfäden. Die letzteren sind in den frischen, nicht verflüssigenden Oberflächencolonieen sehr reichlich vertreten.

Mit der im Brütschrank gewachsenen Glycerin-Agarcultur aus Harn wurde wiederum eine Maus an der Schwanzwurzel geimpft. Sie starb nach 2 Tagen; es fand sich hochgradige Leberverfettung; der untere Dünndarm entzündet und hämorrhagisch; in demselben die Bacillen in reichlicher Nenge, aber nicht in den Organen.

\section{Fall VIII.}

Dragoner F. Erkrankte am 24. Juli 1891 Abends mit Kopfschmerz, Uebelkeit und Schlingbeschwerden. Er glaubt, dass seine Erkrankung vom Schwimmen herkomme; zum letzten Mal habe er am 22. Juli in der Donau gebadet. Bei der Aufnahme in's Lazareth (am 25. Juli) Temperatur $39 \cdot 5^{\circ}$. Leber und Milz nicht vergrössert. Am 27. Juli Temp. $40.1^{0}$. Klagen über Schmerzen in den Waden und Oberschenkeln. Schwindel beim Aufrichten. Am 28. Juli beginnender Icterus. Temperatur $39 \cdot 2^{\circ}$. Am 29. Juli Temp. $38 \cdot 3^{0}$; Icterus sehr deutlich; die Leberdämpfung überragt in der Mammillarlinie den Rippenbogen um 3 bis 4 Querfinger. Urin stark eiweisshaltig. Apathie bei freiem Sensorium. Am 30. Juli Temp. 38.4 ${ }^{\mathbf{0}}$. Am 31. Juli Temp. $38 \cdot 8^{\circ}$. Milzvergrösserung beträchtlich; Lebervergrösserung geht zurück. Eiweissgehalt des Harns hat abgenommen. 1. Aug. am Rücken zahlreiche Petechien. Temperatur $37 \cdot 8^{\circ}$. Am 2. Ang. Temperatur $37 \cdot 6^{\circ}$; am 3. Ang. Temp. 38.9. Recidiv. 5. Aug. Eiweissgehalt wieder vermehrt. Während die Erscheinungen sich langsam bessern bleibt noch leichtes Fieber $\left(38 \cdot 0^{\circ}\right.$ bis $\left.38 \cdot 3^{0}\right)$ bis zum 30. August bestehen. 3. Septbr. in Erholungsurlaub entlassen.

In diesem Falle war das Ergebniss der Culturversuche ein negatives: Zunächst wurden mit dem Harn unmittelbar zwei Mäuse, die eine sub- 
cutan, die andere in die Bauchhöhle inficirt. Beide Mäuse blieben gesund. Ferner wurden mit dem Harn Glycerin-Agar und Gelatine beimpft; desgleichen auch mit aus der Fingerkuppe entnommenem Blute. Auf dem mit Blut beimpften Glycerin-Agar wuchsen nur einige Colonieen einer als Verunreinigung aufzufassenden, sich mit Gentiana sebr intensiv färbenden Kokkenart; in der Cultur aus Harn auf Glycerin-Agar fanden sich einige gelbliche Colonieen; dieselben bestanden auscheinend aus Kokken, doch waren dieselben mit Stäbchen vermischt. Es wurde daher aus dieser Cultur eine Maus an der Schwanzwurzel geimpft, diese blieb aber gesund; auf den aus derselben Cultur angelegten Gelatineplatten wuchs nichts. Charakteristisches.

Es ist möglich, dass die mit Stäbchen vermischten Kokken in der Cultur aus dem Harn die gesuchten Organismen waren, aber das negative Resultat des Thierversuches und der Weiterzüchtung spricht dagegen. Als Ursache dieses Misserfolgs ist mir das Wahrscheinlichste, dass die Untersuchung zu spät stattgefunden hatte, nämlich erst am 31. Juli, da mir vorher nichts von der betreffenden Erkrankung bekannt geworden war.

\section{Fall IX.}

Grenadier W. Fühlte sich am 1. Aug. Nachmittags unwohl, so dass er sich auf's Bett legte. Am 2. (Sonntage) Mrorgens bekam er Erbrechen. Er genoss an diesem Morgen nichts, nahm dann das Mrittagsessen aus der Menage ein, trank im Verlauf des Mittags zwei Glas Bier in der Stadt ohne etwas zu essen und kehrte schon am Mittag in die Kaserne zurück, wo er sich wieder zn Bett legte. Am 3. August hatte er Stadturlaub und wollte Erdarbeiten verrichten, war aber dazu nicht im Stande, sondern legte sich in der Nähe des Arbeitsplatzes auf einer Wiese einige Stunden nieder, hoffend, dass es bald besser werde. Am Nachmittag kehrte er wieder in die Kaserne zurück mit der Klage, er fühle sich unwohl, weshalb ihm erlaubt wurde, sich wieder auf's Bett zu legen, bis es ihm besser würde. In der Nacht auf den 4. August Morgens $1 \mathrm{Uhr}$ auf dem Wege zum Abort brach er ohnmächtig zusammen, so dass er schwer auf Gesicht und Knie stürzte. Der herbeigerufene Arzt fand ihn im Collaps mit starker Cyanose und Dyspnoe und kaum fühlbarem Puls. Aetherinjectionen und Verbringung in's Lazareth. Der Puls besserte sich nun etwas, er betrug 148 Schläge. Temper. $40 \cdot 8^{\circ}$ im Rectum bei eiskalten Extremitäten. Patient hatte mehrere diarrhöische Stühle unter sich gehen lassen, war apathisch und somnolent, gab aber auf Fragen Antwort, wenn auch mit etwas gestörter Sprache; Pupillen ungleich, reagiren aber gut auf Licht. Bezüglich der Ursache seiner Erkrankung gab er wiederholt und sehr bestimmt an, er habe am 1. d.M. eine sogen. "schwarze Wurst" (eine Art Blutwurst) gegessen, welche stark gerochen und schlecht geschmeckt habe. Diese Angabe hat er dem gerufenen, wachhabenden Arzt in der Kaserne gemacht, dann demselben im Lazareth wiederholt und dort auch dem Stationsarzt mit 
gleicher Bestimmtheit abermals wiederholt. Puls und Athmung besserten sich trotz der angewandten Reizmittel nicht; plötzlich $9^{3} / 4$ Uhr Morgens erfolgte unter einigen krampfhaften Zuckungen der Tod. Obduction 23 Stunden post mortem. Ueber dem linken Stirnlappen des Gehirns ein thalergrosser Bluterguss in die weichen Hirnhäute. A uf dem inneren Blatte des Herzbeutels in der Gegend der grossen Gefässe sind zahlreiche Hämorrhagieen von verschiedener Grösse; stecknadelkopfgrosse Blutpünktchen ziehen sich am rechten Vorhof und Ventrikel bis zur Herzspitze herab. Die Schleimhaut des Kehlkopfes, der Luftröhre und der grösseren Bronchien ist entzündlich geröthet und zeigt venöse Stauung. Die Leber von normaler Grösse, makroskopisch ohne Abnormität. Die Gallenblase mit braungelber Galle gefüllt. Milz gleichfalls nicht vergrössert, nur die Nieren .überschreiten um Weniges die normalen Maasse.

Die Speiseröhre stark geröthet, die Magenschleimhaut zeigt in der Gegend des Pförtners in weiter Ausdehnung zahllose kleine Hämorrhagieen. Auf dem Gekröse sind ebenfalls an vielen Stellen stecknadelkopfgrosse Ecchymosen sichtbar. Die Blutgefüsse des Dünndarms sind stark gefüllt, zwischen ihren Verästelungen sind zahlreiche Blutergüsse vorhanden. Die Péyer'schen Plaques sind nicht geschwollen. Die mikroskopische Untersuchung der Leber und Nieren ergab in frischen Schnitten hochgradige Verfettung der Zellen. In der Leber zeigte sich der acinöse Bau an vielen Stellen fast völlig verwischt, die Leberzellen mit grösseren und kleineren Fetttröpfchen angefüllt; auch in den Nierenschnitten fanden sich viele Zellen, welche dieselbe Fettinfiltration zeigten wie die Leberzellen. In der Milz wurden krankhafte Veränderungen des Gewebes nicht constatirt. Dagegen fanden sich in gefärbten Schnitten aus allen genannten Organen gelbe amorphe Pigmentschollen und Körner wie im Fall I, „Serg. M.", sowie kleinzellige Infiltrationen in das Parenchym dieser Organe.

Organstücke wurden in Alkohol gehärtet und alsdann in Schnitten auf Bakterien untersucht. Hier zeigte sich nun schon in den ersten Schnitten das ganze Gewebe der Leber, der Wilz und der Nieren ganz massenhaft mit Bacillen durchsetzt; besonders in den Nieren konnte ich in jedem Schnitt ganze Blutgefässe von dicken Bacillen vollgestopft finden; daneben lagen die Organismen aber auch frei im Gewebe in unabsehbarer Menge, hier aber vorwiegend in "Kokkenform"; zuweilen auch in Haufen wie im Fall I. Die Abbildung Taf.I, Fig. 9 u. Taf.IV, Fig. 2 veranschaulicht diese Verhältnisse. Man erkennt hier deutlich eine morphologische Uebereinstimmung dieser Organismen mit denen, welche der Fall $I$ kennen gelehrt hat. Die reichliche Menge der hier gefundenen Bakterien ermöglicht aber auch, in einem und demselben Schnitt den Wechsel in Form und Grösse, welcher diese Bakterien auszeichnet, zu constatiren und damit ihre Identität mit den durch das Culturverfahren gewonnenen mehr zu veranschaulichen.

Steht schon dieses Ergebniss der Schnitt-Untersuchungen in richtigem 
Verhältniss zu dem foudroyant verlaufenen Krankheitsfalle, so zeigten sich auch die Resultate des Culturverfahrens und das Thierexperiment in vollem Finklang damit, so dass dieser Fall die bisher durch mancherlei widrige äussere Umstände unvermeidbar gebliebenen Lücken, wie ich glaube; im Wesentlichen ansfüllte.

Sofort nach der Obduction wurden aus Leber, Milz and Nieren sowohl auf Glycerin-Agar als auf Gelatineculturen angelegt, erstere für den Brütschrank, letztere für Zimmertemperatur bestimmt. Zugleich wurden zweien Mäusen je ein Organstückchen aus Milz und aus Niere unter die Haut an der Schwanzwurzel gebracht. Schon am folgenden Tage waren auf allen Glycerin-Agarflächen überall dieselben Reinculturen gewachsen, die Agarflächen mit dichten feinen Tröpfchen übersät. Am zweiten Tage waren diese Colonieen zum Theil confluirt und zu einem dichten gelblichweissen Belage geworden; die Substanz des Agar hatte eine grünliche Fluorescenz angenommen und enthielt Gasblasen. Auch alle Gelatineplatten waren schon nach zwei Tagen mit Culturen einer einzigen Art dicht besät; dieselben präsentirten sich zunächst als feine wasserhelle 'Tröpfchen, welche bei schwacher Vergrösserung als meist kreisrunde, hellgelbe, stark granulirte Colonieen erschienen. Alsdann nahmen sie in exquisiter Weise den Choleratypus an, besonders die in der nächsten $\mathrm{Cm}$ gebung der mit der Gelatine auf die Platte gebrachten Organstückchen gewachsenen Colonieen. Hier war auch etwas Verflüssigung angedeutet; die Gelatine weich, das Organstückehen kraterartig eingesunken; ausgesprochene Verflüssigung trat aber nirgends ein. Daneben finden sich Oberflächencolonieen mit zarter schön gezeichneter Ausbreitung; stark gebuchtet. Im hängenden Tropfen erwiesen sich die Organismen, aus welchen diese Colonieen bestanden, als lebhaft bewegliche Kurzstäbchen von beträchtlicher Grösse, meist zu zweien gelagert mit abgerundeten Enden; im Innern Lückenbildung; dazwischen grosse Scheinfäden. In den Culturen auf Glycerin-Agar fanden sich im Wesentlichen dieselben Verhältnisse, doch waren bier nur Kurzstäbchen von Kokkenform zu finden. Eine intensive Färbung der Bakterien gelang nur mitteis erwärmtem Methylenblau oder Carbolfuchsin.

Aus der am 5. August aus der Leber angelegten Glycerin-Agarcultur wurden am 7. August zwei Mäuse inficirt und zwar erhielt die erste $0 \cdot 1^{\mathrm{ccm}}$ einer Bouillon-Aufschwemmung der Cultur in die Bauchhöhle, die zweite wurde in gewöhnlicher Weise subcutan an der Schwanzwurzel geimpft.

Die aus der Reincultur in die Bauchhöhle geimpfte Maus war am anderen Morgen todt. (Der Tod trat zwischen 12 und 16 Stunden ein.) Die Milz war bedentend verorössert; Leber und 
Nieren zeigten beträchtliche Verfettung. In Ausstrichen fanden sich die Bacillen in Milz, Niere und Lungen massenhaft vor, im Herzblut waren sie nicht aufzufinden.

Drei Tage nach der Infection starb sodann die mit der Reincultur an der Schwanzwurzel geimpfte Maus. Milz um's Doppelte vergrössert; in den Lungen verschiedene pneumonische Herde, linke Niere gleichfalls sehr vergxössert. In Ausstrichen fanden sich hier die Bacillen auch im Herzblut, sowie in der Milz und Leber, besonders reichlich aber in der vergrösserten Niere. Es fiel hier besonders die Transparenz, die Färbung der Pole und die häufig gekrümmte F'orm, ausserdem aber aụch die Verschiedenheit der Grösse der Bakterien auf. In den mit Carbolfuchsin hergestellten Präparaten erschienen viele Exemplare, doch nicht alle, mit einem ungefärbten Hofe umgeben; als eine eigentliche Kapsel möchte ich denselben jedoch nicht unbedingt ansprechen.

Am achten Tage nach der Impfung ging die erste der unmittelbar mit einem Organstück subcutan geimpften Mäuse ein. Milz um's Doppelte vergrössert. Leber mit weissen Punkten besetzt; bei mikroskopischer Beobachtung zeigt sie sich hochgradig verfettet; meist füllen kleinste Fetttröpfchen die Leberzellen an; dazwischen auch grosse Fetttropfen. In der Lunge viele hämorrhagische Herde. In den Nieren fettige Degeneration der Epithelien. In Milz, Nieren und Leber massenhaft die grossen gekrümmten Bakterien.

Die zweite, gleichfalls am 5. August mit einem Organstückchen subcutan geimpfte Maus ging nach 11 Tagen ein. Obduction: Leber mit einzelnen weissen Punkten besetzt; sehr brüchig. Die Milz fast um's Dreifache vergrössert. In den Lungen eine Anzahl pneumonischer Herde. Im Darm nichts Abnormes. Nieren nicht vergrössert. In der Milz die Bakterien in sehr typischer Form, aber nicht sehr reichlich; in der I Leber ebenso; in den Nieren noch spärlicher. Leber hochgradig fettig degenerirt: kleine Fetttröpfchen besetzen die Zellen dicht. Im Herzblutausstrich finden sich keine Bacillen.

Es sind also hier sämmtliche Mäuse bei den verschiedenen Arten der Beibringung des Materials der Infection erlegen, und zwar stand der Tod der Thiere in einem richtigen Verhältniss zum Infectionsmodus, indem die mit Reincultur in die Bauchhöhle geimpfte Maus noch nicht ganz einen Tag, die mit Reincultur subcutan geimpfte nach drei Tagen und die mit Organstücken inficirten nach 8 und 11 Tagen zu Grunde gingen. Die Zeit zwischen Infection und Tod bewegt sich in diesen Versuchen in demselben Spielraum wie bei den bezüglichen Versuchen in Fall I, wo die erstgeimpfte Maus nach 13 Tagen, die später 
in die Bauchhöhle inficirten Mäuse nach durchschnittlich 16 Stunden eingingen und wo von den beiden Tauben eine nach 16 Stunden, die andere nach 10 Tagen der Infection erlegen war.

Was die Culturen, welche ich aus den Organen dieser Mäuse anlegte, betrifft, so baben hier die auf Glycerin-Agar im Brütschrank gewachsenen sich völlig übereinstimmend gezeigt mit den unmittelbar aus den Organen der Leiche des betreffenden Mannes erhaltenen. Auf den Gelatineplatten haben sich eigenthümliche Verhältnisse ergeben. Zunächst war, wie erwähnt, auf den Platten, welche unmittelbar aus den Organen der menschlichen Leiche angefertigt waren, von Verflüssigung so gut wie nichts, oder doch höchstens nur an einer Stelle eine Andeutung bemerkt worden. Genau ebenso rerhielten sich die Colonieen, welche aus der nach ca. 16 Stunden gestorbenen, mit Reincultur in die Bauchhöhle geimpften Maus erhalten worden waren; desgleichen diejenigen Culturen, welche von der die längste Zeit lebend gebliebenen, mit Organstück subcutan geimpften, stammten. Die Organe der zwei anderen Müuse dagegen (beide waren subcutan, die eine mit Reincultur, die andere mit Organstück geimpft) ergaben bei der Plattenaussaat zwischen den nicht verflüssigenden Colonieen zahlreiche verflüssigende; auf einzelnen dieser Platten hatten manche Colonieen sehr das Aussehen von Proteus. Das letztere war aber nicht nur bei verflüssigenden, sondern auch bei nicht verflüssigenden Colonieen der F'all.

In allen Fällen aber war das mikroskopische Verhalten der Colonieen sowohl als auch der Bakterien selbst ein völlig mit allen bisherigen Culturen übereinstimmendes, und gerade diese Neigung dieser Bakterien, ein Peptonisirungsvermögen bald energisch zu bethätigen, bald in capriciöser Weise zu verleugnen, ist nach meinen Untersuchungen ein für dieselben besonders charakteristisches Verbalten, welchem wir noch in den nachfolgenden Untersuchungen wieder begegnen werden.

Schon lange war es den Militärärzten Ulms aufgefallen, dass die „Weil'sche Krankheit" nicht auch in der Civilbevölkerung zur Beobachtung kam. Wenn auch der Hauptgrund hiervon in gewissen speciell militärischen Verhältnissen zu suchen sein wird, worauf Hüeber die Aufmerksamkeit gelenkt hat, und was ich im Folgenden noch weiter werde darthun können, so spielte doch hierbei der Umstand mit, dass das Krankheitsbild noch neu, wohl hier und da mit dem gewöhnlichen katarrhalischen Icterus, in anderen Fällen vielleicht mit Typhus abdominalis zusammengeworfen wurde, wie dies ja anfänglich - allerdings mit gewisser Reserve - auch von Weil selbst geschehen ist. Seit Hüeber's und meinen Untersuchungen hat sich die Aufmerksamkeit der biesigen 
Aerzte diesem Gegenstande vielleicht etwas mehr zugeweudet und so erhielt ich am 6. December 1891 die Mittheilung, dass im städtischen Krankenhaus eine Patientin mit den Symptomen der Weil'schen Krantheit aufgenommen worden sei.

Die Krankengeschichte, für deren gütige Hittheilung und Ueberlassung ich dem ordinirenden Arzte des stältischen Krankenhauses in Ulm, Hrn. Dr. Majer, sowie dem Assistenzarzte daselbst, Hrn. Dr. Baatz, zu Dank verpflichtet bin, ist kurz folgende:

\section{Fall X.}

B. S., Dienstmagd, erkrankte am 26. November 1891 plötzlich mit Frösteln, nachfolgendem Hitzegefühl und allgemeiner Mattigkeit. Ursache angeblich Erkältung. Weiterhin bekam sie Wadenschmerzen und Schluckbeschwerden. Aufnahme in's Krankenhaus: 29. November. Patientin ist leicht icterisch, die Zunge belegt; der weiche Gaumen stark geröthet (wie glacirt). Sensorium etwas benommen. Temperatur bei der Aufnahme $41 \cdot 0^{\circ}$, fällt innerhalb der nächsten sechs Tage unter abendlichen Steigerungen staffelförmig bis zur Norm ab, um vom 10. Krankheitstage an nochmals sich zu erheben; nach drei weiteren Tagen mässigen Fiebers $\left(38 \cdot 4^{\circ}-\mathbf{3 8} \cdot 8^{\circ}\right.$ ), dauernde Rückkehr zur Normaltemperatur. Der Harn enthielt Eiweiss und Gallenfarbstoffe. Beim Recidiv Zunahme des Icterus. Alsdann langsame Reconvalescenz; Entlassung 20. December.

Der am 6: December 1891 erhaltene frisch gelassene, eiweisshaltige Harn, in welchem sich schon nach einigen Minuten einiges Sediment absetzte, wurde sofort mikrosliopisch untersucht und Culturen auf GlycerinAgar (Brütschrank) und Gelatine (Zimmer) angelegt. Die mikroskopische Untersuchung ergab ein aus Nierenepithelien, Cylindern und Detritus bestehendes Sediment, in welchem sich bald zu zweien gelagerte, bald gekrümmte Stäbchen mit stark gefärbten Polen, manchmal nahezu Lückenbildung im Iunern zeigend, in ziemlich beträchtlicher Menge vorfanden. Diesem Befunde entsprechend waren auch die Culturversuche. Die Röhren mit schräg erstarrtem Glycerin-Agar waren schon nach 24 Stuuden mit zarten Colonieen, wach zwei Tagen mit einem dicken gelblich-weissen Belage bedeckt; die Substanz des Glycerin-Agar hatte eine grünliche Fluorescenz angenommen. Die Bouillonröhren zeigten nach zwei Tagen intensive gleichmässige Trübung ohne Bildung eines Häutchens. Auf den Gelatineplatten fanden sich geschlossene Colonieen von dem wiederholt beschriebenen Choleratypus, Oberflächencolonieen von Typhustypus, jedoch am Rande so stark gebuchtet, dass häufig Annäherung an Proteusfiguren zu Stande kam. Ausserdem fanden sich verflüssigende Colonieen mit scharfrandigem Verflüssigungstrichter und pallissadenförmig gestellter Randzone. Diese sämmtlichen verschiedenartigen Colonieen enthielten die- 
selben sehr lebhaft wie ein Mückenschwarm beweglichen Organismen, welche sich mit Gentianaviolett schlecht färbten, nach Gram entfärbten, die Färbung mit Carbolfuchsin oder Löffler's Blau mit Erwärmen gut annahmen, und hier in einem und demselben Präparate derbe Bacillen, Diplobacillen, Scheinfäden, Kokkenformen in buntestem Wechsel erkennen liessen, kurz sämmtliche Merkmale der bisher beschriebenen Culturen darboten. Der Thierversuch gestaltete sich folgendermassen: mit der GlycerinAgarcultur wurde eine Maus an der-Sehwanzwurzel geimpft, eine andere erhielt eine Bouillonaufschwemmung dieser Cultur in die Bauchhöhle. Die letztere Maus starb nach 22 Stunden. Bei der Section fanden sich die Hautgefässe stark injicirt, die Leber ziemlich blass, die ganze rechte Lunge und der linke Oberlappen entzündet; die Milz ziemlich vergrössert. Mikroskopisch zeigte sich die Leber hochgradig fettig degenerirt, mit zahllosen feinen Fettröpfchen in den Zellen. Bacillen fanden sich am reichlichsten in den Nieren, gleichfalls sehr reichlich in der Milz, etwas spärlicher in der Leber und nur wenige in den Lungen und im Herzblut. - - Die subcutan geimpfte Miaus blieb am Leben.

Wir haben also in den vorstehend mitgetheilten Beobachtungen drei lethal verlaufene und obducirte Fäle der in Rede stebenden Krinkheit kennen gelernt, von denen zwei bakteriologisch untersucht wurden. Betrachten wir zunächst, wie sich der pathologisch-dnatomische Befund in diesen drei Fällen zu den wenigen bisher veröffentlichten verbält. Wir haben in unseren Fällen als wesentlichste Veränderungen kennen gelernt: Icterus (welcher besonders durch das in's Grünliche spielende Colorit schon während des Lebens das Bild eines Icterus gravis bot), blasse, fettig. infiltrirte bezw. degenerirte Leber, Verwischung des acinösen Baues und kleinzellige Infiltrationen im Gewebe. Ferner Verfettung und trübe Schwellung der Nierenepithelien sowie auch hier kleinzellige Infiltrationen; acute parenchymatöse $\mathrm{Ne-}$ phritis; endlich grössere und kleinere Hämorrhagien in den verschiedenen Organen und schliesslich - zwar meist in mässigem Grade - den Begleiter aller schweren Infectionen: die Milzschwellung. Veränderungen am Darme wurden bei unseren drei Fällen nur in einem einzigen, hier aber sehr in die Augen fallend, beobachtet (Fall IX, Grenadier W.), doch hat es sich auch hier nur um starke Injection der Gefässe, zahlreiche Hämorrhagieen und oberflächliche Erosionen der Schleimhaut von der Speiseröhre bis zur Bauhin'schen Klappe hin gehandelt. Nicht unterlassen darf ich, besonders hervorzuheben, dass Veränderungen, wie 
sie dem Abdominaltyphus zukommen, Geschwüre oder Infiltrationen der Peyer'schen Plaques, der solitären Follikel oder der Mesenterialdrüsen in unseren Fällen niemals zur Beobachtung kamen. Diese Befunde stimmen Punkt für Punkt überein mit den zwei ron Nauwerck veröffentlichten Leichenbefunden, nur hat $\mathrm{Nauwerck}$ in seinem ersten Falle ,kleine rundliche oberflächliche Geschwüre, das grösste 5-6 ${ }^{\mathrm{mm}}$ gross“, beobachtet, auch fand er hier die Schleimhaut zellig infiltrirt, stellenweise nekrotisch. Bezüglich der Leber sagt Nauwerck: ,es bietet sich ein Bild ähnlich der acuten gelben Leberatrophie. Vom normalen Gefüge der Leberzellenbalken kaum noch etwas zu sehen. Vielfach sind die Leberzellen zu einem körnig fettigen Detritus geworden .... auch die Epithelien der Gallengänge sind vielfach hochgradig verfettet. Von der acuten Leberatrophie entfernt sich das Bild insofern, als zahlreiche kleinere Herde von Leukocyten vorhanden sind; an anderen Stellen besteht eine mehr diffuse, aber sehr lockere Durchsetzung des Gewebes mit Leukocyten." In seinem zweiten Falle berichtet er: „Nieren vergrössert; auf der Oberfläche zahlreiche Hämorrhagieen. Leber: Läppchenzeichnung verwischt. Ausgedehnte albuminoide Trübung, Verfettung nnter Bildung ron Fettzellen und Nekrose der Leberzellen. Weiterhin sind besonders im Gebiete der stärker entarteten (Leber-)Läppchen zahlreiche entzündliche leukocytäre Infiltrationsherde vorhanden. In den Nieren die Epithelien der Rinde theils albuminoid getrübt, theils verfettet oder nekrotisch. Darm bietet nichts besonderes," doch hat Nauwerck hier, wie leider auch ich in meinen Fällen, die mikroskopische Untersuchung des Darms unterlassen. Da sich aber in Nauwerck's erstem Falle immerhin nennenswerthe Veränderungen des Darms erst bei der mikroskopischen Untersuchung herausgestellt haben, so wäre gewiss bei künftigen Fällen diese Untersuchung stets auch noch auszuführen. Ein weiterer tödtlich verlaufener und obducirter Fall wurde von Brodowski und Dun in veröffentlicht; der Befund war folgender: Schleimhaut des Rachens, Kehlkopfs, der Trachea und dickeren Bronchien geröthet, leicht geschwollen, stellenweise mit kleinen dunkelrothen, von capillären Blutextravasaten herrührenden Flecken bedeckt. Lungen stark hyperämisch; man fühlt viele milzartige Verdichtungen, die sich leicht zerquetschen lassen. Bronchialdrüsen bedeutend vergrössert, erweicht, röthlichgrau. Milz um das Fünffache vergrössert; kleine Blutextravasate in derselben. Nieren fast zweimal grösser. Auf der Schleimhaut des Magens und Darmcanals nichts besonderes. Die Mesenterialdrüsen, ebenso die Lymphdrüsen am Halse und an den Schenkelbeugen vergrössert, erweicht, grauroth. 
Mikroskopisch fanden sich: kleinzellige Infiltration in Lungen, Leber, Milz und Nieren. In den peripheren Zellen einiger Leberläppchen Fettinfiltration. In den Harncanälchen Blutextravasate; die Epithelzellen gequollen und getrübt.

In diesem Falle, welcher auch klinisch ganz unzweifelhaft dasselbe Krankheitsbild geboten hatte wie unsere und Nauwerck's Fälle, herrscht in anatomischer Beziehung so vollkommene Uebereinstimmung mit den genannten, dass mir die einzige nicht zusammenpassende Erscheinung, die Erkrankung sämmtlicher Lymphdrüsen, insofern nicht in's Gewicht za fallen scheint, als, wie gleich nachher erwähnt werden soll, für diese $\mathrm{Ab}$ weichung die Erklärung durch die bakteriologische Untersuchung sich gefunden hat.

Sehen wir von der nur in Brodowski's Fall beobachteten Lymphdrüsenerkrankung vorläufig ab, so haben wir in den hier zusammengestellten sechs Fällen ein Bild kennen gelernt, welches nunmehr, wie ich glaube, der anatomischen Einheit nicht mehr ermangelt. Allerdings besitzt dasselbe mit demjenigen, wie es bei Gelbfieber sowie bei der acuten gelben Leberatrophie gefunden wird, die grösste Aehnlichkeit und scheint mir die bei Nauwerck's und meinen Fällen beobachtete kleinzellige Infiltration zur definitiven Scheidung dieser Processe kaum ausreichend. Nur die ätiologische Erforschung dieser drei Krankheiten kann hier Licht schaffen.

Auf Mikroorganismen wurde bis jetzt untersucht von Nauwerck, ${ }^{1}$ Goldschmidt ${ }^{2}$ und ron Brodowsky und Dunin. ${ }^{3}$ Von den beiden erstgenannten wurde die Untersuchung anscheinend nur mikroskopisch, ohne Anwendung des Culturverfahrens ausgeführt, die letzteren Autoren haben auch Züchtungsversuche gemacht. Nauwerck hat in seinem ersten Falle in der Darmschleimbaut einen positiven Befund gehabt, den er folgendermassen schildert: „Innerhalb des nekrotischen Gewebes und in den angrenzenden Theilen der Schleimhaut liegen Ballen von Spaltpilzen, die schon bei ganz schwacher Vergrösserung leicht erkennbar sind. Die kleinen Haufen liegen zum Theil innerhalb der Drüsenlichtung, zum Theil im Schleimhiutbindegewebe, wie es scheint manchmal in erweiterten Lymphgefässen, die grösseren Zooglöamassen lassen bestimmte räumliche Beziehungen nicht mehr erkennen. Weitaus die meisten Ansiedelungen

1 Nauwerek, Zur Kenntniss der fieberhaften Gelbsucht. Münchener medicin. Wochenschrift. 1888. Nr. 35 .

${ }^{2}$ Goldschmidt, Ein Beitrag zur neuen Infectionskrankheit Weil's. Deutsches Archiv für klinische Medicin. Bd. XL.

3 Brodowsky und Dunin, Ein Fall der sogen. Weil'schen Krankheit mit lethalem Ende. Ebenda. Bd. XIIII. 
bestehen aus sehr kleinen kurzen, nur aušnahmsweise etwas längeren und schlankeren ziemlich plumpen Bacillen, deren Enden abgerundet und meist intensiv gefärbt sind, während die Mitte häufig nahezu farblos geblieben ist. Die Bacillen sind hier und da $z u$ zweit angeordnet, längere Ketten fehlen; nicht selten erkennt man beginnende Quertheilung.

Die Abgrenzung der Ballen ist keine ganz scharfe, indem sich die Anordnung an der Peripherie lockert und man einzelne Bacillen in der Nähe derselben verstreut nachweisen kann. Die Bacillen färben sich schwer und erscheinen auch an Präparaten, welche 24 Stunden in $\mathrm{Löff-}$ ler's alkalischer Methylenblaulösung behandelt und nachher mit Alkohol entfärbt wurden, verhältnissmässig blass gefärbt; an Schnitten, welche aus der gleichen Stelle des Darmes stammten und nach der Gram'schen Methode behandelt wurden, liessen sich diese Bacillenansiedelungen nicht nachweisen."

Goldschmidt hat in einem Falle, der günstig verlaufen ist, den Harn mikroskopisch untersucht und darin Cylinder gefunden, welche mit Kurzstäbchen dicht besetzt waren.

Brodowski und Dunin berichten, dass sie zwar zwischen den kleinzelligen Infiltrationen (in welchen Organen?) vergrösserte Zellen gefundeu haben, deren Körper mit Mikrokokken angefüllt war, dass aber die mit Milzpartikeln geimpfte Gelatine und Agar steril geblieben seien. Von den Lymphdrüsen dagegen bekamen sie nur Staphylococcus albus. Weitere Kulturversuche sind anscheinend nicht gemacht worden.

Niemand wird im vorliegenden Falle den Staphylococcus als den Erreger dieses merkwürdigen tödtlich verlaufenen Krankheitsfalles ansehen wollen, auch den Autoren selbst liegt eine solche Annahme offenbar fern; demgemäss ist der vorliegende Fall dahin zu beurtheilen, dass hier das bakteriologische Resultat in Bezug auf Entdeckung des Krankheitserreger's ein negatives gewesen und dass durch das Culturverfahren nur eine die Lymphdrüsenerkrankung erklärende secundäre Staphylokokkeninvasion nachgewiesen worden ist.

Während einerseits dieser negative Fall ebenso wenig gegen als für eine Uebereinstimmung mit meinen Untersuchungen spricht und der Befund von Goldschmidt eine Vergleichung mit den meinigen nicht eingehend genug zulässt, hat andererseits Nauwerck in vorstehend wiedergegebener Schilderung die von ihm gesehenen Bacillen in einer Weise beschrieben, dass ich in derselben kein Wort zu ändern brauchte, um die von mir in Schnitten gesehenen Bakterien zu beschreiben und dass meine in Figur 1 und 14 gegebenen Abbildungen füglich auch als Ilustrationen für Nauwerck's Beschreibung des Aussehens und der Lagerung dieser Bacillen angesehen werden dürften. Hiermit soll selbstverständlich nicht 
mehr gesagt sein, als dass es mir wahrseheinlich ist, dass Nauwerck in den Darmschnitten dieselben Organismen gesehen hat, welche ich in den Organen der zwei von mir untersuchten lethal verlaufenen Fälle in Schnitten gefunden, durch das Culturverfahren isolirt und auf Thiere verimpft habe.

Was die Lagerung der von mir aufgefundenen Bakterien im Gewebe betrifft, so zeigt ganz besonders ein Blick auf Figur 14, wo ein mit den Bacillen vollgestopftes Blutgefäss an der Stelle seiner Verästelung durch den Schnitt längs getroffen ist, dass es sich hier um Parasiten handelt, welche während des Lebens dahin, wo sie jetzt liegen, gebracht worden sind. An dem Schnitte Figur 1, wo die Bakterien in dichtem Haufen beisammen liegen (welcher auch ähnlich, wie dies Nauwerck beschreibt, schon bei schwacher Vergrösserung leicht zu finden ist), und wo sich von diesem Haufen aus einzelne Bacillen nach verschiedenen Richtungen zerstreut umhergelagert finden, ist es nicht wohl zu entscheiden, ob dieselben hier innerhalb oder ausserhalb von Gefässen liegen. Durch die Untersuchung sehr zahlreicher Sehnitte bin ich zu der Ueberzeugung gelangt, dass meine Bakterien vielfach auch ausserhalb der Gefüsse liegen.

Aus dem Blute konnte ich meine Bakterien niemals züchten; ich muss indessen hervorheben, dass ich Blutuntersuchungen am Lebenden in den lethal verlaufenen Fällen niemals ausgeführt habe, dass mir ferner zur Untersuchung bei den günstig verlaufenen Fällen stets nur die minimale Menge des aus der Fingerkuppe auf einen Nadelstich entleerten Tropfens zur Verfügung stand und dass endlich auch selbst in dem ersteu tödtlich verlaufenen Falle die Bakterien relativ sehr spärlich gefunden wurden. Fälle, wo sie im Blute in solcher Menge vorhanden sind, wie in Fall IX, dürften wohl sehr selten sein.

Bedeutungsvoller, und wie ich glaube, namentlich diagnostisch wichtig, ist die Auffindung der Bakterien im Harn des Lebenden. In 4 der 6 in dieser Richtung untersuchten Fälle habe ich die Bakterien unzweifelhaft gefunden und durch Züchtung in meinen Besitz bekommen; im fünften Falle fand ich sie nur mikroskopisch im Harnsediment, während der Culturversuch fehlschlug, und im sechsten Falle waren sie wahrscheinlich in der Glycerin-Agarcultur vorhanden, aber hier gelang ihre Isolirung nicht.

Die Thierversuche an Mäusen erwiesen sich, soweit die äusseren Um. stände solche zuliessen, bezw. rechtzeitig zuliessen, in den lethal verlaufenen Fällen zuverlässig. Insbesondere haben dieselben im Falle IX sehr exacte Resultate ergeben. Weniger zuverlässig waren die Experimente, wo die aus dem Harn der Kranken gewonnenen Culturen auf Thiere übergeimpft wurden: in den 4 Fällen, in welchen ich Reinculturen aus dem 
Harn erhalten hatte, wurde je eine Maus geimpft und zwar in Fall II erst nach 6 monatlichem Weiterzüchten, mit Culturaufschwemmung in die Bauchhöhle; das Ergebniss war, wie erwähnt, negatir (rgl. Seite 546); dieser Fall dürfte wegen des langen Zeitraums ausser Betracht zu bleiben haben. Die aus Cultur von Fall VI, an der Schwanzwurzel geimpfte Jlaus war schwer krank und wurde durch Chloroform getödtet; sie erwies sich, wie beschrieben, schwer inficirt und würde an der Nierenaffection ohne Zweifel noch gestorben sein. Aus Fall VII starb die subcutan geimpfte Maus nach 2 Tagen und endlich im Fall X starb die in die Bauchhöhle geimpfte Maus nach 22 Stunden, die subcutan geimpfte zeigte keine Krankheitserscheinungen. Dass es sich bei diesen Fällen um einen geringeren Virulenzgrund der Bakterien gehandelt hat, ist nicht unwahrscheinlich, waren es doch gerade die leichteren Fälle, welche in dieser Weise zur Untersuchung gelangten und galt ja bisher die Weil'sche Krankheit auch für den Menschen als eine relativ leichte, nicht zum Tode führende Infectionskrankheit.

Fragen wir nun, wie sich der anatomische Befund bei den Versuchsthieren $\mathrm{zu}$ demjenigen beim Menschen verhält, so ist eine Uebereinstimmung unverkennbar. Zwar fehlte Icterus sowohl bei den Tauben als bei den Mäusen, andererseits war aber die Verfettung der Leber und namentlich der Nieren eine so regelmässige und so auffallende Krankheitserscheinung, dass diese mir eine sehr wesentliche Uebereinstimmung mit unseren Leichenbefunden darzuthun scheint. Ferner waren auch öfters kleine Hämorrhagieen und Nekrosenherde beobachtet und endlich ziemlich häufig eine Enteritis mässigen Grades (auch bei subcutan geimpften Mäusen); endlich war eine beträchtliche Milzschwellung regelmässig vorhanden: Auf zwei Erscheinungen will ich hier bezüglich der Diagnose bei den Versuchsmäusen noch aufmerksam machen; einmal, dass die Mäuse sehr regelmässig eine Conjunctivitis mit eitriger Verklebung der Augenlider bekommen und zweitens, dass sie im Tode stets eine sehr charakteristische Haltung haben, ähnlich wie dies bei Mäusesepticämie beobachtet wird. Die Abbildung Taf. I, Fig. 10 giebt diese Stellung wieder.

Fasse ich alles Vorstehende zusammen, so glaube ich, dass ich in den hier beschriebenen Bakterien, welche ich in $z$ wei tödtlich verlaufenen Fällen in Schnitten aus den Organen in charakteristischer Anordnung gefunden habe, und welche ich in Reinculturen sowohl aus den Organen der Leichen, als auch aus dem Harn der Lebenden züchten und auf Thiere erfolgreich unter Erzeugung von der Weil'schen Krankheit ähnlichen Veränderungen verimpfenkonnte, die Erreger dieser Krankheit in Händen habe. 
Auf die Frage: waren diese Bakterien in allen untersuchten Fällen zu finden? kann ich antworten: in keinem der untersuchten Fälle haben sie bestimmt gefehlt; nur zweimal gelang mir der Nachweis aus dem Harn nicht mit Sicherheit; übrigens darf die Forderung, dass sie im Harn regelmässig gefunden bezw. lebend gefunden werden müssen, vorläufig noch gar nicht gestellt werden.

Ob diese Bakterien auch bei anderen Krankheitsprocessen vorkommen mögen, kann ich noch nicht sagen. In einem Falle von unzweifelhaftem gewöhnlichen catarrhalischen Icterus, welcher obne Fieber, ohne Eiweissgehalt oder Sedimentirung des Harnes verlief, habe ich den Harn wie in den bisherigen Fällen in sterilem Gefässe aufgefangen und auf Gelatine und Glycerin-Agar zur Aussaat gebracht: alle Nährsubstrate blieben steril. Im Uebrigen wird die Frage über die Stellung dieser Bakterien und ihr sonstiges Vorkommen im Folgenden noch näher zu erörtern sein und hier wäre zunächst auf dasjenige einzugehen, was über die Entstehung des fieberhaften Icterus in ätiologischer bezw. epidemiologischer Richtung bisher schon bekannt geworden ist, und dabei wäre zu untersuchen, wie sich diese Erfahrungen zu meinen Ergebnissen verhalten.

Meine Untersuchungen haben ergeben, dass es sich bei den Erregern dieser fieberhaften Gelbsucht um eine pathogene Proteusart handelt, also um eine derjenigen Bakterienarten, welche mit den Fäulnissvorgängen in innigster Beziehung stehen, um eine Bakterienart, von welcher gesagt werden kann, dass mindestens für ihre nächsten Verwandten alle Fäulniss ihr wahres Element ist. Diese Thatsache stimmt in überraschender Weise überein mit den bisher bezüglich der muthmasslichen Krankheitsursache gemachten Beobachtungen. Da ist zunächst die Thatsache zu erwähnen, auf welche zuerst Fiedler aufmerksam gemacht hat, dass die Krankheit in überwiegender Häufigkeit in der heissen Jahreszeit vorkommt. Von seinen 13 Fällen kamen 3 im Juni, 3 im Juli, 3 im August, 3 im October und $1 \mathrm{im}$ November vor. Im Anschluss an diese Beobachtungen gebe ich nachstehend eine Uebersicht über die Vertheilung unserer in der UTmer Garnison beobachteten Fälle von 1885 bis 1891, bezüglich Jahreszeit, Truppentheil und Ausgang der Krankheit.

\begin{tabular}{c|c|c|c}
\hline Jahr & Truppentheil & $\begin{array}{c}\text { Zugang im } \\
\text { Lazareth }\end{array}$ & $\begin{array}{c}\text { Abgang } \\
\text { als }\end{array}$ \\
\hline \hline 1885 & Pionier & $17 . / 6$. & geheilt \\
1886 & Pionier & $18 . / 6$. & $\cdot$ \\
1887 & - & - & - \\
& Pionier & $15 . / 7$. & geheilt
\end{tabular}




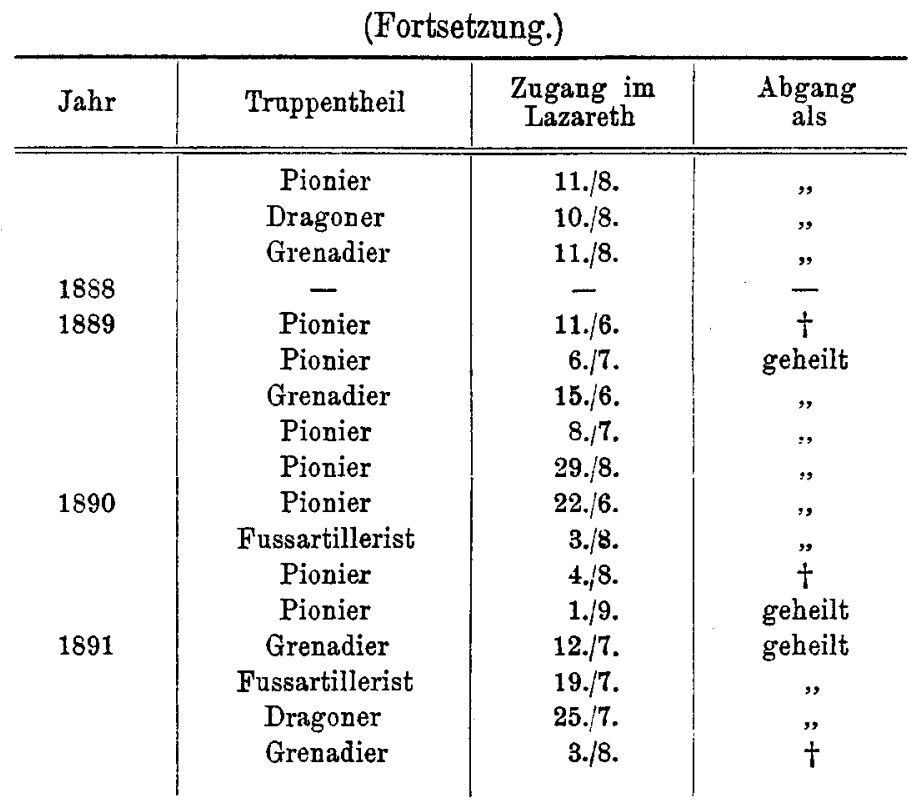

Diese sämmtlichen 19 Erkrankungen fallen also in die Monate Juni bis September und zwar 5 auf den Juni, 6 auf den Juli, 7 anf den August und eine auf den (1.) September. Der einzige Fall, welcher in der Civilbevölkerung beobachtet worden ist, fiel auf Anfang December. Unter den 19 Erkrankten befanden sich 11 Pioniere, 4 Grenadiere, 2 Fussartilleristen und 2 Dragoner. Es muss hierbei erwähnt werden, dass von Pionieren und Fussartillerie in Ulm je 1 Bataillon steht, von Dragonern 3 Eskadronen, Grenadiere 3 Bataillone; die 3 Bataillone des Regiments 124 und das Feldartillerieregiment haben kein Contingent zu der Ḱrankheit geliefert; auch die auf dem rechten Donauufer garnisonirenden bayrischen Truppentheile sind verschont geblieben. Im Verhältniss zur Kopfstärke der Truppentheile tritt also das Vorherrschen der Krankheit unter den Pionieren noch schärfer hervor, und damit kehre ich nach dieser statistischen Abschweifung zur Besprechung der ätiologisch wichtigen Momente zurück.

Nächst der Fäulnissvorgänge fördernden hohen Temperatur hat gleichfalls Fiedler auf die Thatsache aufmerksam gemacht, dass 9 ron seinen 13 Kranken als Metzgergehilfen im Dresdener Schlachthofe bis zum Tage ihrer Erkrankung thätig gewesen waren. Zwei der anderen Kranken haben anscheinend verdorbene Wurst gegessen. Ferner sind hier die zwei Fälle anzuführen, welche $\mathrm{Stirl}^{1}$ mittheilt, und bezüglich

${ }^{1}$ Stirl, Deutsche medicinische Wochenschrift. 1889. Nr. 39. S. 799. 
deren er betont, dass sie Licht darüber verbreiten, dass der Verdauungstractus der Weg sei, auf welchem die Infection erfolge: Zwei Canalarbeiter stürzten in einen Jauchecanal und bekamen dabei Jauche in reichlicher Menge zu schlucken. Beide erkrankten unter den Symptomen des Weil'schen Icterus; der in Spitalbehandlung befindliche Arbeiter genas, der andere soll gestorben sein. Aehnliche Beobachtungen wurden auch von Ducamp ${ }^{1}$ veröffentlicht: Bei Reinigung eines durch stark stinkende Stoffe verstopften Siels erkrankten die 6 dabei beschäftigten Arbeiter; 3 leichter an Magencatarrh, die drei anderen an den Symptomen des Weil'schen Icterus. Schliesslich gehören hierher die nunmehr umfangreichen Mittheilungen, welche das Baden in verunreinigtem Flusswasser als Ursache der Entstehung nicht nur des Abdominaltyphus und ähnlicher infectiöser Darmaffectionen, sondern auch des infectiösen Icterus beschuldigen. Zuerst haben Kirchner und Schaper ${ }^{2}$ Fälle dieser Krankheit beschrieben und als muthmassliches ätiologisches Moment das Baden in der Oder (unterhalb Breslau) bezw. in der Ocker bei Braunschweig genannt. Alsdann hat $\mathrm{Pfuhl} \mathrm{l}^{3}$ eine "mit Gelbsucht begleitete Typhusepidemie" in bestimmter Weise mit der Aufnahme von verunreinigtem Elbewasser beim Baden bei Altona in Beziehung bringen können und schliesslich hat Hüeber* in seiner zweiten Publication über diesen Gegenstand unsere Ulmer Fälle unter denselben Gesichtspunkt gebracht und das Baden der Mannschaften der Garnison, bezw. die Wasserübungen der Pioniere in der Donau unterhalb der Stadt Ulm beschuldigt, zu diesen Erkrankungen Anlass gegeben zu haben; wenn er hierbei die Pfuhl'schen Fälle nicht als Fälle von Abdominaltyphus gelten lassen will, sondern dieselben der Weil'schen Krankheit zurechnet, so kann ich mich dieser seiner Auffassung und seinen Ausführungen nur anschliessen.

Es ist hier der Ort, auf die Veröffentlichung von Globig š einzugehen. Derselbe berichtet von einer Epidemie, welche sich bei einer in Lehe garnisonirenden Matrosen-Abtheilung im Sommer 1890 ereignete und deren Ursache gleichfalls mit grosser Bestimmtheit in dem Baden in verunreinigtem Wasser gesucht werden muss. Auf eine klinische Besprechung; ob Globig's Fälle mit der Weil'schen Krankheit identisch sind oder nicht, möchte ich hier nicht näher eingehen; manches spricht ja dafür, so besonders das Verhalten der Körpertemperatur. der Abfall derselben bis auf oder unter die Norm beim Fortbestehen schwerer Erscheinungen;

${ }^{1}$ D ucamp, Une petite epidemie d'ictère infectieux. Revue méd. 1890. Juin.

2Deutsche militär-ärztliche Zeitschrift. 1888. Hft. 5.

s A. a. O. Hft. 9.

4 A. a. O. 1890 .

${ }^{5}$ Globig, a. a. O. 1891. Hft. 7 u. 8. 
andererseits glaube ich mich mit Globig darin in Uebereinstimmung zu befinden, dass das Fehlen von Icterus und Nephritis - der zwei wesentlichsten Symptome der Weil'schen Krankheit - gebietet, die in Lehe vorgekommenen Erkrankungen nicht in die Symptomengruppe der noch so wenig gekannten Krankheit einzureihen. Was Globig's bakteriologische Befunde, die in seinen fünf untersuchten Fällen im Darm in Reinculturen vorgefundenen lebhaft beweglichen, rasch wachsenden, auf gewöhnliche Art schlecht färbbaren Kurzstäbchen betrifft, so sprechen die eben angeführten Merkmale wohl für eine Uebereinstimmung mit den meinigen, auch zeigt der negative Blutbefund und das Verhalten des Thierexperiments noch weitere Uebereinstimmung, andererseits scheint Globig die pleomorphen Eigenschaften bei seinen Balsterien nicht beobachtet zu haben und gerade diese möchte ich als ein wesentliches Charakteristicum der von mir in dieser Arbeit beschriebenen Organismen betrachtet wissen.

Suchen wir also der Frage näher zu treten, ob wirklich das Baden in der Donau bei den Mannschaften der Ulmer Garnison für die Erkrankungen verantwortlich gemacht werden kann. Seit Hüeber auf diesen 7usammenhang aufmerksam gemacht hat, wurde in den späteren Ǩrankheitsfällen auch anamnesisch versucht, in dieser Richtung Anhaltspunkte zu gewinnen. Bezüglich des ersten vorn beschriebenen Falles, welcher lethal endete und den Ausgangspunkt meiner Untersuchungen gebildet hat, wurde schon von mir seinerzeit in der Anamnese das Erkranken des Mannes auf der von Hüeber näher beschriebenen „Depotwache“, welche hart an der Einmündung des mit städtischen Abwässern überladenen Armes der Blau in die Donau gèlegen ist, festgestellt. Der Iraun will auf dieser Wache nun zwar weder Wasser getrunken noch gebadet haben; mit was für Wasser das Glas, aus welchem er Bier trank, gespült wurde, konnte nicht in Erfahrung gebracht werden. Die Möglichkeit, dass er auf diesem Wege inficirt wurde, ist nicht ausgeschlossen, allerdings kann er auch schon vor jenem Wachdienst sich inficirt haben. Der als Fall II besprochene Unterofficier hat am 2. und 6. Juni in der militärischen Schwimmanstalt in der Donau gebadet und ist am 18. erkrankt. Hier müsste also, wenn die Donaubäder die Krankheit herbeigeführt haben, die Incubation 12 bis 16 Tage betragen haben. Pionier K. (Fall III) gab an, „dass er glaube, dass die Donaubāder zu seiner Erkrankung beigetragen haben". Fussartillerist Br. (Fall IV) hat 3 Wochen vor seiner Erkrankung in der Donau gebadet; dieser Fall wird also wohl nicht auf das Baden bezogen werden dürfen. Dagegen hat Pionier L. (Fall $\nabla$, der tödtlich endete) bis zu seiner Erkrankung täglich in der Militärschwimmschule gebadet. Fall VI, Grenadier B., hat vom 28. Juni bis 2. Juli dreimal in der Donau gebadet und erkrankte am 11. Juni, also 9 Tage 
nach dem letzten Bade. Fall VII, Fussartillerist B. hat bis 11 Tage vor seiner Erkrankung regelmässig gebadet. Fall VIII, Dragoner F., der auch selbst das Baden beschuldigt, hat bis 2 Tage vor seiner Erkrankung täglich gebadet. Fall IX gehört ätiologisch nicht hierher. Er hatte nicht in der Donau gebadet, dagegen hat er bestimmt angegeben eine verdorbene Wurst gegessen zu haben; dieser Fall würde sich also den von Fiedler beschriebenen anreihen. Fall $\mathrm{X}$, das Dienstmädchen in einer Wirthschaft erkrankte ausserhalb der Badezeit; auch hier würde eher an eine Infection durch den Verkehr mit verdorbenen Lebensmitteln zu denken sein. Es sind also 7 von den 10 Erkrankten der Gefahr der Infection durch das Donauwasser ausgesetzt gewesen und während von den drei übrig bleibenden Fällen die beiden letzten eime andere Infectionsquelle ziemlich deutlich vermuthen lassen, bleibt nur einer (Fall IV) ohne muthmassliche Erklärung, während für die 7 anderen Fälle ausser der Infection durch die Donau keinerlei Ursache der Erkrankungen sich hat auffinden lassen. Es hat also das anamnastische Material die Verdachtsgründe, welche schon vorher sich auf die Donaubäder in der Militärschwimmschule und -Badeplatz gerichtet hatten, nur bestärken können. Worauf sich diese gegründet hatten, hat Hüeber ${ }^{1}$ ausgeführt.

Dieser Verdacht konnte auf seine Berechtigung am sichersten geprüft werden durch eine bakteriologische Untersuchung des Reinheitsgrades der Donan und eine solche habe ich in Rücksicht auf die in Rede stehende Frage, bezw. zur Entscheidung, ob der militärische Badeplatz als gesundheitsschädlich zu betrachten sei, wiederholt vorgenommen und ich gebe im Folgenden die Resultate dieser Untersuchungen. Zunächst ist über die örtlichen Verhältnisse einiges vorauszuschicken, wobei ich auf die beiliegende Skizze (Taf. VII) verweise. Die Donau vereinigt sich unmittelbar oberhalb der Stadt mit der viel stärkeren reissenderen und reineren Iller, einem Bergstrom, welcher auf seinem Laufe verhältnissmässig nur wenige und kleine bewohnte Orte berührt und somit einer Verunreinigung nur wenig ausgesetzt ist. Die Stadt Dlm ist durchzogen von der Blau, einem kleinen rasch strömenden Flüsschen, welches in dem wegen seines prachtroll blauen Wasserspiegels und seiner romantischen Lage viel besuchten Blaultopf bei Blaubeuren entspringt. Die Blau, an ihrem Ursprung und in ihrem Oberlauf ein krystallklares kaltes Forellenwasser, nimmt schon von den zwischen Ulm und Blaubeuren liegenden Ortschaften manchen Unrath auf, ihre reichlichste Zugabe erhält sie aber in Ulm, wo sie theils zur Speisung der Festungsgräben verwendet wird, theils die Stadt in mehreren grösstentheils offenen Bächen durchzieht; ein Theil strömt in der Rasch-

1 A. a. 0 . 
heit, mit welcher das Wasser in die Stadt eintritt, weiter und treibt verschiedene Mühlen, ein anderer schleicht träge und dem Versumpfen nahe in den Stadtgräben der mittelalterlichen Reichsstadt dahin. Die hier auf der alten Stadtmauer stehenden, von der ärmeren Bevölkerung bewohnten Grabenhäuschen entleeren allen möglichen Unrath in die Blau. In anderen Stadtthejlen münden die Abtritte direct in das Wasser. Hauptsächlich aber hat die Stadt sich die Gelegenheit dieser natürlichen Entwässerung nicht entgehen lassen, sondern hat die Canäle für Tagwässer theilweise in die Blau eingeleitet. Der Mǘndungsstellen der Blau in die Donau sind es, wie aus der Skizze ersichtlich, drei. Der weitaus der grössten Verunreinigung ausgesetzte Arm mündet ziemlich weit unterhalb der Stadt, er berührt also die Frage, in welchem Wasser gebadet werden soll, nicht. Von der 14000 Einwohner zählenden bayrischen Stadt NeuUlm auf dem rechten Donauufer münden gleichfalls einige städtische Canäle in die Donau, doch sind die Zuflüsse ron hier aus relativ spärlich. Aus dieser Darlegung ist ersichtlich, wo für das Baden reines Wasser und wo unreines $\mathrm{zu}$ erwarten ist. Auf den Gebrauch der Donau als Trinkund Nutzwasser ist die Stadt nicht angewiesen, dieselbe besitzt eine für diese Zwecke sowie für Feuerlöschen und Strassenreinigung völlig ausreichende vortreffliche Wasserleitung.

Es kam mir bei meinen Untersuchungen der Donau nun darauf an, möglichst die Badeplätze als Untersuchungsstellen auszuwählen, sodann aber auch die Untersuchung soweit stromabwärts fortzusetzen, dass aus den Ergebnissen ein Schluss sollte gezogen werden können, in welchem Maasse in dem rasch strömenden Wasser eine Selbstreinigung stattfinde.

Die erste Untersuchung wurde am 30. October 1889 vorgenommen. Zur Ausführung derselben wurde mir von dem damaligen Commandeur des Pionier-Bataillons, dem inzwischen verstorbenen Hrn. Najor Gaede, ein Ponton mit der nöthigen Bemannung in entgegenkommendster Weise zur Verfügung gestellt. Dampfer gehen auf der Donau bei Ulm nicht, und der Nachenschiffahrt stehen insofern Schwierigkeiten im Wege, als die sehr starke Strömung kein Fahren stromaufwärts gestattet, die Nachen, bezw. Pontons vielmehr mit grosser Mühe stromaufwärts, ,gestreitelt“" werden müssen. Dieser Umstand hat verhindert, die Untersuchung bis Elchingen auf einmal vorzunehmen. Es sind deshalb die Keimzahlen ron den Entnahmestellen XIII und XIV mit den übrigen nicht vergleichbar, da bei dieser ersten Untersuchung an diesen zwei Entnahmestellen die Wasserproben erst am 1. Norember entnommen wurden.

Die ausgewählten Stellen sind auf der Skizze (Taf. VII) durch rothe $\square$ bezeichnet. Sie waren folgende: 
I. Donau oberhalb Illereinfluss. Wasser sehr ruhig, durch die weiter unten einströmende Iller zurückgestaut; weisse Blasen in der Mitte des Flusses. Probe entnommen $9 \mathrm{Uhr} 50$ Minuten Vormittags, $6^{\text {m }}$ rom rechten Ufer entfernt. Stromtiefe $1 \mathrm{~m}$.

II. Iller unmittelbar vor Einfluss in die Donau. Rasch fliessendes klares Wasser, keine Blasen. Probe entnommen $3^{\mathrm{m}}$ vom linken nllerufer. Stromtiefe $1 \mathrm{~m}$.

III. H-M'sche Badeanstalt. Sehr klares Wasser. Probe entnommen $10 \mathrm{Uhr} 15 \mathrm{Min} .6^{\mathrm{m}}$ vom rechten Ufer. Stromtiefe $90^{\mathrm{cm}}$.

IV. Königl. bayrische Militärschwimmschule. Probe entnommen $10 \mathrm{Uhr} 18 \mathrm{Min} .8^{\mathrm{m}}$ vom rechten Ufer. Stromtiefe $90 \mathrm{~cm}$.

V. Obere Fähre. Blasen auf dem Wasser. Probe entnommen $5^{\mathrm{m}}$ vom linken Ufer. Stromtiefe $70 \mathrm{~cm}$.

VI. Schwimmbad. Probe entnommen $8^{\text {in }}$ rom linken Ufer. Stromtiefe $1.50 \mathrm{~m}$.

VII. Oberhalb der Donaubrücke (unterhalb der zwei Blau-Zuflüsse). Probe entnommen $6^{\mathrm{m}}$ vom linken Ufer. Stromtiefe $50^{\mathrm{cm}}$.

VIII. M's Badeanstalt. Wasser sieht schmutzig aus und ist im Strom undurchsichtig. Keine Blasen. Schlachthausabwasser.

IX. Gegenüber Villa L. Probe entnommen $8^{\mathrm{m}}$ vom rechten Ufer. Stromtiefe $60 \mathrm{~cm}$.

X. Bei Bastion 24. Probe entnommen $7^{\mathrm{m}}$ vom linken Ufer. Stromtiefe $70 \mathrm{~cm}$.

XI. Königl. württ. Militärschwimmschule. Sehr trübes, undurchsichtiges Wasser. Probe entnommen 10 Uhr 45 Min., $6^{\mathrm{m}}$ Abstand rom linken Ufer. Stromtiefe $1 \mathrm{~m}$.

XII. Beim hohen Steg (oberhalb Blaueinmündung). Ziemlich durchsichtiges Wasser. Probe entnommen $10 \mathrm{Ohr} 50 \mathrm{Min} .4^{\mathrm{m}}$ Abstand vom linken Ufer.

Wenn auch, wie oben erwähnt, die Untersuchungen an den zwei folgenden Stellen nicht unmittelbar mit den übrigen verglichen werden können, so mögen sie wenigstens als allgemeine vorläufige Orientirung gelten und daher hier Platz finden.

Bei den Orten Thalfingen und Elchingen gehen Stege über die Donau. Von diesen aus wurden zur Wasserentnahme sterilisirte Gläser an einer Leine in den Strom hinabgelassen.

XIII. Thalfinger Steg. Färbung des Wassers im Strom grau. Auf demselben treiben Holz- und Papierstücke; keine Blasen. 
XIV. Elchinger Steg. Wasser bis auf den Grund durchsichtig; wenig Blasen, dagegen treiben auf demselben Papierstücke, verbrannte Zündhölzchen und andere dem menschlichen Haushalt entstammende Gegenstände. Etwa $300^{\mathrm{m}}$ oberhalb dieses Elchinger Steges eine Kiesbank, welche eine Wasserströmung gegen das linke Ufer zu veranlasst. Hier entsteht ein Wirbel von sehr schmutzigem mit bräunlich-gelben Blasen bedeckten Wasser. Hier allerlei Papier, Zündhölzer, Federn.

Die Keimzahlen bei den vorgenannten 14 Untersuchungen stellen sich wie folgt:

\begin{tabular}{|c|c|c|}
\hline & Linkes Ufer & Rechtes Ufer \\
\hline I. Donau, oberhalb Iller . . . . & 470 & - \\
\hline II. Iller allein . . . . . . . . & - & 320 \\
\hline III. H-M'sche Badeanstalt. . . . & - & 600 \\
\hline IV. Bayrische Militärschwimmschule & - & 400 \\
\hline V. Schwimmbassin . . . . . . & 1100 & - \\
\hline VI. Oberhalb der Donaubrücke . . & 2926 & - \\
\hline VII. M's Badeanstalt . . . . . . . . . & 3120 & - \\
\hline VIII. Villa L . . . . . . . . . . . & - & 890 \\
\hline IX. Bastion 24 . . . . . . . . . . & 2322 & - \\
\hline X. Württemb. Militärschwimmschule & 2292 & - \\
\hline XI. Oberhalb dein hohen Steg . . & 2118 & - \\
\hline XII. Thalfinger Steg . . . . . . . & $(4736)$ & - \\
\hline XIII. Elchinger Steg & $(2992)$ & - \\
\hline
\end{tabular}

Nan erkennt hier ein Ansteigen und Abnehmen dieser Zahlenwerthe genau in dem Verhältniss wie es aus der örtlichen Lage a priori erwartet werden muss: Das Donauwasser tritt in einem Zustande der Reinheit in die Stadt ein, welche selbst manches noch als gut bezeichnete Trinkwasse nicht besitzt; es behält diese Reinheit auf dem rechten Ufer eine erhebliche Strecke bei und wird hier überhaupt relativ unbedeutend verunreinigt. Auf dem linken Ufer dagegen entspricht jeder Anstieg der Keimzahl genau einem der Blau-Zuflüsse, bezw. der Ausmündung eines städtischen Abwassercanals. Nachdem der letzte derartige Zufluss oberhalb der Entnahmestelle VII in die Donau gelangt ist, nimmt die Keimzahl wieder $a b$, jedoch nur in mässigem Grade, so dass bei dieser Untersuchung das Wasser bei der württembergischen Militärschwimmschule noch die fünffache Menge der Bakterien enthielt, mit welchen es in die Stadt eingetreten war. 
Später habe ich noch drei Untersuchungen ausgeführt; bei der ersten derselben entnahm ich die Wasserproben von den verschiedenen Brücken, Stegen und Fähren aus, die zwei darauf folgenden habe ich bei Gelegenheit von grösseren Vergnügungswasserfahrten ausgeführt, was den Vortheil hatte, dass ich eine grössere Strecke als sonst der Untersuchung unterwerfen konnte.

Die Ergebnisse meiner zweiten Untersuchung (am 18. December 1889) waren folgende:

\begin{tabular}{|c|c|c|}
\hline & & Keimzahl \\
\hline I. Oberhalb der Eisenbahnbrücke . . . & . . & 896 \\
\hline II. Obere Fähre . . . . . . . . . . . & . . & 1266 \\
\hline III. Donaubrücke . . . . . . . . . . & . & 1236 \\
\hline IV. Gänsthor . . . . . . . . . . . & . & 1396 \\
\hline V. Beim Wasenmeister . . . . . . . & . & 4984 \\
\hline VI. Beim hohen Steg (oberhalb der Blau) & . & 3360 \\
\hline VII. Beim hohen Steg (unterhalb der Blan). & . & 4554 \\
\hline VIII. Steinhäule & . & 3300 \\
\hline IX. Thalfinger Steg . . . . . & . & 2672 \\
\hline X. Elchinger Steg. . . . . . . & . & 1708 \\
\hline
\end{tabular}

Die Zahlen haben hier keine solche unmittelbare Abhängigkeit von den einzelnen Zuflüssen erkennen lassen wie bei der ersten Untersuchung. So ist bei der Untersuchung $\mathrm{V}$ eine durch örtliche Verhältnisse nicht motivirte Steigerung der Keimzahl zu Tage getreten; rom „Gänsthor" bis zum "Wasenmeister" nimmt die Donau keine Schmutzwässer auf; und dass es sich nicht um etwas ganz Zufälliges handelt, geht aus der gleichfalls hohen Zahl bei Untersuchung VI hervor. Ich glaube, dass in der rasch fliessenden Donau die Zuflüsse, deren Unreinheit ja nicht continuirlich dieselbe ist, sondern stossweise wechselt, auch in dem Flusse nicht sehr rasch zur Mischung gelangen. Die nächstfolgende Untersuchung zeigt durch ihre geringen absoluten Zahlen ganz erstaunlich, wie unmittelbar abhängig die Reinheit des Wassers von dem augenblicklichen Zufluss ron Schmutzwasser ist. Die betreffenden Proben wurden am 1. August 1890, einem Sonntag Nachmittag zwischen 2 und $4 \mathrm{Uhr}$, also zu einer Zeit entnommen, zu welcher weder Gewerbe noch Haushaltungen Abwasser dem Fluss übergeben. Es war schon mehrere Tage kein Regen gefallen, der Strom krystallklar. In Günzburg wurden die Wasserproben in einem guten Keiler bis zum 
dbend aufbewahrt; über Nacht in meiner Wohnung im Eisschrank gehalten und am folgenden Morgen verarbeitet. Sie waren somit in einer für das Konstantbleiben des Keimgehaltes möglichst günstigen Temperatur von $9-12^{\circ} \mathrm{C}$. geblieben. Dass während der Aufbewahrung keine nennenswerthe Vermehrung der Keime stattgefunden hatte, geht gleichfalls aus den sehr niedrigen Zahlen herror. Dieselben sind:

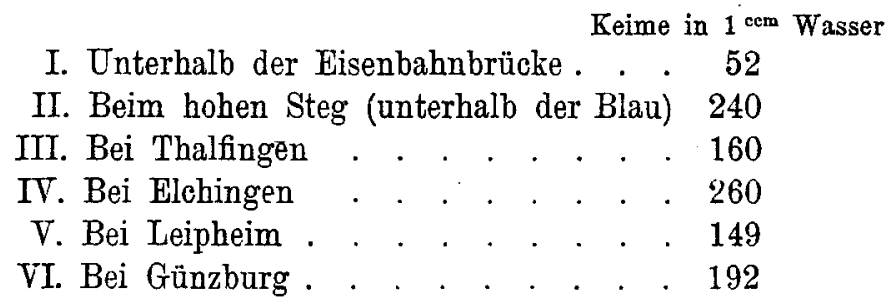

Noch eine weitere, gleichfalls im Hochsommer, am 22. Juli 1891, einem Werktag, Mittags zwischen 2 und 3 Uhr vorgenommene Wasseruntersuchung ergab wiederum ein gesetzmässiges, von den Zuflüssen abhängiges Ansteigen der Keimzahlen, wenn auch hier ebenfalls einige Werthe sich finden, welche unmotivirt niedrig sind. Am Tage der Entnahme, einem Mittwoch, war das Wetter sehr schön, das Wasser ziemlich klar, doch hatten an den vorher gegangenen Tagen einige Gewitterregen den Strom geschwellt und demselben vielleicht mancherlei Unrath von den Ufern zugeführt, besonders aber am Kiesgrund abgesetzte Stoffe aufgewühlt. Die bei einer Nachenfahrt entnommenen Proben wurden sofort an Ort und Stelle (Steinhäule) in mit Gelatine beschickte Roszahegky'sche Flaschen übertragen und zwar je $0.5^{\mathrm{ccm}}$ Wasser pro Probe.

Nachdem die mit dem Wasser inficirte Gelatine flach ausgebreitet, in den Flaschen erstarrt war, wurden diese verpackt und sofort durch einen Diener in's Laboratorium nach Ulm zurückgebracht.

Das Ergebniss war folgendes:

\begin{tabular}{|c|c|}
\hline Ex & Keime in $1^{\mathrm{ccm}}$ Wasser \\
\hline I. Oberhalb der Eisenbahnbrücke & 270 \\
\hline II. Bei M's Badeanstalt. . . . & 55440 \\
\hline III. Bei der Trassmühle . & 788 \\
\hline IV. Bei der K. W. Militärschwimmschu & 97020 \\
\hline V. Oberhalb dem „,hohen Steg" & 1250 \\
\hline VI. Beim Steinhäule (unterhalb d. hoh & 131670 \\
\hline
\end{tabular}

Es drücken sich also auch bei dieser letzten Untersuchung die örtlichen Verhältnisse in den gefundenen Keimzahlen sehr deutlich aus: die Donau tritt in sehr reinem Zustand in die Stadt ein; nachdem sie die drei Blauzuflüsse, sowie noch einige kleinere städtische Canäle aufgenommen 
hat (wovon derjenige, welcher beim städtischen Spital, hart unterhall) II's Badeanstalt liegt, und welcher neben vielen Strassensiehlen alle Abwässer des Spitals aufnimmt, besonderer Erwähnung werth ist), steigt der Keimgehalt ganz enorm. Erstaunlich niedrig ist derselbe weiter unten bei der Trassmühle gefunden worden; hier ist die Flossgasse, welche der Nachen befahren musste, sehr nahe dem rechten Ufer, man hat es also hier vorzugsweise mit dem reinen Illerwasser zu thun. Dass sich Donau und Iller sebr lange nicht völlig mischen, kann Jeder beobachten, der nach einem Regen sich die vereinigten Flüsse betrachtet; man sieht eine verschiedene Färbung der beiden Wässer der ganzen Stadt entlang. Auch in der Temperatur des Wassers drückt sich dies aus; die Donau führt auf der Mlerseite im Sommer stets 1 bis 2 Grade kühleres Wasser als auf der linken Seite. Die auf Probe III folgende hohe Zahl der Probe IV ist der Ausdruck dafür, dass wir uns hier wieder näher dem linken Ufer befinden; hier war das Wasser auch von trübem Aussehen und so langsamer Strömung, dass man mehrere dort Badende stromaufwärts schwimmen sehen konnte, was in der Donau bei Ulm im freien Strom im Allgemeinen nicht möglich ist. Beim hohen Steg fand sich wieder näher dem rechten Ufer eine sehr mässige Keimzahl, welche ich auch wieder weniger der Selbstreinigung durch Sedimentiren als dem Umstande, dass die Probe dem reinen rechtsuferigen Illerwasser entstammte, zuschreiben möchte. Die Probe beim Steinhäule giebt wieder Kunde von der bedeutenden Menge von Schmutzstoffen, welche beim hohen Steg durch den letzten Blauarm der Donau zugeführt werden.

Diese Untersuchungen sind ja an Zahl zu gering und haben die verschiedenen hier noch weiter in Betracht kommenden örtlichen und physikalischen Verhältnisse, Stromtiefe und -Geschwindigkeit, Jahres- und Tageszeiten der Wasserentnahme, das specifische Gewicht des Wassers u. s. w. nicht genügend berücksichtigt, um zu der wichtigen Frage der Selbstreinigung der Flüsse einen massgebenden Beitrag zu liefern, aber sie erlauben in dieser Richtung wenigstens das Urtheil, dass eine Selbstreinigung auf die untersuchten ziemlich kurzen Strecken nicht nennenswerth zum Ausdruck kam. Ganz besonders möchte ich in dieser Richtung auf die oft unerwartet hohen, von den stattgefundenen Zuflüssen anscheinend unabhängigen Keimzahlen aufmerksam machen, welche beweisen, dass in einem Fluss mit solch' rascher Strömung und so wechselndem Strombett und Wasserstand, wie es die Donal bei Ulm ist, keine solche Gleichmässigkeit in der Mischung der Zuflüsse mit dem reinen Wasser und in dem Absetzen der Schmutzstoffe besteht, wie sie z. B. Frank ${ }^{1}$ in der Spree gefunden hat und gerade auf die Bedeutung dieser

${ }^{1}$ Diese Zeitschrift. 1887, Bd. III. 
ungleichmässigen Mischung für die Entstehung der in Rede stehenden und anderer Infectionskrankheiten möchte ich unten noch zurückkommen.

Im Uebrigen haben diese Untersuchungen als zweifellos ergeben, dass die Donau durch die Blau eine sehr erhebliche Verunreinigung erfährt und musste sich somit der Verdacht hauptsächlich darauf lenken, dass eben diese Blau es sei, welche dem Militärbadeplatz die Infectionsstoffe zuführe. Gestützt wurde dieser Verdacht noch weiter durch die Erwägung, dass die Civilbevölkerung, wie es scheint, ganz oder fast ganz von der Krankheit verschont geblieben war: ein Blick auf die Karte zeigt, dass die Ulmer Badeplätze sämmtlich oberhalb der Blaueinflüsse liegen, mit Ausnahme der M.'schen, welche jedoch weitaus die kleinste und wenigst besuchte von allen ist. Das sehr frequentirte Schwimmbassin liegt zwar unterhalb des „Kobelgrabens", dieser führt jedoch für gewöhnlich kein Wasser oder nur höchst spärliche Mengen, da er, durch Schleussen verschlossen, nur einen Ueberlauf bei starken Regengüssen darstellt; die Schleussen werden geschlossen gehalten, um den anderen Blauarmen die zum Treiben von Mühlen nöthige Wasserkraft zukommen zu lassen.

Die Civilbevölkerung bedient sich aber der Blau nur um Abwasser und Unrath in dieselbe abzugeben, entnommen wird dem Flüsschen in Ulm kein Wasser, weder zu gewerblichen noch zu hauswirthschaftlichen Zwecken.

Da bei der Civilbevölkerung keine Fälle von Weil'scher Krankheit vorkamen, so war auch die Vermuthung nicht berechtigt, dass die Ulmer Bevölkerung die Infectionsstoffe vermittelst der Blau in die Donau und an den militärischen Badeplatz gebracht habe. Die Ursache musste also in der Blau schon oberhalb $01 \mathrm{~m}$ gesucht werden. Die Blau kommt schon unrein nach Ulm, und da ist vor Allem das 2500 Einwohner zählende Dorf Söflingen, welches, wie aus der Skizze Tafel VII zu ersehen ist, in verschiedenen Richtungen von dem Flüsschen durchzogen wird. Es finden sich aber in diesem Dorfe noch viel mehr solcher Bäche; fast durch jede Strasse zieht ein solcher. Die Bevölkerung dieses Dorfes benutzt das Wasser im Oberlauf theilweise auch zum Waschen und Putzen im Hause, jedoch nicht als Trinkwasser. Dagegen münden von allen Seiten Rinnsteine, welche Jauche aus den Viehställen und ron den Dunglagen führen, in diese Bäche ein.

Bei Nachforschungen in dieser Richtung begegnete ich einer Thatsache, welche geeignet schien, Licht in die Frage zu bringen. Ich erfuhr nämlich, dass in Söflingen schon seit mehreren Jahren eine Geflügelseuche auftrete, welche rorwiegend im Frühjahr, wenn das Geflügel die Bäche wieder aufsucht, beginne und dann 
meist den Sommer über fortdauere, wogegen sie im Winter erlöscht. Befallen sollen hauptsächlich werden Enten und Gänse, aber auch Hühner. Auffallenderweise wurde mir von einer sehr verständigen Frau im genannten Dorfe, welche seit Jahren selbst eine grosse Zahl Geflügel hält, schon ohne Vorfrage mitgetheilt, dass die Erkrankungen stets fast ausschliesslich entlang dem „Bläule" genannten Wasserlauf aufgetreten seien.

Es gelang mir nun, im Verlaufe von einem Jahre fünf Stück der Seuche erlegenen Geflügels zur Untersuchung zu erlangen. Es ist mir, seit ich auf die Seuche aufmerksam geworden, noch eine grössere Anzahl von Geflügel bezeichnet worden, welches derselben erlegen sei, bei der Indolenz der bäuerlichen Bevölkerung war es aber nicht möglich, diese Thierleichen zur Untersuchung zu erhalten, weil sie, bevor ich vom Eingehen dieser Thiere Kenntniss erhielt, - in die Blau geworfen worden waren!

Ich gehe zur Beschreibung dieser Untersuchungen über.

Es musste zunächst an eine der bisher bekannten Geflügelseuchen gedacht werden, besonders an die durch Vibrio Metschnikoff erzeugte; doch stellte sich bald heraus, dass keine dieser Krankheiten im Spiele war.

Die erste Untersuchung fiel in die Zeit, als ich noch mit meinem Fall I der Weil'schen Krankheit beschäftigt war, also in eine Zeit, in welcher ich, wie früher erwähnt, noch nicht in der Lage war, Thierrersuche anzustellen, und so sind auch hier in dieser Beziehung meine späteren, bezw. letzten Untersuchungen die wesentlichsten und beweisendsten.

$$
\text { Fall } 1 .
$$

Huhn I. Am 21. März 1890, Nachmittags $4^{1 / 2}$ Uhr, wurde mir aus Söflingen ein todtes Huhn gebracht, welches am Morgen des selbigen Tages eingegangen war. Einige weitere Thiere, namentlich Enten und Gänse, sollen an den Tagen vorher eingegangen sein. Leider konnte ich nur dieses eine Stück erhalten. Section: Grosses, kräftiges, altes Huhn. Unterhautzellgewebe intensiv dunkel-goldgelb, icterisch verfärbt; ${ }^{1}$ in demselben kleine Körnchen, aus Fett bestehend und von Senfkorngrösse eingelagert. Mesenterien gleichfalls icterisch. Leber etwas blass, fleckig; an einer Stelle mit einem ganz dünnen, grauweissen Belag überzogen. Die Serosa des Darmes im Ganzen nicht besonders geröthet, doch sind die grösseren Gefässe prall gefüllt; sehr kleine Ecchymosen auf der Schleimhaut; leichte Enteritis. Lungen, Milz, Nieren makroskopisch von normalem Aussehen. Mikroskopisch weist die Leber sehr bedeutende Verfettung auf. In Ausstrichen aus Lungen, Leber, Milz und

1 Die Liagnose Icterus wurde auch von Hrn. Stadthierarzt Motz ausgesprochen, noch bevor ich denselben über die näheren Umstände, welche diesen Fall so interessant machten, in Kenntniss gesetzt hatte. 
Nieren, selbst mit dem Darminhalt, konnten keine Bakterien aufgefunden werden. Bei der weiteren Untersuchung der gehärteten Organe in Schnitten fanden sich in den Nieren kleine Nekrosenherde, sowie Stellen mit kleinzelliger Infiltration; ausserdem aber auch sowohl in den Nieren als in der Milz Bacillenhaufen. Die Bacillen erschienen ganz und gar in der Gestalt wie die in dem Falle I von fieberhaftem Icterus in den Schnitten gefundenen Organismen; besonders fiel die Transparenz und die starke Färbung der Pole auf; desgleichen bei vielen Individuen die Krümmung. Auf Taf. $\nabla$; Fig. 1 ist ein Schnitt aus der Niere dieses Huhnes mit diesen Bacillen wiedergegeben. Auf dem Photogramm findet sich auch eine völlig vibrionenförmige Aneinanderlagerung der Einzelglieder; eine solche habe ich auch in Ausstrichen aus Reinculturen nicht selten beobachtet. Sehr zahlreich waren die Bacillen in den Schnitten nicht.

Auf den aus den Organen dieses Huhnes angelegten Gelatineplatten aus Herzblut, Leber, Milz, Nieren, Lunge und Darm begannen sich am dritten Tage Colonieen in ziemlich spärlicher Zahl zu entwickeln, welche zunächst einigermassen an Typhuscolonieen erinnerten; neben diesen entwickelten sich auch solche, welche, mit blossem Auge gesehen, als erhabene, glashelle, schwach gelblich gefärbte Tröpfchen der Gelatine aufsassen. Bei schwacher Vergrösserung sah man aber an allen diesen Colonieen einen Randbezirk, welcher sich in feinen Schlieren als dünner Belag auf der Gelatine ausbreitete. Bei Untersuchung der diese Colonieen zusammensetzenden Bakterien im gefärbten Ausstrichpräparat fanden sich Doppelstäbchen von meist sehr beträchtlicher Dicke, daneben aber auch viel kleinere, obwohl das Präparat aus einer Plattencolonie stammte. Bei Färbung mit Carbolfuchsin ohne Erwärmen sah man lückenbildende Kurzstäbchen bis zu Kokkenform; häufig längere Verbände, zuweilen auch gekrümmte Formen. Mit Methylviolett wurde nur mangelhafte Färbung erzielt. Bei Untersuchung im hängenden Tropfen zeigten sie dieselbe intensive Beweglichkeit, das lebhafte Durcheinanderschiessen, das Oscilliren, wenn sie irgendwo festgehalten waren. Dieser lebhaften Beweglichkeit entsprechend, findet man bei Untersuchung auf Geiselfäden die Bacillen an beiden Langseiten mit ganzen Schwärmen solcher besetzt, ganz in derselben Weise, wie dies bei den früher beschriebenen Culturen der Fall gewesen. war und genau das Bild gebend, wie Geisseln des Bacillus proteus vulgaris.

Auch im übrigen culturellen Verhalten erwies sich bei diesen Bakterien Uebereinstimmung mit den früher erhaltenen Culturen, doch war die Tendenz zur Verflüssigung der Gelatine hier stets besonders stark: wohl hielten sich dieselben manchmal ziemlich lange auf der Platte nicht verflüssigend, mit der Zeit trat aber bei allen Verfüssigung ein. In den Stichculturen kam es, wenn die Temperatur ziemlich kühl war, zur Bildung einer Luftblase wie bei Cholera, bei etwas höherer Temperatur stellte sich Verflüssigung wie bei Finkler ein. Auf Agar im Brütschrank wuchsen die Culturen unter grünlicher Verfärbung des Nährbodens mit dichtem gelblich-weissen Belage innerhalb 48 Stunden; zuweilen traten im Agar Gasblasen auf. Auf Kartoffeln bildete sich derselbe gelbbraune Belag unter bleigrauer, später rothbrauner Verfärbung der Kartoffelsubstanz. In Bouillon stellte sich völlige Trübung ein, und es bildete sich ein reichlicher, dicker, gelblich-weisser Bodensatz. 
Thierversuche an weissen Mäusen anzustellen war mir, wie erwähnt, aus äusseren Umständen erst Monate nach Obduction dieses Huhnes möglich. Es wurde eine Maus mit im Brütschrank auf Glycerin-Agar gewachsener Cultur an der Schwanzwurzel geimpft und eine zweite mit gleichfalls im Brütschrank gewachsener Bouilloncultur gefüttert. Sowohl die geimpfte als auch die gefütterte Maus blieben am Leben. Einen Monat später wiederholte ich den Impfversuch, indem ich in der S. 542 beschriebenen Weise $0 \cdot 1^{\mathrm{com}}$ einer Mischaufschwemmung frischer und alter Glycerin-Agar-Brütschrankcultur in die Bauchhöhle injicirte. Die Maus war am folgenden Tage schwer krank, fiel um, wenn das Glas, in welchem sie sass, geneigt wurde, erholte sich aber am Abend wieder und blieb von da an gesund.

\section{Fall 2.}

Huhn II. Im December 1890 brach die Krankheit unter einer kleinen Zucht junger Hühner wieder aus; mehrere derselben sollen leicht krank gewesen sein, dünne Excremente entleert und nicht gefressen haben; eines sei sehr krank gewesen und zwei starben. Davon war das erste sofort in die Blau geworfen worden, und nur das zweite konnte ich am 6. December zur Untersuchung erhalten. Section: Kein Icterus. Im Peritoneum ein plastisches, gelbes Exsudat; Lungen stark geröthet, besonders die linke. Milz nicht vergrössert; Leber makroskopisch ohne Abnormität. Nieren gross, blutreich. Der obere Dünndarm entzündet. Mikroskopisch: Verfettung der Leberzellen und Nierenepithelien; meist sehr feine Fetttröpfchen. Im Exsudat, im Blut, in Niere, Milz und Lungen vereinzelte Bacillen, etwas reichlicher im oberen Dünndarm; dieselben sind gross, zum Theil leicht gekrümmt; sie sind in Ausstrichen fast in Reincultur zu finden.

Zunächst wurden Culturen angelegt aus Niere, Nilz, Leber, Lunge auf Glycerin-Agar (Brütschrank), sowie ans denselben Organen und dazu noch aus Herzblut, Darm und peritonealem Exsudat auf Gelatineplatten. Auf sämmtlichen schräg erstarrten Glycerin-Agarröhren war schon am folgenden Tage ein reichlicher dicker Belag gewachsen und das Glycerin-Agar war grünlich verfärbt. Auch auf den Gelatineplatten stellte sich aus allen $\mathrm{Or}$ ganen Wachsthum ein; nur die aus Milz angelegte blieb steril. Auf der Platte aus Leber wuchsen etwa 30, auf derjenigen aus Niere 5, auch aus Herzblut vereinzelte; reichliches Wachsthum stellte sich ein aus Lnnge und Peritonealexsudat. Bei den aus dem Darm (Gewebe und Inhalt) angelegten Platten blieben die Verdünnungen I und II steril, die Originalplatte enthielt eine Anzahl Verflüssigungskrater, in welchen aber nur steril gebliebene Gewebsfetzen lagen. An einer solchen Stelle fand sich aber eine ganze Menge rom Gewebe herausgewachsener Colonieen der charakteristischen Bacillen.

Die auf diesen verschiedenen Gelatineplatten gewachsenen Colonieen producirten sich als feine klare Tröpfchen, bei schwacher Vergrösserung als kreisrunde, scharf contourirte, ziemlich blasse Colonieen und nahmen späterhin den früher beschriebenen Choleratypus an. Bei einzelnen entwickelte sich typhusähnliche Flächenausbreitung, bei anderen war exquisiter Proteustypus in der Flächenausbreitung zu erkennen; es zeigten sich 
häufig völlig von der Muttercolonie losgelöste Inseln. Verflüssigung blieb dagegen hier völlig aus. Das Wachsthum im Gelatinestich bestand in einer in manchen Culturen besonders schön entwickelten baumförmigen Verzweigung, wie sie auf Taf. I, Fig. 7 zur Anschauung gebracht ist; der Stich nahm nach einigen Wochen eine braunrothe Farbe an; häufig entwickelten sich in der Gelatine Gasblasen, häufig setzten sich von der Oberflächenausbreitung nach unten zierliche Krystallbündel an; ebenso vom Stich aus. Im hängenden Tropfen zeigten sich sehr lebhaft bewegliche Bacillen. Ausstrichpräparate aus den flächenhaft ausgebreiteten Colonieen ergaben bei Färbung mit heissem Carbolfuchsin ganz charakteristisch dieselben grossen gekrümmten Bacillen, welche bei dem vorigen Falle, sowie bei den Fällen Weil'scher Krankheit gefunden waren. In Ausstrichen aus noch geschlossenen Colonieen waren mehr kurze Formen zu sehen, doch kamen auch hier lange, vielfach gekrümmte Scheinfäden zum Vorschein. Mit Gentianaviolett waren die Organismen nur schlecht färbbar, mit Carbolfuchsin ohne Erwärmen zeigten sie die Lückenbildung, nach Gram's Methode trat Entfärbung ein.

Nach einem Monat konnte ich die aus dem Hühnchen gewonnene Cultur auf eine weisse Maus verimpfen und zwar geschah dies in der schon früher erwähnten Weise: Aufschwemmung einer vier Wochen alten und einer frischen Cultur und hiervon Injection von $0.1^{\mathrm{cem}}$ intraperitoneal. Die Maus zeigte sich am Abend nach der Impfung krank; am folgenden Morgen waren beide Augen durch Secret verklebt und Mittags (nach 24 Stunden) war sie todt. Section: In der Musculatur oberhalb des Sternum zwei Hämorrhagieen; sehr starke Injection aller Cutisgefässe; mässiger Ascites, nicht blutig gefärbt. Leber weich, brüchig, Milz bedeutend vergrössert; in den Lungen pneumonische Herde. Nieren ohne makroskopisch sichtbare Abnormität. Darm normal. In Ausstrichen aus Lungen und Leber waren die Bacillen massenhaft vorhanden, auch in der Milz ziemlich zahlreich.

Dieser Thierversuch wurde gleichzeitig mit den auf S. 542 und 579 beschriebenen ausgeführt; das Ergebniss desselben, die Krankheitserscheinungen, die Zeit des Eintritts des Todes, der anatomische und bakteriologische Befund bei allen diesen Thieren war vollkommen übereinstimmend. Durch das Culturverfahren erhielt ich aus den Organen dieser Maus die eingeimpften Bakterien wieder. Eine dieser Culturen zeigte in den späteren Wochen im Gelatinestich beginnende Verflüssigung; Bildung eines tiefen mit Flüssigkeit gefüllten Kraters, in dessen Umgebung ein Theil der Cultur sich ohne Verflüssigung flächenhaft ausbreitete; bei den späteren Umzüchtungen blieb dagegen jede Verflüssigung wieder aus.

Vom Dezember 1890 an kamen den Winter durch, soweit ich in Erfahrung bringen konnte, keine Geflügelerkrankungen in Söflingen mehr vor, bis um Mitte März 1891 die Seuche wieder losbrach; bei dieser Gelegenheit konnte ich drei Stück Geflügel, welche erlegen waren, der Untersuchung unterwerfen, und zwar eine Ente, ein Huhn und eine Gans. 


\section{Fall 3.}

Ente. Das Thier war angeblich am 14. Abends plötzlich eingegangen. Am 16. früh kam es in meine Hände und wurde sofort untersucht. $\mathrm{Ob}$ duction: Musculatur brüchig, dunkelroth. Leber auffallend gross, blass, brüchig mit unzähligen weissen Punkten bedeckt. Der Herzbeutel mit zahllosen punktförmigen Hämorrhagieen durchsetzt. Der Magen enthält gelbgrünen Schleim, Sand, Steine. Milz mässig vergrössert, fleckig. An den Nieren nichts Auffallendes. Darm frei von Entzündung; Lungen sehr blutreich, injicirt. Mikroskopische Untersuchung: Leber in colossalem Grade verfettet; von der acinösen Structur des Gewebes buchstäblich nichts mehr zu erkennen; Alles besteht aus Fetttropfen von den grössten bis zu den allerfeinsten. In den Lungen grosse Mengen von Kurzstäbchen, meist zu zweien, häufig auch allein, dann sehen sie. fast wie Kokken aus. Auch in der Milz sehr zahlreich dieselben Bakterien.

Aus Lunge, Milz, Leber und Nieren wurden Gelatineplatten angelegt, ausserdem wurden zwei weisse Mäuse inficirt, der einen wurde ein Stückchen Lunge in die Bauchhöhle gebracht, die andere erhielt ein Milzstückchen unter die Haut an der Schwanzwurzel. Die beiden Mäuse starben, und zwar die in die Bauchhöhle inficirte nach 12, die subcutan inficirte nach 17 Stunden. Obduction der in die Bauchhöhle inficirten Maus: Aus der Wunde hängt ein Stück blutiges, vertrocknetes Bauchfell vor, (welches die Maus hervorgezerrt hat). Das eingeimpfte Gewebsstück liegt frei in der Bauchhöhle. Darm nirgends verletzt, aber da, wo das Stück lag, entzündet. Milz etwas vergrössert. Die Leber- und Nierenepithelien hochgradig verfettet. Im Herzblut massenhaft Bacillen, ebenso in der Leber, Lunge, Milz, Niere. - Obduction der subeutan geimpften Maus: Milz bedeutend vergrössert, enthält verfettete Zellen und massenhaft Bacillen; auch sonst mit den obigen übereinstimmende Befunde. Aus den Lungen der ersten und aus der Milz der zweiten Maus Gelatineplatten angelegt. Ueber die Ergebnisse des Culturverfahrens bei diesem, sowie bei den zwei noch folgenden Fällen, werde ich unten zusammen berichten.

\section{Fall 4.}

Huhn III. Am 16. Abends erhalten; dasselbe war am Morgen des 16. todt im Stalle gefunden worden. Untersuchung am 17. Obduction: Haut, bezw. Unterhautzellgewebe deutlich icterisch, besonders aber das Fettgewebe der Mesenterien. Leber nicht vergrössert, überhaupt zeigen die inneren Organe makroskopisch keine nennenswerthe Abnormität. Die mittleren Abschnitte des Dünndarms zeigen leichte Injection. In den Ausstrichen Bacillen nicht mit Sicherheit nachweisbar. Frische, mittels Gefriermikrotom hergestellte Schnitte weisen hochgradige Verfettung nicht bloss der Leber, sondern auch der Lungen und Nieren auf. Mit einem Stückchen Niere wurde Abends $5^{1 / 2}$ Uhr eine Maus subcutan geimpft; dieselbe war am folgenden Morgen um $9 \mathrm{Uhr}$ schwer krank; sie sass mit geschlossenen verklebten Augen und struppigem Fell zusammengekauert im Käfig; wurde das Glas bewegt, so fiel sie um. Gegen Abend erholte sie sich merklich; am 
folgenden Tag war sie anscheinend wieder krank, erholte sich dann aber dauernd. Eine zweite, am 20. mit der noch aufbewahrten Lunge des Huhnes geimpfte Maus zeigte sich gleichfalls etwa 8 Stunden nach der Impfung nicht ganz munter, schloss die Augen und sträubte das Fell, erholte sich dann aber gleichfalls wieder.

Von Milz, Lunge, Leber, Niere des Huhnes wurden Gelatineplatten angelegt.

\section{Fall 5 .}

Gans. Am 18. März Abends erhalten; dieselbe war angeblich am Morgen desselben Tages eingegangen. Obduction am 19. März Vormittags: Haut, bezw. Unterhautzellgewebe eigenthümlich diffus geröthet; Fett der Bauchhöhle intensiv icterisch. Herzbeutel mit zahllosen Hämorrhagieen durchsetzt. Im Herzbeutel $2^{\mathrm{ccm}}$ blutig-röthliche Flüssigkeit. Leber wohl etwas vergrössert und mit feinen weissen Punkten ganz übersät. Der letzte Abschnitt des Dickdarms und dessen Mesenterium zeigen zahlreiche Hämorrhagieen. Im Dünn- und Dickdarm finden sich viele kleinere Ecchymosen, auch oberflächliche Geschwüre, bezw. Erosionen; dieselben geben dem Darm ein Aussehen ähnlich einem mit Typhusgeschwüren besetzten.

In Zupfpräparaten wurde hochgradige Verfettung der Leber, Lungen, Nieren und Milz nachgewiesen. In gefärbten Gewebsausstrichen liessen sich überaus zahlreiche kleine, fast kokkenähnliche und daneben weniger zahlreiche grosse Bacillen erkennen, welche sich stärker färbten als die kleinen, doch war an diesen Präparaten nicht zu entscheiden, ob es sich um zwei Arten von Bakterien oder um Zerfall der grossen Bacillen in kleine Einzelglieder handelte.

Aus der Milz dieser Gans wurde eine weisse Maus subcutan geimpft; dieselbe starb nach 16 Stunden. Obduction: Milz bedeutend vergrössert; Verfettung in allen Organen, Fetttropfen sogar im Herzblut. Ueberall sehr zahlreiche Bakterien. Die Grösse derselben schien in der Mitte zu stehen zwischen den grossen und den kleinen in der Gans selbst gefundenen. Die Taf. V, Fig. 2 ein Ausstrich aus Herzblut, giebt diese Bakterien wieder. Gelatineplatten wurden angelegt aus Herzblut, Leber und Darm der Gans, sowie aus der Milz der mit einem Organstück der Gans geimpften Maus.

Auf allen Gelatineplatten, welche aus den verschiedenen Organen dieser drei Stück Geflügel angelegt worden waren, desgleichen auf den Platten, welche von den Organen der durch Impfung getödteten Mäuse angelegt waren, entwickelten sich Culturen, welche unter einander völlig übereinstimmten. Bei Besichtigung mit blossem Auge erschienen die Colonieen wie feine helle Tröpfohen, welche in der Umgebung des auf die Gelatine mit übertragenen Organstückchens sehr dicht standen. Betrachtete man diese kleinen runden Colonieen mit schwacher Vergrösserung, so boten sie exquisit das schon mehrfach beschriebene Bild, welches ich als "Choleratypus" bezeichnet habe; an Stellen aber, wo die Colonieen weniger dicht standen, kamen sie zu grösserer Entfaltung, erreichten die Oberfläche und bildeten hier stark gebuchtete Beläge; einzelne derselben mit einem Durchmesser bis etwa $1 \mathrm{~cm}$. Verflüssigung der Gelatine blieb bei den ersten Plattenculturen aus, nach mehrmaligem Umzüchten auf Platten stellte sich das Verflüssigungs- 
vermögen bei sämmtlichen Culturen ein und - was besonders merkwürdig war - mit den weiteren Umzüchtungen nahmen die in der Mitte verflüssigten und am Rande stark gebuchteten Oberflächencolonieen mehr und mehr den Proteustypus an, so dass sich schliesslich auf allen Platten zwischen geschlossenen kleinen, in der Tiefe sitzenden Colonieen grosse echte Proteuscolonieen vorfanden. Im Gelatinestich zeigte sich grüne Fluorescenz, desgleichen auf Glycerin-Agarculturen; hier kam es auch zuweilen zur Entwickelung von Gasblasen. Auf Kartoffeln entwickelte sich der Anfangs gelbliche, später braune Belag und die Kartoffeln erhielten den bleigrauen, später in's Braunrothe übergehenden Farbenton wie bei den früher beschriebenen Culturen. Die Bakterien, aus welchen die Colonieen bestanden, waren sehr lebhaft bewegliche Kurzstäbchen von überaus wechselnder Grösse in einem und demselben, einer jungen Plattencolonie entnommenen Präparate.

Das Verhalten dieser Bakterien gegen die Anilinfarben war genau dasselbe wie bisher beschrieben: etwas ablehnend gegen die gewöhnlichen wässerigen Farblösungen, bei Färbung mit Carbolfuchsin ohne Erwärmen starke Lückenbildung bis zu Zerrbildern, Carbolfuchsin oder Löffler'sche Lösung mit Erwärmen schöne Bilder; bei Gram'scher Methode Entfärbung.

Von den Reinculturen, welche auf den Gelatineplatten aus Fall 3, 4 und 5 erhalten waren, sowie von denjenigen, welche von den mit Organstücken unmittelbar geimpften und an der Impfung gestorbenen Mäusen stammten, wurden nunmehr weitere Mäuse an der Schwanzwurzel geimpft, und da stellte sich denn heraus, dass die kleinen, geschlossenen Colonieen, welche Choleracolonieen glichen, die für die Mäuse pathogenen Organismen waren. Die zwei Mäuse, welche mit solchen Culturen geimpft waren, die schon vermittelst der directen Infection je eine Maus passirt hatten, starben nach 21 , bezw. 23 Stunden. Die Mäuse dagegen, welche mit direct aus den Geflügelorganen gewonnenen Culturen geimpft waren, erkrankten merkwürdigerweise nicht.

Aus den Organen dieser durch Infection mit solchen Reinculturen getödteten Mäuse wurden abermals Reinculturen angelegt und mit diesen wieder zwei Mäuse geimpft. (Die eine Cultur stammte also von der Ente, die andere von der Gans ab.) Beide Mäuse erlagen der Infection. In beiden Fällen war die Milz bedeutend vergrössert; in den Nierenepithelien und im Blute Fetttröpfchen; in einem Falle eine stark vergrösserte hämorrhagische Inguinaldrüse, welche gleichfalls hochgradige Verfettung aufwies. Der ganze Dünndarm in einem Falle intensiv entzündet. Die Bacillen waren in allen untersuchten Organen reichlich vorhanden, auch im Herzblut; hier jedoch spärlicher.

In Gewebsschnitten aus den Organen der inficirten Mäuse konnten die Bacillen in überaus reichlicher Menge und ebenso haufenweise angeordnet vorgefunden werden wie in den Organen der am Weil'schen Icterus Verstorbenen.

Ich habe schon oben erwähnt, dass die aus diesem Geflügel durch Züchtungsverfahren und mehrmalige erfolgreiche Verimpfung auf Mäuse gewonnenen Culturen im Verlaufe wiederholter Umzüchtungen auf Platten mehr und mehr die Eigenschaften von Proteusculturen annahmen. Es war daher von Interesse und konnte als eine Controle dienen, wenn man eine 
solche, ich möchte sagen ,zum Proteus degenerirte" Cultur auch auf eine Maus verimpfte. Dies wurde ausgeführt und zwar beinahe drei Monate nach Beginn dieser Untersuchungen. Die an der Schwanzwurzel mit einer solchen Proteuscolonie geimpfte Maus starb nach 20 Stunden unter denselben Erscheinungen wie die früheren; in den Organen war Verfettung zu constatiren, auch fanden sich die Bakterien in Ausstrichen vor.

Nunmehr wurden auch die Fütterungsversuche wiederholt. Es wurde eine Bouilloncultur angelegt und im Brütschrank bei $37 \cdot 5^{0}$ gehalten; nachdem reichliches Wachsthum erfolgt war, wurde mit dieser Bouillon die Nahrung von zwei Mäusen inficirt. Nach zwei Tagen schienen beide Mäuse krank zu sein; die Augen waren verklebt; am folgenden Tage erholten sie sich aber wieder, und obgleich die Fütterung mit inficirtem Brot noch zehn Tage fortgesetzt wurde, traten keine neuen Krankheitserscheinungen mehr ein.

Aus den vorstehend mitgetheilten Untersuchungen geht hervor, dass es sich bei dem Söflinger Geflügel um eine Seuche handelt, als deren Ursache ich eine Bakterienart aufgefunden habe, welche in allen morphologischen und biologischen Merkmalen völlig übereinstimmt mit den vorher beschriebenen, bei dem fieberhaften Icterus aufgefundenen Bakterien. Diese Geflügelseuche ist, soweit ich übersehe, bis jetzt noch nicht als eine ätiologisch gesonderte beschrieben. Die von mir gefundenen Bakterien sind sicher nicht identisch mit den Bacillen der Hühnercholera; von diesen unterscheiden sie sich durch ihre Beweglichkeit und dadurch, dass sie auf Kartoffeln gut gedeihen; dieselben Jerkmale lassen sie auch unterscheiden von dem Bacillus gallinarum E. Klein's. Eher denkbar wäre die Möglichkeit einer Identität meiner Bakterien mit den gleichfalls ron Klein beschriebenen Bakterien der .Grouse disease"; diese zeigen sowohl in ihrer Form als in ihren Wachsthumserscheinungen auf der Gelatineplatte gewisse pleomorphe Eigenschaften, wenn auch das Auftreten eigentlicher Proteustypen von Klein nicht beschrieben wird. Auch die von diesem Autor in seiner zweiten Arbeit mitgetheilte Beweglichkeit ist ein übereinstimmendes Merkmal, ebenso die Thatsache des Wachsthums auf Kartoffeln. Andererseits haben Klein's Culturen anscheinend niemals die Gelatine verflüssigt, während die meinigen sich durch grosse Variabilität ibrer peptonisirenden Kraft auszeichnen, allerdings habe auch ich bei gewissen Culturen (Fall 2, Huhn II) niemals ausgesprochene Verflüssigung gesehen. Weiter kann ich jedoch für jetzt nicht gehen, als die Möglichkeit zuzugeben, dass es sich bei Klein's und meinen Untersuchungen um identische oder verwandte Organismen handeln könnte. In Bezug anf die Frage, wie sich meine bei dem Geflügel gefundenen Bakterien zum Vibrio Metschnikoff verhalten, 
kann ich mich auf das früher Gesagte berufen, da ich ja meine Bacillen der fieberhaften Gelbsucht und der Geflügelseuche als unter sich identisch bezeichnen muss.

Auch die Entscheidung der Frage, ob die Symptome und die anatomischen Veränderungen; welche ich bei dem von mir untersuchten Geflügel und meinen Versuchsthieren gefunden habe, übereinstimmen mit den bei den vorgenannten anderen Geflügelkrankheiten beobachteten Erscheinungen, muss späteren Untersuchungen vorbehalten bleiben.

Um so bestimmter aber kann ich aussprechen, dass nicht nur die bakteriologischen Befunde, sondern auch die gesammten pathologisch-anatomischen Veränderungen beim Weil'schen Icterus einerseits, und bei unserer Geflügelseuche andererseits sich völlig deckende Bilder ergeben. Soll ich das diesen beiden Krankheitsgruppen gemeinsam zukommende anatomische Bild hier nochmals kurz skizziren, so finden wir in allen Fällen: hochgradige fettige Infiltration, bezw. Degeneration der Leber, meist auch der Nieren, parenchymatöse Nephritis, herdweise kleinzellige Infiltrationen und Nekrosenherde in diesen Organen und in der Milz, mässige Vergrösserung der letzteren; mehr oder weniger intensive Hyperämieen im Dünn- und Dickdarm (diese Erscheinung nicht constant) bis zur Bildung von grösseren und kleineren Blutaustritten in's Gewebe und zll kileinen Erosionen und Nekroseherden. Grössere und kleinere Hämorrhagieen in den parenchymatösen Organen; auf der äusseren Haut, besonders aber in den serösen Häuten. Endlich (beim Menschen fast regelmässig, bei dem Geflügel unter drei Hühnern zweimal beobachtet) Icterus. - Besonders eclatant war, auch schon beim makroskopischen Aussehen, die Uebereinstimmung in Fall IX der Fälle Weil'scher Krankheit und Fall 5 der Söflinger Geflügelseuche; hier boten die Hämorrhagieen und Erosionen auf der Darmschleimhaut, die Hämorrhagieen in den Mesenterien und die Petechien auf dem Herzbeutel so absolut gleiche Bilder, dass der Beobachter schon hieraus auf den Gedanken eines Zusammenhanges beider Krankheiten hingelenkt werden musste.

Ebenso verbielt es sich bezüglich der mikroskopischen Veränderungen: die Bilder, welche man bezüglich der Leber- und Nierenverfettung bei den zwei untersuchten Fällen fieberhaften Icterus erhält, sind genau dieselben wie die aus denselben Organen des Geflügels erhaltenen. Schliesslich ist die Uebereinstimmung im Aussehen und in der Anordnung der Bacillen im Gewebe in den verschiedenen Schnitten aus den beigegebenen Abbildungen (vgl. Taf. II Fig. 1 u. Taf. V Fig. 1) ohne Weiteres ersichtlich. 
Darf ich somit den Nachweis, dass die Söflinger Geflügelseuche und die Ulmer Fälle Weil'scher Krankheit ätiologisch und anatomisch identische Krankheitsprocesse sind, als erbracht ansehen, so interessiren nun noch hauptsächlich drei Fragen:

1. Kommt die Weil'sche Krankheit auch unter den Bewohnern von Söflingen vor?

2. Kann der Infectionstoff von Söflingen aus in die Donau gelangen, und kann er im inficirten Wasser nachgewiesen werden?

3. Wie kommt die Krankheit an das Geflügel?

Die erste dieser Fragen kann ich mit Ja beantworten; ich verdanke Hrn. Dr. Hugger in Söflingen hierüber höchst interessante Mittheilungen, welche ich mit seiner freundlichen Erlaubniss hier wiedergebe. Derselbe hat folgende Fälle aus seiner Praxis sich aufgezeichnet.

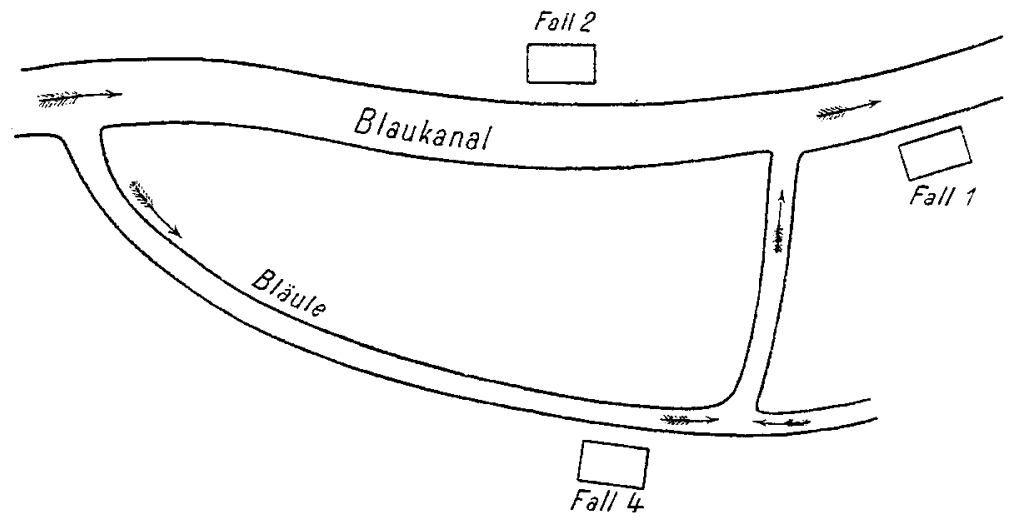

„1. Franziska M., 65 Jahre alt, Wittwe, erkrankte am 10. September 1883 unter den Erscheinungen eines heftigen Icterus mit hohem Fieber und profuser Diarrhoe. Von Anfang an bestanden Delirien, starke Somnolenz, überhaupt sehr entwickelte Cerebralerscheinungen, ähnlich denjenigen bei Typhus. Ob Albuminurie vorhanden war, ist nicht aufgezeichnet. Genesung nach etwa 8 Tagen ohne Recidiv.

2. Marie Sch., 21 Jahre alt, erkrankte am 2. Februar 1889 an Icterus unter schweren Cerebralerscheinungen; starke Delirien. Tod am 9. Februar.

3. Georg D., Bauer auf Oberberghof $\left(2 \cdot 5^{\mathrm{km}}\right.$ nördlich von Söflingen), erkrankte am 12. Februar 1890 an schwere m Icterus mit hohem Fieber und starker Leberschwellung. Genesung nach 14 Tagen.

4. Johanna K. Ende Februar 1890 mit denselben Erscheinungen wie Fall 1, nur dass die icterische Färbung noch längere Zeit anhielt." 
Was die örtliche Ausbreitung dieser Fälle betrifft, so entnehme ich der Mittheilung des Hrn. Dr. Hugger die vorstehende Skizze.

Man sieht also, sämmtliche in Söflingen selbst beobachtete Fälle sind in Häusern vorgekommen, welche an einem der Blauarme liegen und zwar einer davon an demjenigen, an welchem schon lange in überwiegender Zahl die Fälle der Geflügelseuche aufgetreten waren; der andere Fall (Fall 1) ereignete sich unterhalb der Einmündung des "Bläule" in den Blaucanal, der dritte an dem Canal selbst, bezüglich des letzten ist es nicht möglich, der Infectionsquelle noch weiter nachzuspüren. Auffällig ist, dass alle diese vier Fälle nicht, wie sonst die Weil'sche Krankheit, in den Sommer fielen, sondern drei in den Februar, einer in den September. Dagegen ist daran zu erinnern, dass die Geflügelerkrankungen fast ausschliesslich auf den März fielen, und dass jedes Mal gerade, wenn sie auftraten, ungewöhnlich warme Witterung war, so dass ich mich der Ansicht nicht verschliessen kann, die Krankheit tritt bei dem Geflügel zu derjenigen Zeit auf, wenn es die Wasserläufe wieder aufsucht, und bei den Menschen zu der Zeit, wenn sie sich des Wassers zum Baden oder - wie in Söflingen - zu hauswirthschaftlichen $\mathrm{Z}_{\text {wecken }}$ bedienen. Hierdurch scheint sich mir: auch das häufigere Erkranken der weiblichen Berölkerung in Söflingen (im Gegensatz zu allen bisherigen Beobachtungen) zu erklären: hier werden diejenigen inficirt, welche das Wasser zum Waschen und Scheuern gebrauchen.

Zur Beantwortung der zweiten Frage musste es Angesichts dieser Thatsachen, dass Krankheitsfälle, welche offenbar mit dem in unserer Garnison beobachteten infectiösen Icterus höchst übereinstimmendes Verhalten darbieten, in Söflingen an demselben Wasserlaufe sich ereignet hatten, an welchem auch die Geflügelerkrankungen fast ausschliesslich vorgekommen waren, und Angesichts des dringenden Verdachtes, welchen man bezüglich der Erkrankung unter den. Mannschaften der Garnison auf eine Infection der Donau durch die Blau richtete, musste es, sage ich, von grösstem Werth sein, zu versuchen, den beim Geflügel gefundenen Erreger auch in dem betreffenden Wasserlaufe nachzuweisen. Die im März 1891 wieder heftiger ausgebrochene Seuche bot dazu die beste Gelegenheit, und es gelang mir in der That, die pathogenen Proteusculturen vermittelst des Thierexperimentes aus diesem Wasser zu erhalten. Das Verfahren war folgendes: am 20. März 1891 entnahm ich aus dem „Bläule“ zwei Wasserproben mittels steriler Gläser. Der Bach zeigte sich durch allerlei Unrath sehr verunreinigt. Unmittelbar vor einem Hause, wo zwei Tage zuror zwei Hühner krepirt waren, fand sich das Wasser durch Schmutz theilweise gestaut und besass hier eine schillernde Haut. Hier wurde die erste Probe entnommen; eine 
zweite Probe wurde 15 bis $20^{\mathrm{m}}$ weiter abwärts geholt, an einer Stelle, an welcher soeben einige Enten den reichlich am Boden sitzenden Schlamm aufgewühlt hatten. Von den beiden Wasserproben wurden zunächst Gelatineplatten angelegt, da aber die bisher beobachteten Culturen in Folge ihrer grossen Variabilität keine sehr sicheren Anhaltspunkte zu bieten schienen, um sie aus zahlreichen anderen Colonieen herauszufinden, so wählte ich einen anderen Weg zu ihrer Auffindung. Ich brachte von jeder Wasserprobe $1^{\mathrm{cm}}$ in eine Röhre mit steriler Bouillon und stellte diese in den Brütschrank, von dem Gedanken ausgehend, dass so die eventuell pathogenen Bakterien gegenüber den anderen darin anwesenden unter die günstigsten Bedingungen gebracht seien. Nach zwei Tagen war die Bouillon stark getrübt und besass an der Oberfläche ein dünnes schleimiges Häutchen. Aus diesen beiden Bouillonröhren injicirte ich je einer weissen Maus $0.3 \mathrm{~cm}$ in die Bauchhöhle. Zwei andere weisse Mäuse wurden ebenso mit den Söflinger Wasserproben unmittelbar inficirt und eine Maus erhielt zur Controle, ob der Eingriff an sich tödtlich wirke, $0.3^{\mathrm{cm}}$ Leitungswasser in die Bauchhöhle. Diese Controlmaus und die beiden mit dem Bläule-Wasser unmittelbar inficirten Mäuse blieben völlig munter; die $z$ wei mit den Boullonproben geimpften Mäuse starben nach 16 Stunden. Bei den beiden Thieren fand sich nicht nur hochgradige Verfettung von Leber und Nieren, sondern auch die rothen Blutkörperchen des Herzblutes waren mit feinsten Fetttröpfchen vollgestopft. Die Milz war in beiden Fällen bedeutend vergrössert. Der Darm war in seinen oberen Partieen injicirt. Leber, Milz und Nieren waren überfüllt mit Bakterien, auch im Herzblut waren solche sehr reichlich vorhanden: es fanden sich theils lange dicke Stäbchen, meist etwas gekrümmt, theils Doppelstäbchen, Kokkenformen; viele derselben erschienen etwas transparent; sie färbten sich nur mit Carbolfuchsin oder Löffler's Methylenblau unter Erwärmen gut und intensiv. Taf. VI Fig. 1 giebt ein Ausstrichpräparat aus der Mrilz einer solchen Maus wieder.

Bei der Aussaat aus Milz und Herzblut dieser Mäuse auf Gelatine (Esmarch'sche Rollröhren) fand sich in beiden Fällen übereinstimmend, dass auf den aus Herzblut angelegten Platten ausschliesslich unter sich völlig übereinstimmende Colonieen von flächenhafter (typhusähnlicher) Ausbreitang heranwuchsen, welche die Gelatine nicht verflüssigten; anf den aus Milz angelegten Rollröhren wuchs gleichfalls eine Reincultur die Gelatine verflũssigender, bei schwacher Vergrösserung das choleraähnliche Aussehen darbietender Colonieen. Die verflüssigenden wie die nicht verflüssigenden Colonieen bestanden aus sehr lebhaft beweglichen 
Bacillen; die Art der Bewegung war genau dieselbe wie diese bei den bisher beschriebenen Organismen beobachtet wurde; auch gegenüber Farbstoffen verhielten sich dieselben ebenso wie die früher beschriebenen und endlich bot das Wachsthum im Gelatinestich, sowie auf Glycerin-Agar und Kartoffeln dieselben Erscheinungen dar, wie die bisher beschriebenen Culturen. Insbesondere aber war zwischen diesen zwei aus den Organen ein und desselben Thieres gezüchteten Reinculturen der einzige Unterschied der des verschiedenen Peptonisirungsvermögens. Im Verlauf der späteren Umzüchtungen behielt jede der beiden Culturen ihr eigenthümliches Peptonisirungsvermögen bei, im Uebrigen aber nahmen beide bei mehrmaliger Plattenumzüchtung ganz den Proteuscharakter an, so dass man die verflüssigende Cultur als dem Proteus vulgaris, die nicht verflüssigende als dem Proteus Zenkeri am nächsten stehend zu bezeichnen hätte.

In Folge Abcommandirung konnte ich erst nach mehreren Wochen mit diesen Reinculturen Mäuse impfen. Ich inficirte Vormittags $11 \mathrm{Vhr}$ je eine Maus an der Schwanzwurzel mit einer verflüssigenden und einer nicht verflüssigenden Gelatinecultur. Am Abend dieses Tages waren beide Mäuse krank; sie sassen mit geschlossenen, durch Secret verklebten Augen und gesträubtem Fell zitternd und mühsam athmend im Käfig ohne zu fressen; so blieb der Zustand über den folgenden Tag; am dritten Tage erholten sich aber beide Thiere wieder und blieben ron da $a b$ gesund. Zu einer Wiederholung dieser Thierexperimente, verbunden mit dem Versuche, die Culturen durch Züchtung in eiweissreicherem Nährsubstrat im Brütschrank virulenter zu machen, fehlte mir bisher noch die Zeit.

Aus diesen Untersuchungen geht hervor, dass der Infectionsstoff, welcher die Krankheit des Söflinger Geflügels herbeiführt, auch im Wasser sich nachweisbar und virulent $z u$ erhalten vermag, dass er in einem Theile der nach kurzem fernerem Laufe in die Donau mündenden Blau (ca. $3^{\mathrm{km}}$ ) sich hat nachweisen lassen. Bedenkt man hierbei die schon früher erwähnte Thatsache, dass das krepirte Geflügel meist der Blau übergeben wird und nachweislich von dieser aus in die Donau abwärts geschwemmt wird, so wird der Zusammenhang zwischen den Erkrankungen der Mannschaften beim Baden und der Geflügelseuche in Söflingen in die Augen springen.

Hierbei möchte ich auf das zurückkommen, was ich bei der Bestimmung der Keimzahlen in der Donau hervorgehoben habe. Warum, wenn der Infectionsstoff auf dem angegebenen Wege von der Blau in die Donau gelangt, vertheilt sich derselbe nicht in dieser dermassen, dass entweder (wenn reichliche Infectionsstoffe hineingelangten) Massenerkrankungen unter den Badenden auftreten, oder dass der Infectionsstoff durch die 
reichen Wassermassen bis zur Unschädlichkeit verdünnt wird? Ich habe auf die zuweilen ganz unmotivirt hohen Keimzahlen hingewiesen, welche den im Uebrigen gesetzmässig verlaufenden Anstieg und Abfall der Zahlenwerthe brüsk unterbrechen; es handelt sich hier eben nicht um lösliche Stoffe, sondern um körperliche; daher kommt es nicht zu einer homogenen Mischung, sondern viele Unreinigkeiten bleiben mehr compakt beisammen, und hier führen die pathogenen Bakterien eine für länger gesicherte Existenz weiter. Namentlich aber gelangen feste Substanzen, Koth, Stallstreu- und Futterreste, ja besonders das krepirte Geflügel aus der Blau die Donau hinab. Solche feste Körper geben das Transportmittel ab; dabei werden die Gegenstände von Wasser umspült und ausgelaugt; es kommt z. B. zur Bildung solcher schillernder Kamhäute, wie ich sie in dem Bache in Söflingen gefunden und wehe Demjenigen, welcher zufällig: mit einem Schlucke Badewassers ein Stückchen einer solchen Kamhaut in sich aufnimmt, das, getragen von einer Fettschicht des Körpers, dem es enstammt, daherschwimmt!

Gerade bei der Natur dieses Infectionsstoffes ist meines Erachtens dieser von mir angenommene Modus der Infection besouders zu beachten: handelt es sich ja doch um einen pathogen wirkenden Proteus; also eine Bakterienart, die sich in fäulnissfähigen Substanzen in ihrem wahren Elemente findet, die für den Kampf gegen concurrirende andere Baliterien auf's Beste ausgerüstet ist und von der schon seit Hauser's Untersuchungen bekannt ist, dass sie sehr giftige Stoffwechselproducte producirt. Ich bin der Ueberzeugung, dass gerade die Einverleibung relativ grösserer Mengen schon ausserhalb des Förpers gebildeter Toxine wichtige Vorbedingung ist für das Eindringen der Proteusbakterien in die Gewebe und in den menschlichen Kreislauf und für ihre Vermehrung innerhalb von Blut und Gewebe: für ihre Pathogenität im strengen Sinne des Wortes.

Hiermit bin ich schon in die Beantwortung der dritten Frage eingetreten: wie kommt die Seuche an das Söflinger Geflügel?

Mittheilungen über pathogene Proteusarten verdanken wir italienischen Forschern: zuerst hat Bordoni-Uffreduzzi ${ }^{1}$ einen Proteus hominis capsulatus als Erreger einer neuen Infectionskrankheit des Menschen beschrieben. Besonders in dem zweiten der nach klinischem und anatomischem Verhalten etwas kurz geschilderten Fälle findet man ein. namentlich meinem Falle IX nicht unähnliches Bild. Von Icterus, von fettiger Entartung der parenchymatösen Organe ist nichts beschrieben, wohl aber

11887 rorläufige Mittheilung in Riforma medica und Centralblatt für Bakteriologie, Bd. II, Nr. 3; sodann: diese Zeitschrift, 1888, Bd. III, S. 333. 
von verschiedentlichen Hämorrhagieen und von Congestion der Baucheingeweide. Beide Kranken starben sehr frühzeitig, schon nach 4, bezw. 2 Tagen, so dass allerdings ein Icterus, wie er bei den Weil'schen Fällen bisher als pathognostisch angesehen wurde, ebenso wenig Zeit hatte, sich zu entwickeln, wie in meinem Falle IX. Bordoni-Uffreduzzi fand in diesen beiden Fällen Stäbchen, so lang und dick wie Milzbrandbacillen, meist in kleinen Gruppen angehäuft, jedoch nicht sehr zahlreich. Die von ihm gezüchteten Bakterien machen einen dem Proteus Zenkeri ähnlichen Formenkreis durch, unterscheiden sich aber sowohl von den gewöhnlichen Proteusarten als von den von mir in dieser Arbeit beschriebenen erstens durch den Besitz einer Kapsel (auch in der Cultur), zweitens dadurch, dass sie nach Gram sich färben und drittens dadurch, dass sie unbeweglich sind. Die pathogene Wirkung auf Mäuse ist, was die Krankheitserscheinungen, die Zeit, innerhalb welcher der Tod eintritt, und die anatomischen Veränderungen betrifft, derjenigen meiner Bakterien ziemlich ähnlich. Foà und Bonome haben alsdann mit dem Proteus capsulatus Bordoni-Uffreduzzi's weitere Untersuchungen angestellt, welche sie zu dem Schluss geführt haben, dass derselbe keine von den Proteusarten Hauser's verschiedene Species sei, sondern vielmehr dieser angehöre. Da der Hauser'sche Proteus eine sehr lebhafte Beweglichkeit besitzt, zu deren Vermittelung er (wie meine Bakterien auch) mit einem reichen Schwarm von Geisselfäden ausgerüstet ist, so muss sich wohl bei den Untersuchungen ron Foà und Bonome auch am Proteus capsulatus Beweglichkeit gezeigt haben. Ein wesentlichster Unterschied wäre noch der, dass Bordoni-Uffreduzzi's Proteus sich nach der Gram'schen Methode färben lässt, die gewöhnlichen Proteusarten und mein pathogener Proteus hierbei entfärbt werden.

Die Akten über die Artabgrenzung dieser pleomorphen Bakteriengruppe sind noch nicht geschlossen, und auch meine vorliegenden Untersuchungen gehen nicht darauf aus, diese schwierige Frage zu einer endgültigen lösung zu bringen; ich habe mir vielmehr die Aufgabe gestellt, den concreten Einzelfall, wo uns dieser pathogene Proteus entgegentritt, durch bakteriologische Methode und hygienische Nachforschung zu verfolgen, und in letzterer Richtung kann ich aus den Arbeiten der italienischen Forscher die Thatsache entnehmen, dass in Italien gefährliche, bezw. tödtliche Erkrankungen durch Proteusarten wiederholt und offenbar öfter wie bei uns bis jetzt beobachtet worden sind.

Diese Erwägung hat auch zu der Vermuthung geführt - und als mehr möchte ich sie noch nicht bezeichnen - dass unsere Söflinger Geflügelseuche und dadurch mittelbar die Weil'sche Krankheit in der Ulmer Garnison auf den umfangreichen Import italienischen 
Geflügels bei uns zurückzuführen sein möchte. Eine wesentliche Stütze erhält diese Vermuthung durch eine Beobachtung, welche Hr. Dr. Hugger in Söflingen gemacht hat, dass nämlich von den in grossem Maassstabe Gärtnerei treibenden Einwohnern dieses Dorfes aus Italien krepirt angelangtes Geflügel den Geflügelhändlern abgekauft und zum Düngen benutzt wird.

Es würde sich sonach sehr wesentlich um die Frage handeln, ob wir einen specifisch pathogenen Proteus von den anderen Proteusarten zu unterscheiden haben, einen Proteus, welcher etwa beim italienischen Geflügel als Parasit angepasst ist und zuweilen von diesem auf den Menschen übergeht, ${ }^{1}$ und welcher sich eben durch seine Pathogenität, Kapselbildung, mangelnde Beweglichkeit und Färbbarkeit nach der Gram'schen Methode von den Proteusarten Hauser's unterscheide, oder ob wir im pathogen wirkenden Proteus im Sinne C. Fränkel's ${ }^{2}$ nur mehr einen Saprophyten sehen sollen, welcher durch Bildung besonders gefährlicher Toxine gelegentlich einmal zur putriden Intoxication führen und in solchen Fällen sogar auch ausnahmsweise in Blut und Gewebe eindringen und so vorübergehend echter Parasit werden kann.

Ich möchte mich mehr der letzteren Anschauung zuneigen. Schon die Bordoni-Uffreduzzi's Befunden widersprechenden Angaben von Foà und Bonome beweisen, wie auch diese Forscher vor dem Pleomorphismus ihrer Culturen wie vor einem Räthsel standen. Ferner haben die genannten Autoren, sowie auch Hauser, übereinstimmend mit mir eine bedeutende Abhängigkeit der Proteusculturen von Temperatureinflüssen und ähnlichen Factoren gesehen; ferner ist auch bei den Thierexperimenten insgesammt ein grosser Wechsel in der Virulenz hervorgetreten und hat sich dieselbe auch ihrerseits wieder von der Zusammensetzung des Nährbodens abhängig gezeigt. Endlich spricht die Thatsache, dass der Proteus beim Menschen in meinen Fällen keineswegs nur in Zusammenhang mit der Geflügelseuche aufgetreten ist, sondern dass es sich z. B. in meinem Falle IX notorisch um eine durch Proteus verursachte Wurstvergiftung gehandelt hat, entschieden dafür, dass der für gewöhnlich bei jeder Eiweissfäulniss betheiligte Proteus zeitweilig unter geeigneten Bedingungen eine hohe Pathogenität annehmen kann.

Diese Bedingungen sind wohl zum Theil klimatische, zum Theil aber auch werden sie in der chemischen Beschaffenheit des Nährsubstrates, in welchem die Bakterien saprophytisch in der Natur sich vermehren, zu

1 Meines Wissens ist übrigens der pathogene Proteus bis jetzt als Parasit des Geflügels noch nicht beschrieben worden.

${ }^{2}$ C. Fraenkel. Grundriss der Bakterienkunde. Dritte Aufl. Seite 262. 
suchen sein. Dass sodann, wenn der Proteus einmal pathogen geworden und durch mehrere Thiere gegangen ist, auch seine Culturen andere, mehr parasitische Eigenschaften annehmen, dass sie die "Proteusnatur" mehr verleugnen und erst durch eine Art „Degeneration" auf den künstlichen Nührböden wieder gewinnen auf Kosten ihrer Virulenz, das ist eine Thatsache, auf die ich bei der vorhergegangenen Beschreibung meiner Untersuchungen genügend glaube hingewiesen zu haben. Damit soll nicht geleugnet werden, dass dem aus dem thierischen Organismus durch Züchtung erhaltenen pathogenen Proteus noch Eigenschaften zukommen, welche ihn von den gemeinen Proteusarten unterscheiden und an und für sich zur Artabgrenzung ausreichend wären. Hierher gehört namentlich die Fluorescenz, und will man in diesem Sinne eine besondere Art annehmen - was vielleicht aus praktischen Gründen empfehlenswerth sein dürfte - so möchte ich für den von mir hier beschriebenen Proteus die Bezeichnung: „Bacillus Proteus fluorescens" in Vorschlag bringeu.

Ich möchte also den Proteusgruppen die Stellung geben, welche etwa die Bacillen des malignen Oedems einnehmeu, als überall in der Natur verbreitete Balkterien, welche unter günstigen Umständen pathogene Eigenschaften bethätigen.

Nach dieser meiner Auffassung muss aber der Protus als weit geführlicher denn die genamnten Erdbakterien betrachtet werden, denn diese inticiren nur von Wunden aus und selbst damn nur, wenn ihnen die Bedingungen der Anaërobiose gesichert sind. Der Protens aber inficirt vom Verdaungstractus ans, und er ist im Stande, in Wasser und gerade in verunreinigtem Wasser, in Jauche, nicht nur zu leben, sondern gerade hier seine grefährlichsten Toxine zu bilclen.

Tritt der Proteus in Schmutzsubstanzen iuf, so ist er bekanntlich der wirksamste Reiniger, weil Beförderer rascher Zersetzung der organischen Substanzen; unter für ihn günstigen Bedingungen wird er zu einem gefïhrlichen Feinde des Menschen und der Thiere.

Von diesem Standpunkte aus romme ich zu dem Schlusse, dass ron Seiten verumreinigten Wassers noch ganz andere Gefahren für die Gesundheit der Menschen bestehen als nur die Uebertragung von Cholera, Iyphus und Dysenterie; unsere Fälle schwersten infectiösen Icterus in der Ulmer Garnison, welche, wie ich glaube bewiesen zu haben, zum grössten Theil auf Infection durch verunreinigtes Donauwasser zuzückgeführt werden müssen, die ähnlichen Erkrankungen, welche Kirchner, Schaper, Pfuhl und Globig beschrieben und gleichfalls vom Genuss unreinen Flusswassers herleiten, endlich der Umstand, dass sogar das an Verschlueken von Schmutzwasser gewöhnte Geflügel einem - vielleicht unter südlichem Himmel 
hoch virulent gewordenen - Proteus nicht Widerstand leisten kann diese- Thatsachen sollten meines Erachtens zur allgemeinen Anerkennung der Berechtigung der Fordertung führen, dass die Eimleitung von Abfallstoffen des menschlichen Haushaltes in die öffentlichen Wasserläufe nicht. ferner geduldet werden darf.

Die Flüsse und Bäche sind ein Gemeingut der menschlichen Gesellschaft, und Keiner hat das Recht, ihr Wasser zu trüben. Auf die Selbstreinigung der Flüsse sich zn verlassen, mag den weiter oberhalb an einem F'lusse Wohnenden immer lejchter fallen als Denjenigen, welche unten wohnen; die Städte und Dürfer stehen häufig so dicht an einem Flusslanf aufgereiht, dass für ihre Bewolner der Trost der Selbstreinigung ihres Flusses illusorisch bleibt.

In kurzer 'Zusammenfassung der Ergebnisse vorstehenler Untersuchungen gelange ich $z u$ folgenden Schlusssätzen:

1. Der fieberhafte Ieterus (Weil'sche Krankheit) ist eine acute Infectionskrankheit, welche symptomatisch, auatomisch und atiologisch ein einheitliches und selbststïndiges Krankheitsbild darstellt.

2. Die fragliche Krankheit hat insbesondere keine Gemeinschift mit Abdominaltyphus, Recurrens oder der gewöhnlichen (durch St:uphylokokken und Streptokokken hervorgerufenen) Septicämie.

3. Eine grössere Verwandtschaft zeigt die Krankheit mit der acuten gelben Leberatrophie und dem Crelblieber; nur die ätiologische Erfor'schnug der letztgenannten Krankheiten kann aber die Entschejdung bringen, ob die Weil'sche Krankheit mit einer dieser Affectionen identisch ist.

4. Die Erreger der Weil'schen Krankheit sind in Bakterien der pleomorphen Proteusgruppe z.u erblicken.

5. Fine specifische pathogene Proteusart ist nicht anzunehmen; vielmehr kïnnen alle Protensarten in einem gewissen Grade als pithogen bezeichnet werden. Die Artmerkmale sind unter den speciellen Lebensbedingungen dieser Bakterien noch hinreichend priignant zur Unterscheidung: (Proteus hominis capsulatus Bordoni-Uffreduzzi's, mein Proteus fluorescens), aber diese Artmerkmale verwischen sich bei saprophytischen Existenzbedingungen relativ rasch.

6. Die Pathogenitït der Proteusarten unterliegt grossen Schwankungen, welche durch ihre äusseren Lebensbedingungen bestimmt werdell.

7. Unter den Factoren, welche die Viruleuz der Proteusbakterien erhöhen, steht in erster Linie die mehrmalige Passage durch den Thierkörper; sodann ausserhalb desselben: hohe Temperatur, reicher Gehalt 
des Nährmediums an Stickstoffsubstanzen; endlich rielleicht die Anwesenheit gewisser anderer Bakterien (Untersuchungen von Penzo).

8. Unter den erwähnten günstigen Bedingungen kamn der Proteus eigentliche pathogene Figenschaften im engeren Sinne innehmen, d. h. er kann in Blut und Gewebe des Körpers eindringen und sich hier vermehren.

9. Unter den in Ziff. 6 und 7 angeführten Gesichtspunkten erscheinen alle stickstoff haltigen fanlenden Substanzen, Fleisch, Fische, durch Jauche verunreinigtes Wasser verdächtig nicht bloss Verdauungsstörungen, Intoxicationen, sondern schwere septische Infectionen herbeiführen zu können.

10. Bezüglich der in Ulm vorgelommenen Fïlle Weil'scher Krankheit ist durch die vorliegenden Untersuchungen nachgewiesen, dass die überwiegende Mehrzihl derselben auf das Baden in einem durch inficirte Zuflüsse verunreinigten Wasser zurückgeführt werden muss.

11. Die Infection des Flusswissers mit hochvirulenten Proteusbikterien erfolgte daselbst durch eine an dem umreinen Donauzufuss, der Blau, aufgetretene Geflügelseuche.

12. Erreger dieser Geflügelsenche ist gleicufalls eine Proteusart, welche von der bei den Fïllen Weil'scher Krankheit gefundenen sich nicht unterscheiden lässt.

13. Diese „pathogen gewordene" Proteusart konnte zur Zeit des Bestehens der Geflügelseuche in dem betreffenden Wasserlaufe nachgewiesen werden.

14. Da die infectiösen Stoffe in grüsseren zusammenhïngenden Massen fortgeschwemmt werden (Stallstreu, Mist, Thiercaldaver), so ist ein Transport derselben in die Donan und die Möglichkeit der Infection der Menschen beim Baden in derselben gegeben.

15. Die geschilderten localen Verhältnisse, zusammengebalten mit den bekannten Lebenseigenschaften der Protensbaliterien, insbesondere mit ihrer Neigung, aus nützlichen Zerstïrern organischer Abfülle zu gefährlichen, nicht bloss toxisch, sondern pathogen wirkenden Feinden sich umzuwandeln, geben das Recht, die Forderung aufzustellen, dass die öffentlichen Flussläufe nicht ferner mehr mit ungereinigten und undesinficirten Abwässern beladen werden dürfen.

Ich möchte diese Arbeit nicht schliessen, ohne, meinem Freunde, Hrn. Hofrath Dr. Wacker in Ulm, für die liberale Ueberlassung seines Laboratoriums herzlichsten Dank zu sagen.

\footnotetext{
1 Centralblatt für Bakteriologie. Bd. X. Nr. 25. S. 822.
} 


\section{Erklärung der Abbildungen. \\ (Taf. I-VII.) \\ Tafel I.}

Fig. 1. Colonieen der bei fieberhaftem Ioterus gefundenen Bakterien auf der Gelatineplatte in jugendlichem Stadium bei 70 facher Vergrösserung.

Fig. 2. Dieselben Colonieen in älterem, vertlüssigentem (Proteus-) Stadium. 70 fache Vergrössernng.

Fig. 3. Dieselben in Gelatinestichcultur mit Cholora-'Typus.

Fig. 4. Wachsthum anf Kartoffeln.

Fig. 5. Ausstrich aus Harnsediment von Fall II. Gezeichnet mit Zeiss $1 / 1$, Ocular 4.

Fig. 6. Theil einer grossen Plattencolonie des nicht verflïssigenden Typus; gezeichnet bei 70 facher Vergrösserung.

Fig. 7. Stichenltur im nicht verfüssigenden 'lypus mit baumförmiger Verz̈stelung an der Oberfläche.

Fiz. 8. Sticheultur zur Veranschaulichung der Fluorescenz.

Fig. 9. Schnittpräparat aus Fall IX beim Nenschen. Niere. Der Sehnitt hat ein mit den Bakterien vollgestopftes Blutgefïss an der 'I'heilungsstelle getroffeu. Zeiss $1 / 12$, Oeular 2 .

Fig. 10. Mit den Bakterien geimpfte, der Infection erlegene Mr̈use; zur Veranschaulichnng der Stellung. welche sie im Tode einzunehwen ptlegen.

\section{Tafel II.}

Fig. 1. Suhnitt aus Niere vom Menschen aus Fall I. Bacillenhaufen.

Fig. 2. Ausstrichprïparat aus Reincultur, gewonnen aus Fall I.

\section{Tafel III.}

Fig. 1. Klatschpriparat aus einer in Proteus-Typus (wie T'af. I, Fig. 2) gewachsenen Plattencolonie.

Fiy. 2. Ausstrich aus Harnsediment von Fall III; grosser Bacillenhaufen.

Tafel IV.

Fig. 1. Klatschpräparat aus einer von Fall VI gewonnenen Plattencultur.

Fig. 2. Schnitt aus Niere vom Menschen; gewomnen von Fall IX; ein Blutgefäss von den Bacillen vollyestopitt.

Fig. 1. Nierensehnitt ron Huhn I.

\section{Tafel $\mathrm{V}$.}

Fig. 2. Ausstrichpriiparat aus dem Herzblut einer von den Culturen ans dem Geflügel geimpften Maus.

\section{Tafel VI.}

Fig. 1. Ausstrich ans der Milz einer mit dem inficirten Bachwasser geimpften Maus.

Tafel VII.

Plan von Uln and Umgebung in Maassitab von 1:50000. 


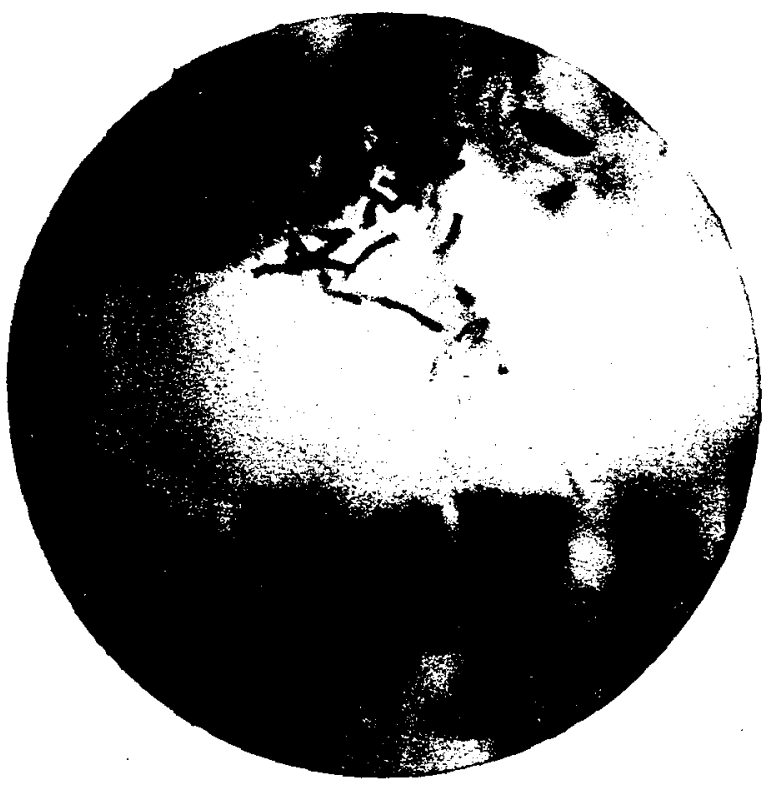

Fig. I.

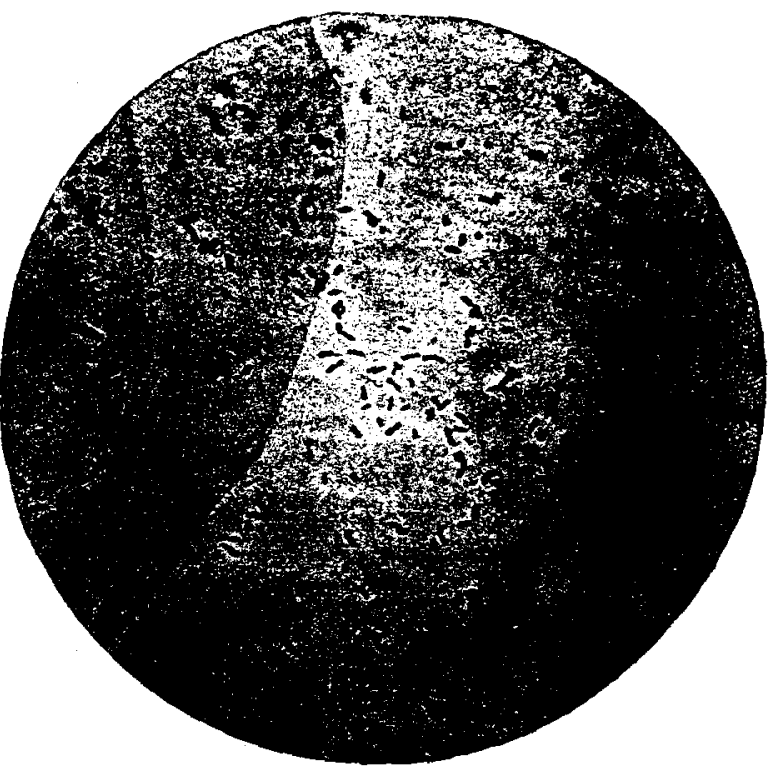

Fig. 2 . 


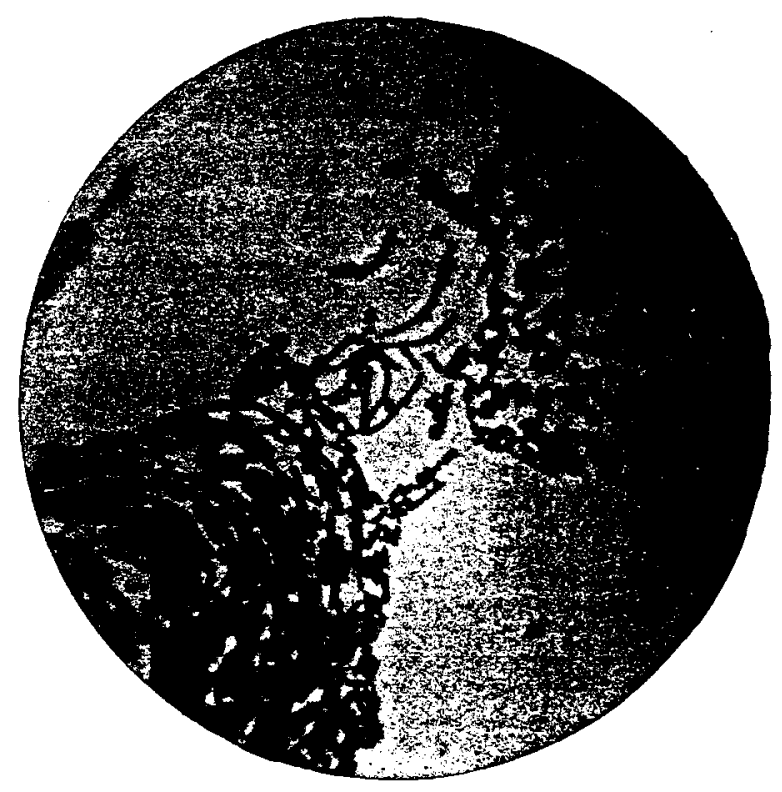

Fig. I.

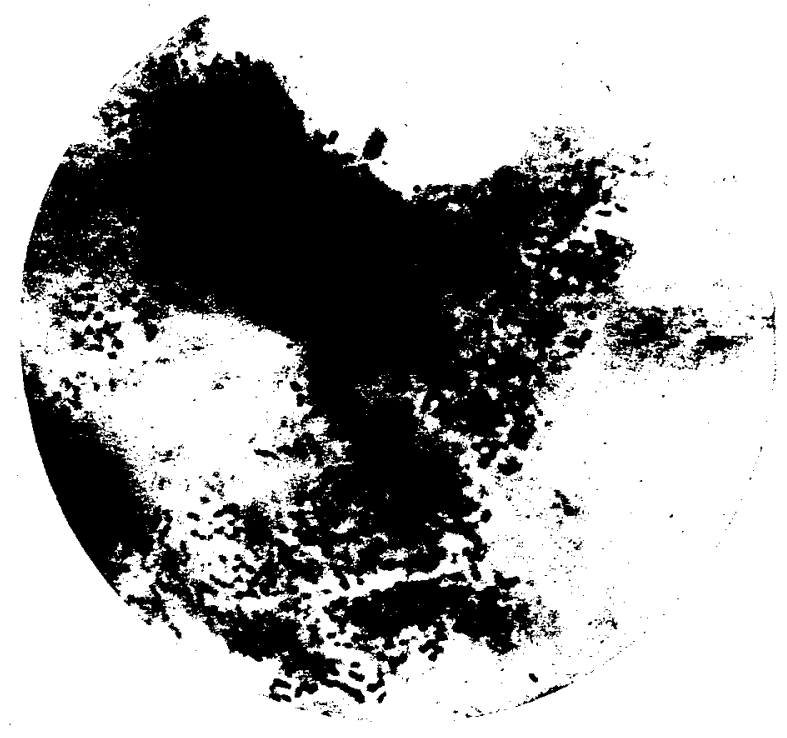

Fig. 2. 


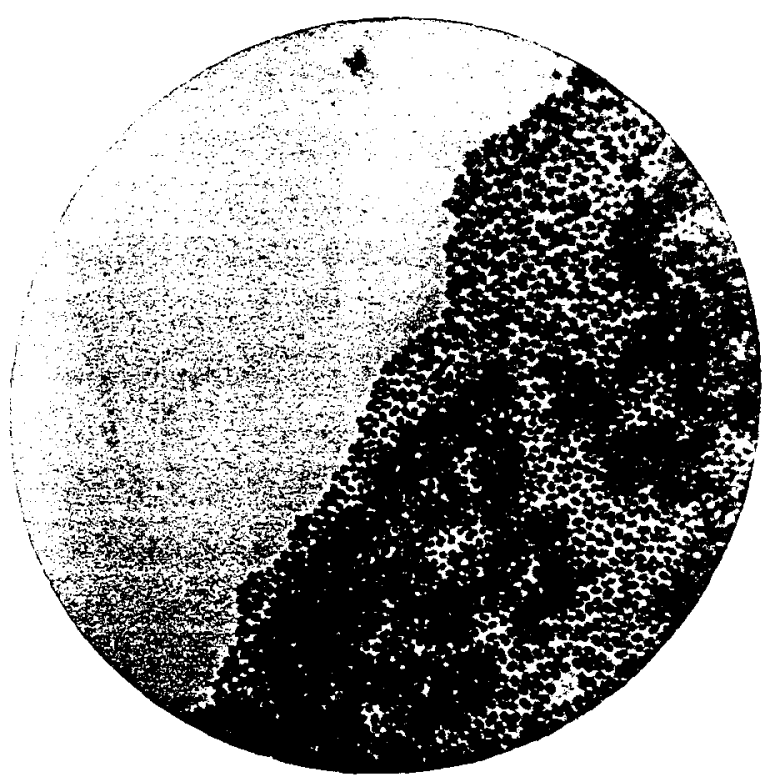

Fig. I.

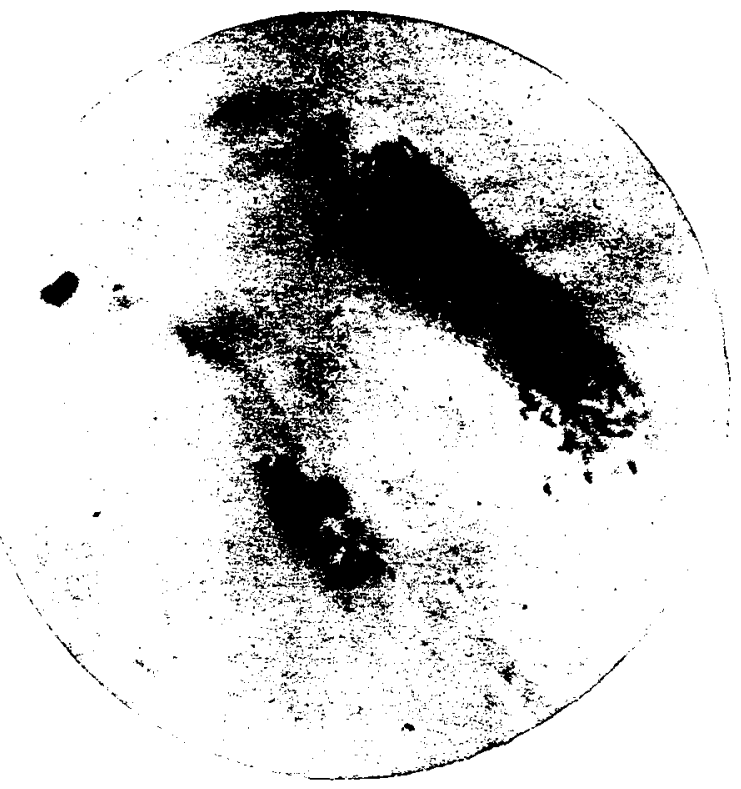

Fig. 2 . 


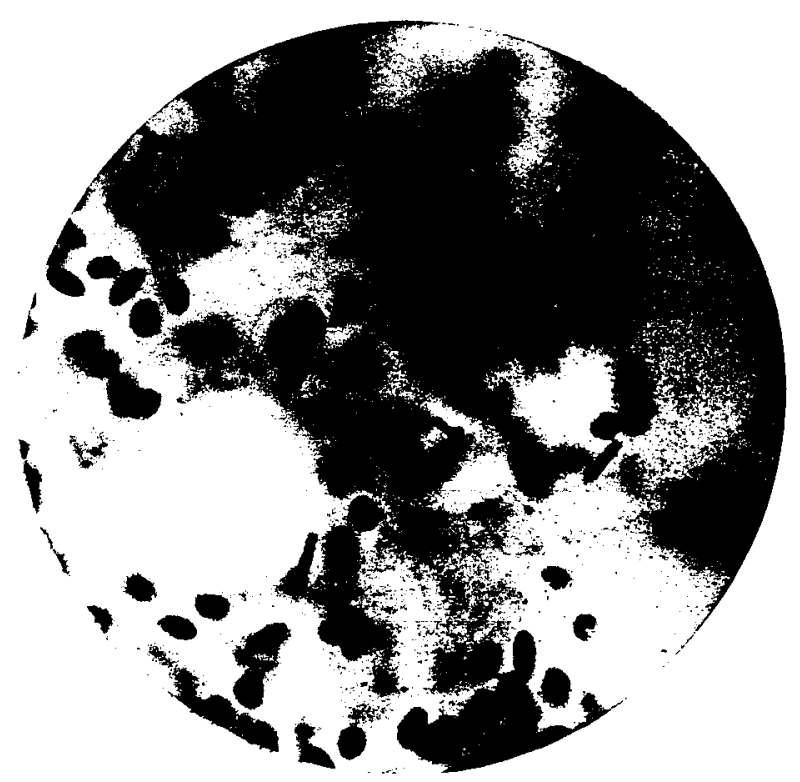

Fig. I.

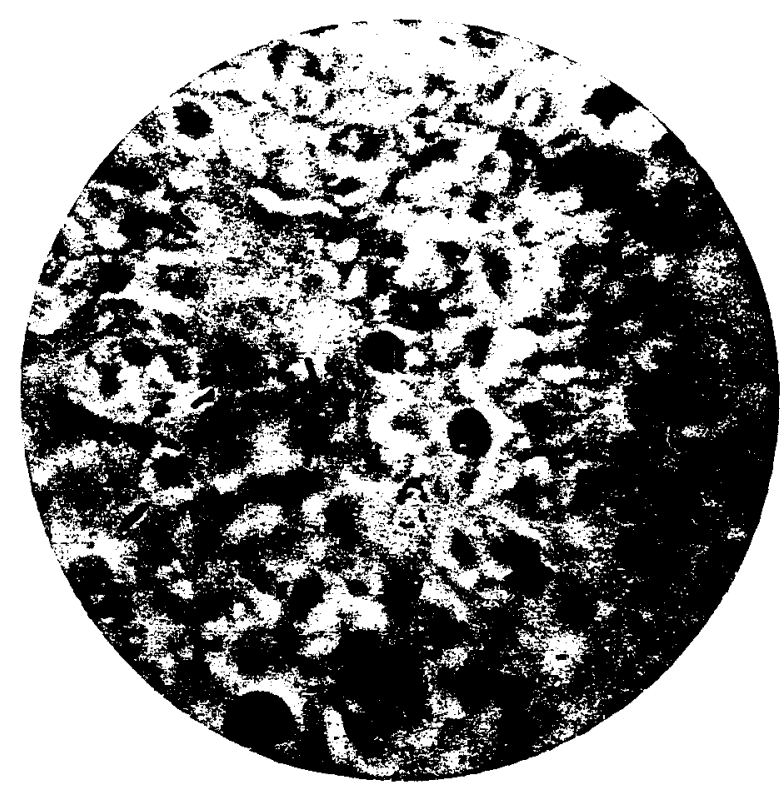

Fig. 2 . 


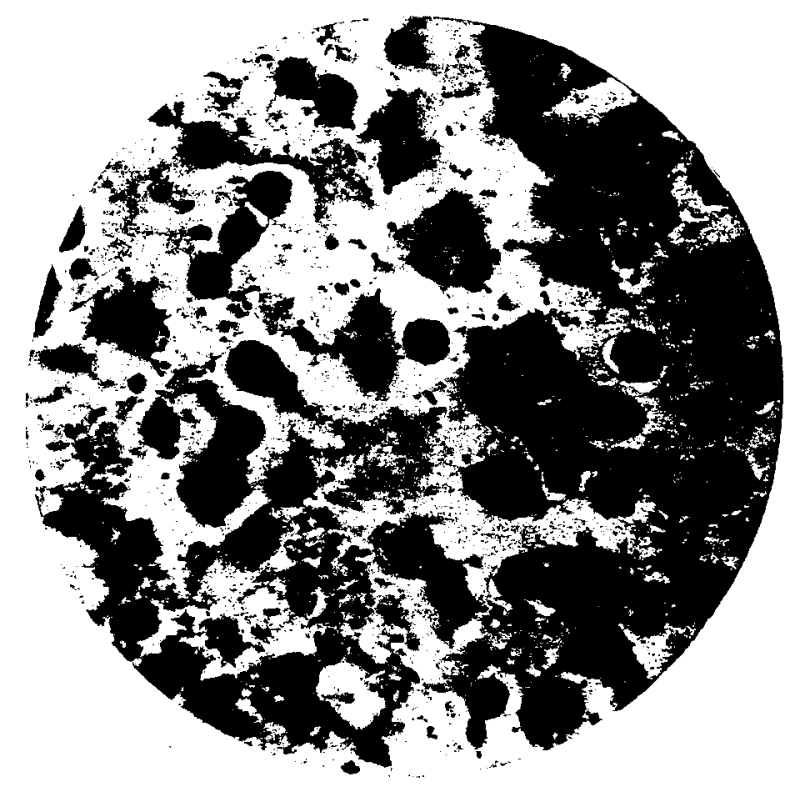

